\title{
THE CASE AGAINST COGNITIVE ENHANCEMENT: \\ RESPONDING TO THE REVERSAL TEST
}

\author{
By \\ Alice Monro \\ A thesis \\ submitted to the Victoria University of Wellington \\ in fulfilment of the requirements for the degree of \\ Master of Arts \\ in Philosophy
}

School of History, Philosophy, Political Science and International Relations

Victoria University of Wellington

2008 


\section{Acknowledgements}

First and foremost, I would like to sincerely thank my supervisor, Nick Agar, for all his advice, guidance and encouragement.

I would also like to thank the rest of the philosophy staff, especially Sondra Bacharach who has made this year so great for all the postgrads.

Special thanks has to go to the postgraduate students in the philosophy department at Victoria (for the great social times as well as the academic feedback), particularly to Tony (for answering my constant questions), Frieder (for putting words into equations), Dan, Matt, Nick, Dennis and Alan (for all the helpful advice).

To my editor and emotional support, Stephen - thanks for reading my entire thesis 6 times in order to find the last misplaced apostrophe.

Last, but certainly not least, a huge thank you to Mum, Dad and the rest of my family for all the important stuff. 


\section{Abstract}

In this thesis I argue against the use of genetic technologies to enhance human cognitive capacities. More specifically, I respond to Nick Bostrom and Toby Ord's "Reversal Test", which they use to argue in favour of genetic cognitive enhancement. The Reversal Test is a burden of proof challenge designed to diagnose status quo bias in arguments against enhancement. By noting that most of those who oppose raising intelligence would also oppose lowering intelligence, the Reversal Test puts the onus on opponents of enhancement to explain why both increases and decreases in our cognitive capacity would be worse than the status quo (our current level of intelligence). Bostrom and Ord claim that if no good reasons can be provided, this indicates that the opposition to enhancement is influenced by status quo bias. Since cognitive biases cannot provide a moral reason against enhancement, opposition to genetic cognitive enhancement shown to be affected by status quo bias can accordingly be discounted.

The aim of my thesis, then, is to overcome the Reversal Test's burden of proof challenge by showing that my reasons for opposing cognitive enhancement are not influenced by status quo bias. However, I do not argue that enhanced intelligence could not be beneficial to the individual. Instead, I claim that the probable unequal distribution of enhancements between the best- and worst-off would be likely to cause serious injustices to those who are unable to afford them. 


\section{Contents}

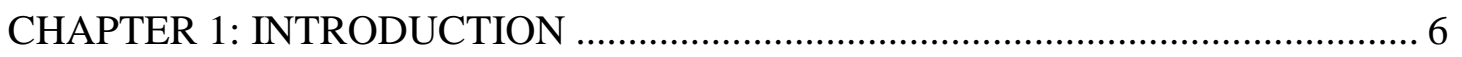

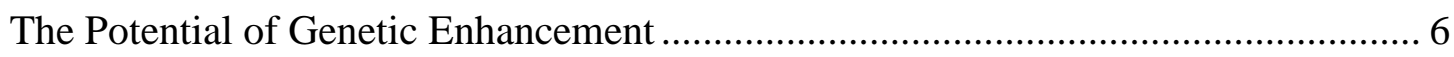

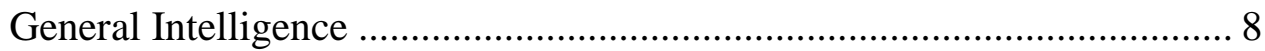

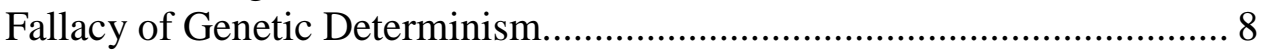

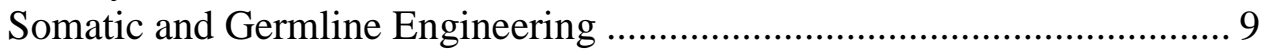

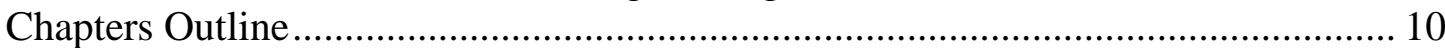

CHAPTER 2: THE REVERSAL TEST ........................................................... 15

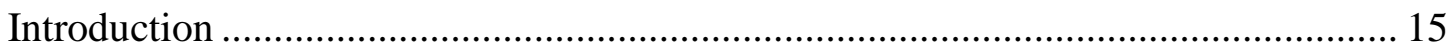

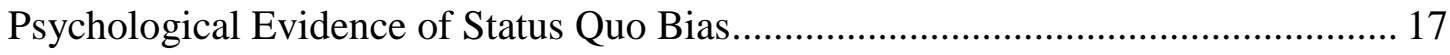

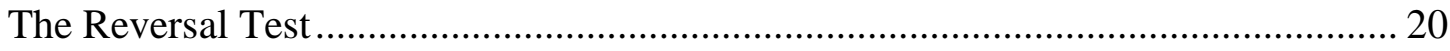

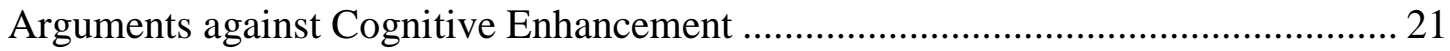

Argument from Evolutionary Adaptation ........................................... 21

Argument from Transition Costs...................................................... 22

Argument from Risk ............................................................................. 23

Argument from Person-Affecting Ethics ............................................. 25

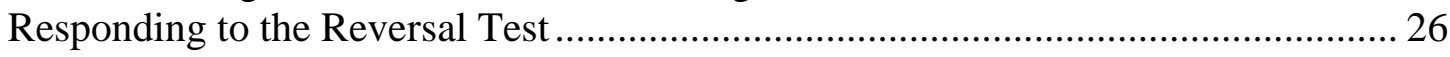

CHAPTER 3: THE CASE AGAINST COGNITIVE ENHANCEMENT ................. 27

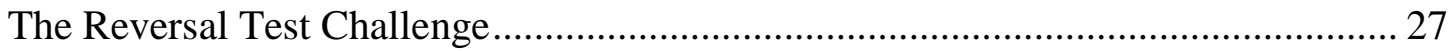

Possible Responses to the Reversal Test .............................................. 28

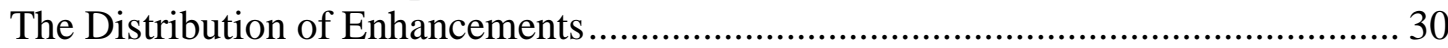

Enhancements Costly and Technologically Complicated ........................ 31

Subsidisation of Enhancements.................................................................. 32

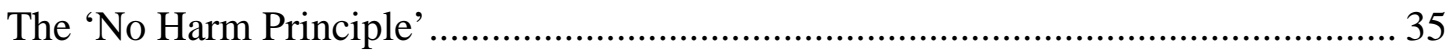

Risk under Uncertainty .................................................................. 38

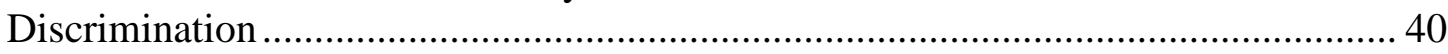

Personhood Criteria for Moral Equality …......................................... 40

Smarter Humans Equals Better Reasoning? ............................................. 44

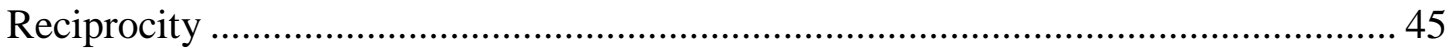

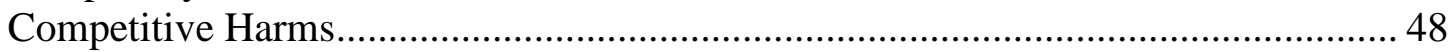

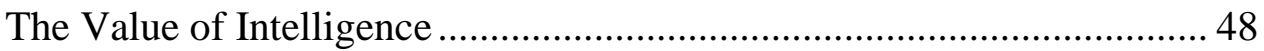

Positional Advantages Create Competitive Harms ................................. 52

Balancing the Benefits and Harms .............................................................................. 53

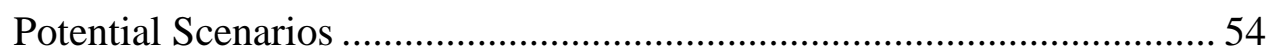

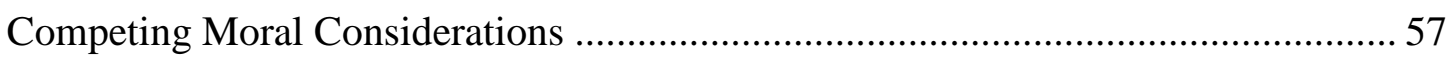




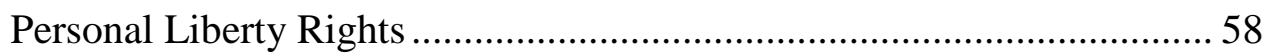

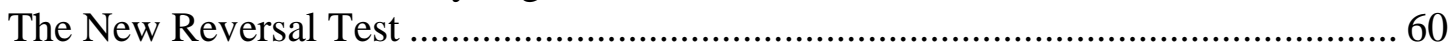

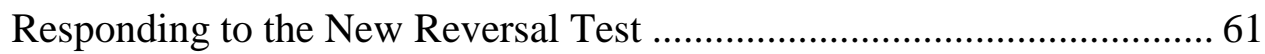

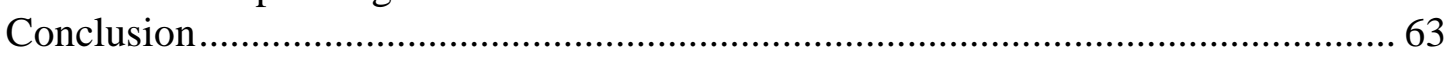

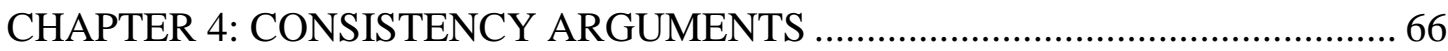

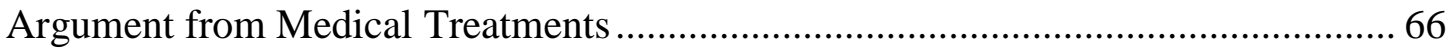

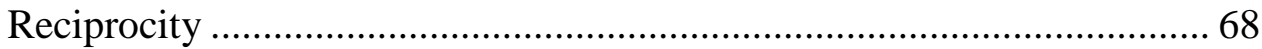

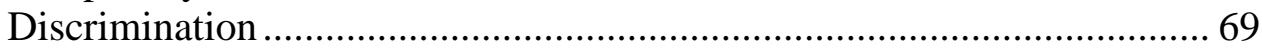

Loss of Support …................................................................................ 70

Competitive Harm .................................................................................. 70

Competing Moral Considerations .......................................................... 73

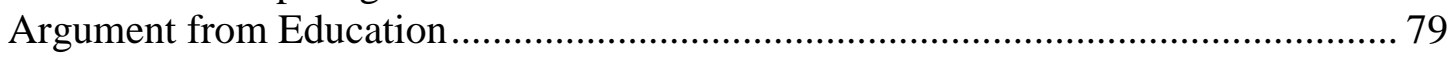

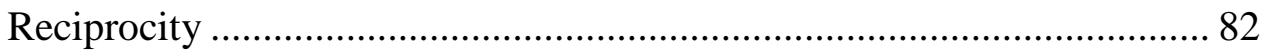

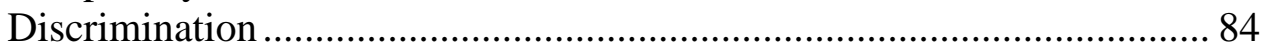

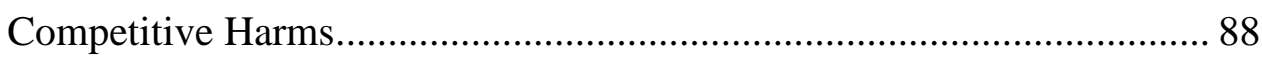

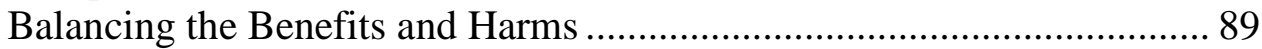

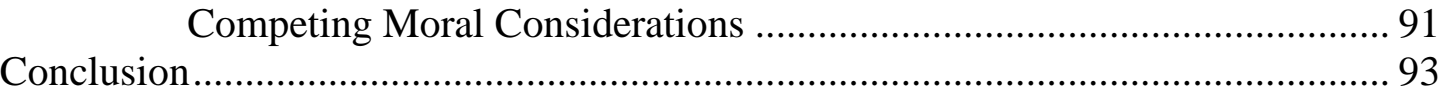

CHAPTER 5: THE DOUBLE REVERSAL TEST ................................................ 96

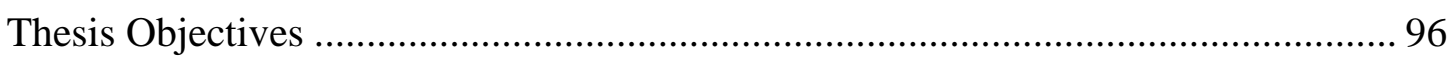

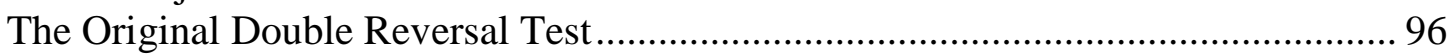

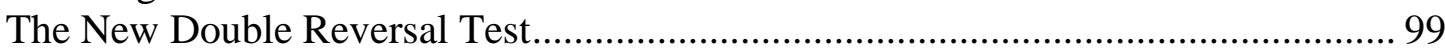

Competing Moral Considerations ....................................................... 100

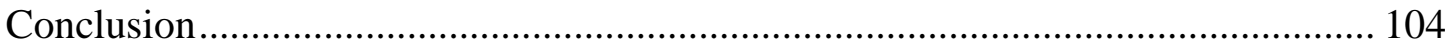

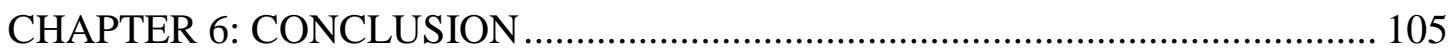

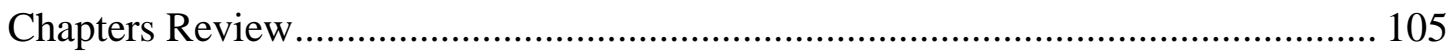

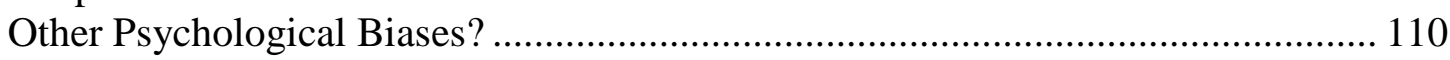




\section{CHAPTER 1}

\section{Introduction}

\section{THE POTENTIAL OF GENETIC ENHANCEMENT}

The Hollywood movie Gattaca depicts a society where pre-implantation genetic diagnosis (PGD) is used to ensure children have the best of their parents' genes. Because the technology is afforded only by the middle and upper classes, huge social divisions based on genetic profiling have resulted. Those born without the aid of such reproductive technologies face serious discrimination and are relegated to performing only menial activities. However, the use of PGD has also ensured that among those born with its use, serious disease has been effectively eradicated.

PGD is not actually the most effective way of ensuring the "best" genes. PGD enables us only to choose the best out of a selection of embryos; with genetic engineering it may become possible not only to select between different embryos, but to enhance embryos (i.e. future people) with specific genetic traits. We may also be able to use genetic technologies to engineer children and adults (i.e. existing people). While this is a situation often depicted in science fiction, it now seems more than just a theoretical possibility. What if, in the future, we could use genetic technologies not just to treat but to enhance both existing and future people's physical and mental abilities? What if we could make people faster, stronger and smarter? Ought we to use these technologies?

The society depicted by Gattaca provides a salient example of the potential of genetic enhancement for both good and bad. Because the consequences of using enhancement technologies may be hugely significant to society as well as to the individual and, furthermore, because the possible outcomes are at this stage uncertain, 
it is important to morally evaluate the potential issues surrounding the use of genetic enhancement technologies before they become a reality.

The moral question of whether we should permit the use of genetic enhancement technologies is a very broad one. And, I think it highly unlikely that any one argument will suffice for determining the moral permissibility or impermissibility of using genetic enhancements generally. A discrete type of enhancement may have its own unique consequences and we may therefore have different moral considerations to take into account in each case. Accordingly, we should not expect an argument for or against a particular type of enhancement to necessarily apply to all other proposed enhancements, and we should not be surprised if it turns out that some sorts of enhancements are morally permissible while other types of enhancements are not. For example, an argument in favour of enhancing human strength may not necessarily entail that we should also enhance our height. Because of this constraint, we should morally evaluate each proposed type of genetic enhancement in its own right.

In this thesis I will only focus on one specific candidate for enhancement. I will examine whether the use of genetic technologies to enhance human intelligence is morally permissible. Ultimately, I will argue that it is not. My arguments are specifically intended to respond to Nick Bostrom and Toby Ord's "Reversal Test", which they use to argue in favour of genetic cognitive enhancement. ${ }^{1}$ The Reversal Test is a heuristic for showing that opposition to enhancement is influenced by the status quo bias. By noting that those who oppose raising human intelligence would also oppose lowering human intelligence, the Reversal Test puts the onus on opponents of enhancement to explain why maintaining the status quo (our current intelligence levels) is the best option. Bostrom and Ord contend that if no sound justification can be provided, the opposition to enhancement suffers from status quo bias, and is therefore not morally compelling. However, before outlining exactly how I intend to respond to the Reversal Test in this thesis, I will briefly discuss some important background information.

\footnotetext{
${ }^{1}$ Nick Bostrom and Toby Ord, "The Reversal Test: Eliminating Status Quo Bias in Applied Ethics," Ethics 116:4 (2006).
} 


\section{General Intelligence}

For the purposes of this thesis, the term "intelligence" will be used interchangeably with "cognitive capacities". Although I do not think it necessary to commit to a precise definition of intelligence, the way I will use the term is to refer to general intelligence (the attribute the IQ test purports to reflect), as well as such traits as numeracy, reasoning, problem solving and the capacity for learning languages. ${ }^{2}$ However, the notion of intelligence that I am interested in examining in terms of its enhancement does not capture traits like musical talent or artistic ability, or other cognitive functions such as empathy and other emotions.

\section{Fallacy of Genetic Determinism}

By talking in such a way about the genetic enhancement of particular phenotypic traits, like intelligence, it may seem as though I am assuming a deterministic view about genetics. However, genetic determinism - the belief that one's genes wholly determine one's phenotype - is false. Both genes and the environment interact to determine one's intelligence. Ainsley Newson and Robert Williamson explain:

\footnotetext{
The current model for intelligence proposes that within a particular population there will be many intelligence genes, and a significant environmental impact. Different 'versions' of these intelligence genes (termed alleles) will contribute either to raising or lowering the intelligence levels of individuals within that population. ${ }^{3}$
}

Adverse environments may cause adverse phenotypic differences. A malnourished child, for example, may be less intelligent than they would have been had they had better nutrition. Genes, however, are still important. Some mentally disabled people will have adverse genetic mutations so severe that no environment among those they are likely to encounter will be able to ensure a normal intelligence. Likewise, the

\footnotetext{
${ }^{2}$ While the notion of general intelligence may be controversial, it does seem as though the IQ test reflects some sort of variation in cognitive ability (even if it is not "general intelligence"). I have also proposed other potentially less controversial traits (like mathematical ability) that the term "intelligence" is meant to capture.

3 Ainsley Newson and Robert Williamson, "Should We Undertake Genetic Research on Intelligence?," Bioethics 13:3/4 (1999), p.329.
} 
different genotypes of chimpanzees and humans significantly contribute to their different intelligence levels.

Nothing in this thesis assumes the truth of genetic determinism. We do not need to deny that the environment plays an important role in determining one's phenotype to postulate that we may be able to enhance our intelligence through genetic engineering. When I talk about genetically enhancing intelligence, I am simply assuming that we can alter existing genes or introduce better genes that significantly influence intelligence in human beings.

\section{Somatic and Germline Engineering}

There are two foreseeable ways in which we may in the future be able to genetically enhance our intelligence. The first of these genotypic modifications is germline enhancement. Theoretically, germline enhancement is where genetic modifications are made to sperm, eggs, or very early embryos. As a practical matter, however, germline engineering would most likely be performed on an egg or early embryo (at either the zygote or blastomere stage), since their relatively large size makes them much easier to modify than a sperm. Since the foetus develops through cell division and differentiation, all genetic information present in the original cell is replicated in each new cell as the foetus grows. Any genetic modification of the ovum, zygote or blastomere ${ }^{4}$ will therefore be replicated in every other cell of the future person, including their reproductive cells, meaning that germline enhancements are heritable.

One potential use for germline engineering is to prevent heritable genetic diseases like $\mathrm{X}$-linked recessive disorders from being passed on. For example, a female zygote that is a carrier for Haemophilia A may be genetically engineered to remove the disorder, therefore preventing carrier status in that particular individual and potential carrier status in her daughters, as well as preventing her sons from expressing the condition. In another case, an individual genetically enhanced for higher intelligence would be

\footnotetext{
${ }^{4}$ In the blastomere case each cell will have to be genetically modified, since at this stage the embryo is composed of multiple cells.
} 
able to pass the genes for high intelligence down to their offspring, since the changes to the genome are passed down through the enhanced reproductive cells.

The second type of genetic engineering is somatic engineering. Somatic cells can basically be seen as body cells (not including the reproductive cells). Somatic cell enhancement involves the addition of "good" genes to specific cells in an individual but not an alteration of the germline. Modifications made through somatic enhancement are therefore not able to be passed down to the enhanced individual's offspring.

Somatic engineering could potentially be used to treat or cure people with diseases caused by genetic mutations by inserting functioning versions of the genes into targeted cells. Possible candidates for somatic engineering are patients with cystic fibrosis, where enhancements may be made to lung cells in order to prevent them from producing mucus. Another use could be for better versions of genes to be added to a "normal" human being (i.e. one with no disease) in order to improve their capacities in a particular respect. With cognitive enhancement it is foreseeable for genes that contribute to higher intelligence to be inserted into the brain cells of a person of average intelligence in order to raise their IQ.

\section{CHAPTERS OUTLINE}

As indicated earlier, in this thesis I argue against the use of these genetic technologies to enhance our cognitive capacities. This is not because there is anything intrinsically wrong with genetic engineering, nor because the consequences to the enhanced will be necessarily bad. Rather, my concern is that the probable distribution of enhancement technologies will cause serious harm to those who do not have access to them. I argue that it is therefore morally impermissible to permit wealth-based access to (i.e. the private purchase of) genetic cognitive enhancements

I noted at the very beginning of this chapter that the specific focus of my thesis is to argue against the "Reversal Test", which I will outline in chapter 2. As previously described, the Reversal Test is a burden of proof challenge posed by Nick Bostrom 
and Toby Ord that they devise as a heuristic for diagnosing status quo bias in arguments against cognitive enhancement.

The Reversal Test simply asks opponents of genetic cognitive enhancement whether it would be good, overall, if our cognitive capacities were reduced. If the answer is 'no', then the opponent of enhancement must provide good reasons for believing that both increases and decreases to human intelligence levels would be worse than the status quo (our current level of intelligence). If no good reason can be offered, Bostrom and Ord argue, this shows that the original opposition to genetic enhancement is influenced by status quo bias. Since cognitive biases cannot provide a moral reason against permitting the genetic enhancement of intelligence, Bostrom and Ord contend that opposition to enhancement is therefore flawed. They assert that removal of the bias lends weight to the view that we should permit genetic cognitive enhancement.

The main goal of my thesis is to provide a sound response to Bostrom and Ord's application of the Reversal Test to intellectual enhancement. I aim to show that there are in fact compelling reasons (not influenced by status quo bias) for opposing cognitive enhancement. If, by the end of the thesis I have passed the Reversal Test by providing good reasons to believe that we should not permit the genetic enhancement of intelligence, then I will consider my goal to have been achieved.

I critically respond to the Reversal Test in chapter 3 by advancing a version of what can be called the "argument from inequality". More specifically, I contend that the probable distribution of genetic enhancements would be likely to result in serious injustices to the poor. I motivate this position first with an argument for the expectation that genetic enhancements would be unequally distributed between the rich and the poor, and secondly with the moral intuition that a policy that benefits already well-off sections of society but risks serious harms to those who are the worstoff is prima facie unjust. I call this the 'no harm principle'. If wealth-based access to enhancement technologies results in harm to the poor, then we have prima facie reason to consider them unjust. 
I illustrate how unequal access to enhancement is likely to harm the poor through moral and political marginalisation. I then show that since intelligence has significant positional value, its unequal distribution is also likely to competitively harm those who are not enhanced (i.e. the poor). This makes enhancements morally different from other unequally distributed goods that do not have these harmful effects.

I also devise a method for balancing the potential benefits of enhancements with the potential harms. Using this method, I am able to show that the benefits to the poor of living in a society where the rich members are cognitively enhanced would not be likely to compensate for the likely harms of living in that society. Since permitting wealth-based access to genetic enhancement would harm the worst-off and so violate the no harm principle, I contend that enhancements are unjust and therefore should not be permitted.

I also critically respond to a revised version of the Reversal Test, which Bostrom and Ord devise to counter such arguments from inequality and I address some other potential arguments that could be made on behalf of the proponent of enhancement. I show why these concerns are not morally compelling.

By the end of chapter 3 I hope to have successfully responded to the initial burden of proof set by the Reversal Test by illustrating how wealth-based access to enhancements would cause harm to the poor. However, my argument may still be potentially objected to on other grounds. In chapter 4 I rebut what I take to be the strongest objections to the argument from inequality. These are consistency arguments, and there are two important ones to consider.

The first consistency argument, the "argument from medical treatments", attempts to show that the argument from inequality entails the implausible conclusion that we should ban non-universal medical treatments for everyone if they are not available for all. I respond to this objection in two ways. First, by illustrating that the nonuniversal use of medical treatments is not as likely to violate the no harm principle as the non-universal use of enhancements. Second, by arguing that while we have a prima facie moral obligation not to risk harm to the poor in the distribution of 
important goods, there are competing moral considerations in the case of medical treatments that override the no harm principle in this case.

The second consistency argument I discuss is the "argument from education". This argument acts similarly to the argument from medical treatments by (rightly) stating that we must be consistent in our attitudes toward education (and other environmental methods of cognitive enhancement) and genetic cognitive enhancement. It then claims that since education, like genetic cognitive enhancement, is unequally distributed between the rich and the poor, then my arguments must, by consistency, lead to the conclusion that education should be banned. Since this is obviously an absurd conclusion, it is claimed that my arguments against cognitive enhancement must be unsound.

In response, I submit that proponents of the argument from education have failed to take into account that education and genetic cognitive enhancement are different in morally relevant ways. These moral differences between the two make it the case that it is not inconsistent to think that we should permit education yet prohibit cognitive enhancement.

I stated earlier that my main aim in this thesis is to rebut the Reversal Test, which I will argue against in chapters 3 and 4 . However, in chapter 5 I present and respond to a further burden of proof argument - the "Double Reversal Test" - which Bostrom and Ord introduce at the end of their paper. I argue that the Double Reversal Test also fails to show that the argument from inequality is influenced by the status quo bias and fails to provide good evidence for thinking that it would be better, all-thingsconsidered, to enhance our cognitive capacities. This is because the Double Reversal Test introduces competing moral considerations that are not present in the normal situation. Once these relevant differences are recognised and removed, it is easy to see how the Double Reversal Test is ineffective in countering my versions of the argument from inequality.

By the end of the thesis I intend my rebuttal of both the Reversal Test and the Double Reversal Test to have met the burden of proof that Bostrom and Ord set by offering a 
convincing argument against cognitive enhancement that is not influenced by status quo bias. If these objectives are met, the goal of this thesis will have been achieved.

I begin in chapter 2 by illustrating the Reversal Test and explaining the requirements for an argument to meet its burden of proof. 


\section{INTRODUCTION}

In the paper "The Reversal Test: Eliminating Status Quo Bias in Applied Ethics", Nick Bostrom and Toby Ord argue in favour of using genetic technologies to enhance the cognitive capacities of existing and future people. ${ }^{5}$ They take a reasonably broad notion of the term "cognitive capacities", referring not only to general intelligence but also to such abilities as social intelligence and musical talent. As discussed in the introductory chapter, I take a slightly narrower definition of the term "cognitive capacities" (not including musical ability, for example). However, it does not matter that Bostrom and Ord take a wider scope - their arguments can be applied just as easily to the narrower definition of cognitive capacities (i.e. general intelligence) I am interested in examining.

Bostrom and Ord point out that intelligence can plausibly be considered an attribute that has not only relative or positional value (i.e. determined by whether and to what extent others also have that attribute) but also absolute or intrinsic value (i.e. an attribute is valuable in itself). To illustrate: some traits, such as height, seem to have largely positional value. While being two metres tall is valuable to a basketball player, this is only because most other people are far shorter. If we were all to increase our height to two metres in the hope of becoming basketball players, then this height would lose all its positional value, making the enhancements pointless in this regard. While height may have some non-positional value - it's absolutely valuable to be able to reach the apple on the tree - most of its value is positional.

\footnotetext{
${ }^{5}$ Bostrom and Ord, "The Reversal Test."
} 
It may seem that most of the value of intelligence is also positional ("what would be the status of Eton, Oxford and Cambridge if all could go there?"6). However, Bostrom and Ord make a good case for the significant absolute value of intelligence. Although enhancing everyone's cognitive capacities may not increase my chances of getting into Oxford (since I would probably still have the same relative intelligence to everyone else), I may be able to better appreciate art and music and have a more comprehensive understanding of physics or biology, and therefore of life. More intelligent people may also be good for society. Bostrom and Ord ask, "why think that greater mental faculties would be of no value if everyone shared in the improvement?"

There are a couple of general assumptions that Bostrom and Ord make in order to argue in favour of cognitive enhancement. First, they assume that the method of enhancement is genetic engineering. Second, they assume that the technology used is affordable and medically safe (in that it is not immediately dangerous to a subject's health to undergo the enhancement). We can suppose, for the sake of argument, that the enhancement "operation" carries an immediate medical risk similar to a minor medical operation, such as a tonsillectomy.

It should be explicitly noted however, that although Bostrom and Ord classify genetic cognitive enhancement as "medically safe", this makes no prediction or evaluation about the potential longer-term medical, psychological, political, social or cultural consequences that may arise as either a direct or indirect result of enhancement. The point that Bostrom and Ord emphasise is that when making a decision of this nature (i.e. a decision under uncertainty), we are faced with a "double epistemic predicament": 8 uncertainty about both the probabilities and utilities of the consequences.

The double epistemic predicament is not exclusive to cases involving cognitive enhancement, but is a factor in many decisions, such as political reform, marriage or the choice about where to go to university. There is no possible way to precisely

\footnotetext{
${ }^{6}$ Ibid., p.663.

${ }^{7}$ Ibid., p.664.

${ }^{8}$ Ibid., p.657.
} 
determine the long-term consequences of our decisions, which makes it even harder to evaluate those consequences. What Bostrom and Ord highlight here is that when faced with a decision of this type, the judgments we make about the utility of the probable consequences "are not based exclusively on hard evidence or rigorous statistical inference but rely also - crucially and unavoidably - on subjective, intuitive judgment." 9

These unavoidably subjective and intuitive judgments, suggest Bostrom and Ord, can be influenced by many kinds of psychological biases. We must recognise and remove these biases in order to improve our ethical evaluations. Bostrom and Ord contend that one specific type of bias - the status quo bias - "may be responsible for much of the opposition to human enhancement in general and to genetic cognitive enhancement in particular."10 The status quo bias is defined as "an inappropriate (irrational) preference for an option because it preserves the status quo."11

\section{PSYCHOLOGICAL EVIDENCE OF STATUS QUO BIAS}

Bostrom and Ord examine some of the psychological evidence for existence of the status quo bias in human decision making.

In Gilovich et al.'s "Mug Experiment"12 two groups of students were given a survey to complete, after which the members of one group were given mugs and the members of the other group were given chocolate. The experimenters then gave the students the option of swapping their reward for the one they had not been given. Around 90 percent of the students chose to keep the reward they had originally received.

Bostrom and Ord note that although the Mug Experiment seems to indicate the existence of a status quo bias, there is another explanation - the endowment effect that can account for the favouring of the status quo in this experiment. They explain:

\footnotetext{
${ }^{9}$ Ibid., p.657.

${ }^{10}$ Ibid., pp.657-658.

${ }^{11}$ Ibid., p.658.

${ }^{12}$ See Gilovich et al., Heuristics and Biases: The Psychology of Intuitive Judgment (Cambridge: Cambridge University Press, 2000).
} 
We have defined the status quo bias as an inappropriate favoring of the status quo. One may speculate that the favoring of the status quo in the Mug Experiment results from the subjects forming an emotional attachment to their mug (or chocolate bar). An endowment effect of this kind may be a brute fact about human emotions and as such may be neither inappropriate nor in any sense irrational. The subjects may have responded rationally to an a-rational fact about their likings. There is thus an alternative explanation of the Mug Experiment which does not involve status quo bias. $^{13}$

While the endowment effect explains that the subjects in the Mug Experiment acted rationally when they chose to keep their original gift, it cannot rationally justify a moral opposition to genetic cognitive enhancement. Simply because you preferred to keep your chocolate bar does not mean that others should be prevented from swapping theirs, if they so desire. Likewise, the emotional attachment a person has to their own cognitive capacities may justify them not becoming cognitively enhanced, but it is insufficient to make the moral claim that others also should not be permitted to enhance themselves. A preference for the status quo due to an endowment effect cannot be good evidence for the moral evaluation that genetic cognitive enhancement should not be permitted. In this sense, favouring the status quo is inappropriate.

Bostrom and Ord then examine two other studies which they believe can only be accounted for by the status quo bias.

In the first study - "Hypothetical Choice Tasks"14 - all participants were asked how best to invest a large (imaginary) inheritance. The potential options for investment were: a moderate risk company, a high-risk company, treasury bills or municipal bonds. Some participants were presented with the scenario in a "neutral" version, where no status quo was indicated (i.e. the money was not currently invested in any of the options). Other participants had the scenario given with one of the options representing the status quo (i.e. with the money already invested in one of the

\footnotetext{
${ }^{13}$ Bostrom and Ord, "The Reversal Test," p.659 - my italics.

${ }^{14}$ See William Samuelson and Richard Zeckhauser, "Status Quo Bias in Decision Making," Journal of Risk and Uncertainty 1:1 (1988), pp.7-59.
} 
options). Participants deemed an investment option much more favourable when the option represented the status quo.

Similar results were observed in a second study - "Electric Power Consumers"15 where customers were asked which option they considered the best out of six different combinations of service reliability and rates. Over 60 percent of consumers who already received high reliability and high rates from their own power company indicated a preference for the status quo with only 5.7 percent choosing the option of low reliability/low rates. Likewise, more than 58 percent of subjects with already low reliability/low rates chose to maintain the status quo while only 5.8 percent preferred high reliability/high rates.

Bostrom and Ord claim that these psychological studies, among many others, indicate widespread presence of status quo bias in human decision making. ${ }^{16}$

One of the major psychological factors identified as a source of status quo bias is "loss aversion". Loss aversion is a "phenomenon of choice under both risk and uncertainty [where] losses loom larger than [corresponding] gains"17 and is captured by a value function "that is steeper in the negative than in the positive domain."18 A consequence of loss aversion is that judgments about a particular decision will be affected differently depending on whether the problem is framed in terms of gains or losses. To illustrate this phenomenon, Bostrom and Ord use the example of the "Asian Disease Problem," 19 where options that were identical in real terms were judged differently depending on whether the problem was framed in terms of a gain (subjects preferred the safe bet) or in terms of a loss (subjects became risk-seeking) indicating loss aversion.

\footnotetext{
${ }^{15}$ See Hartman et al., "Consumer Rationality and the Status Quo," Quarterly Journal of Economics 106:1 (1991), pp.141-62.

${ }^{16}$ It is not entirely clear that these studies could not show an endowment effect instead of a status quo bias. However, for argument's sake, we should accept the interpretation supplied by Bostrom and Ord. Note also, that the endowment effect cannot morally justify opposition to enhancement anyway.

${ }^{17}$ Amos Tversky and Daniel Kahneman, "Advances in Prospect Theory: Cumulative Representation of Uncertainty," in Choices, Values and Frames, ed. Daniel Kahneman and Amos Tversky (Cambridge: Cambridge University Press, 2000), p.46.

${ }^{18}$ Daniel Kahneman and Amos Tversky, "Conflict Resolution: A Cognitive Perspective," in Choices, Values and Frames (Cambridge: Cambridge University Press, 2000), p.481.

${ }^{19}$ Amos Tversky and Daniel Kahneman, "The Framing of Decisions and the Psychology of Choice," Science 211:4481 (1981), pp.453-58.
} 
With relevance to the issue of genetically enhancing intelligence, Bostrom and Ord note that "a tendency to overemphasise the avoidance of losses will... favour retaining the status quo, resulting in a status quo bias." 20 They argue that positive consequences to changes in the status quo will not be given equivalent weight, and will therefore be undervalued. From this point Bostrom and Ord endeavour to identify how arguments against genetic cognitive enhancement are influenced by the status quo bias, and propose a solution for removing the bias.

\section{THE REVERSAL TEST}

Let's now return to the moral question under discussion - would enhancing human cognitive capacities have net negative or positive consequences? In attempting to remove status quo bias from this judgment, Bostrom and Ord pose a simple but challenging question to opponents of cognitive enhancement: should we use genetic technologies to decrease our cognitive capacities? Bostrom and Ord assume that nearly all those who oppose increasing our cognitive capacities would also oppose decreasing our cognitive capacities. However, to maintain that we should neither decrease nor increase our cognitive capabilities is to imply that our current level of intelligence (the status quo) is at its local optimum, and this is a claim that needs sound justification. If no good reasons can be provided, argue Bostrom and Ord, it can be assumed that opponents' judgments about the moral permissibility of genetic enhancement technologies have been influenced by the status quo bias, and therefore hold little moral weight.

Bostrom and Ord call this heuristic for diagnosing status quo bias the "Reversal Test":

When a proposal to change a certain parameter is thought to have bad overall consequences, consider a change to the same parameter in the opposite direction. If this is also thought to have bad overall consequences, then the onus is on those who reach these conclusions to explain why our position cannot be improved through changes to this parameter. If they are unable to do so, then we have reason to suspect that they suffer from status quo bias... The rationale of the Reversal Test is simple: if

${ }^{20}$ Bostrom and Ord, "The Reversal Test," p.662. 
a continuous parameter admits of a wide range of possible values, only a tiny subset of which can be local optima, then it is prima facie implausible that the actual value of that parameter should just happen to be at one of these rare local optima. This is why we claim that the burden of proof shifts to those who maintain that some actual parameter is at such a local optimum: they need to provide some good reason for supposing that it is so. ${ }^{21}$

An argument in favour of maintaining the status quo does not automatically suffer from status quo bias. However, it must provide a good justification for opposing changes to the status quo.

\section{ARGUMENTS AGAINST COGNITIVE ENHANCEMENT}

Bostrom and Ord critically examine a number of possible responses to the Reversal Test in the case of cognitive enhancement. However, they conclude that all responses ultimately fail.

\section{Argument from Evolutionary Adaptation}

One potential strategy for opponents of cognitive enhancement is to argue that the current level of intelligence is at its local optimum because evolution has selected for that particular value, with higher or lower values being selected against. Any change in the current parameter is therefore suboptimal, since if it were best natural selection would have selected for it. This argument puts the burden of proof back on those who advocate a change of the status quo. In this case, proponents of cognitive enhancement will have to show how the argument from evolutionary adaptation is ineffective in opposing cognitive enhancement.

Bostrom and Ord suggest several reasons why the argument from evolutionary adaptation does not succeed. First, they argue that our environment is drastically changing before evolution has time to "catch up". Since our modern environment is radically different from our ancestors' environment, traits that may have once been adaptive are adaptive no longer, and vice versa. For example, a sweet tooth was once

${ }^{21}$ Ibid., pp.664-665. 
a good way to identify high-calorie food in an environment where calorific food was limited, but has now become maladaptive, substantially increasing the risks of lifestyle-related illnesses like obesity and type 2 diabetes. Furthermore, while a life in the Pleistocene did not require sophisticated abstract skills like knowledge of maths or physics, our modern life places great demands on these abilities.

Secondly, evolutionary trade-offs may have made increased brain-power maladaptive, even if increased cognitive capacities would have been beneficial. As an example, Bostrom and Ord submit that the metabolic costs potentially associated with increased intelligence or brain size are no longer prohibitive since we now have an abundance of readily-available food.

Thirdly, they argue that natural selection may not have discovered traits that would be adaptive for humans, especially if those traits (like increased cognitive capacity) incur an initial fitness penalty (like needing substantial amounts of food to survive). However, unlike the blind forces of natural selection, we can now direct genetic modifications toward a specific aim.

Fourth, evolution and human happiness or well-being do not necessarily coincide. For example, rape and murder may have been evolutionarily adaptive in terms of propagating genes but it certainly gives us no reason to think these things are good for our lives. Accordingly, simply because evolution has not brought about higher intelligence provides no sound justification for thinking it would not be good for us all the same.

\section{Argument from Transition Costs}

The second way in which one may try to meet the Reversal Test's burden of proof is to appeal to transition costs. In short, even if it were true that intelligence is not at a local optimum and enhancing human intelligence would have beneficial consequences, if cognitive enhancement would incur substantial transition costs that would outweigh its benefits, then we should not increase our cognitive capacity. 
To illustrate this point Bostrom and Ord consider whether or not the United States should adopt the metric system of measurement. While there is a good case to be made that the metric system is much better than the imperial system, there may be major transition costs associated with change (such as learning the new system, changing school textbooks and buying new measuring equipment), all of which would take time, effort and money. The transition costs may outweigh the benefits, meaning that simply regarding the metric system as better does not automatically give us good reason to assume that it is in the United States' best interests to adopt it.

Bostrom and Ord consider the potential transition costs of cognitive enhancement. Perhaps school curricula would require modification. Games and recreational activities may need updating because they would become too easy or too boring. Family friction may result if very smart children were being raised by less smart parents.

However, Bostrom and Ord suggest that worries about these potential transition costs are overstated. "The cost would be one-off while the benefits of enhancement would be permanent." 22 Rewriting school curricula already occasionally occurs and inventing new games would be simple, they contend. In fact, most games (particularly sports) do not depend on high intelligence to remain exciting or enjoyable. In addition, many children are already much more intelligent than their parents, but we tend to consider the potential resulting friction as a minor inconvenience compared to the value we place on having smart children.

\section{Argument from Risk}

Although a course of action (such as enhancing intelligence) may have potential benefits, if these benefits are relatively low while the potential negatives are relatively high, then the prudent course of action would be to maintain the status quo. While intelligence may not be at a local optimum, one may argue against change because of the risk that increasing intelligence would bring about a situation worse than the status

${ }^{22}$ Ibid., p.668. 
quo instead of better. An argument of this sort can potentially meet the Reversal Test challenge, although Bostrom and Ord maintain that in this case it fails.

First, Bostrom and Ord submit that cognitive enhancement has a number of obvious potential benefits. Increased intelligence could help further scientific study, eradicate poverty, conserve the environment and find cures for diseases. They argue that rather than appropriate levels of risk-aversion weighing heavily on the side of maintaining the status quo, the goal of reducing risk may be a good argument in support of enhancing intelligence, since higher cognitive capacities may enable us to decrease serious medical, social and environmental risks.

Secondly, although some of the long-term effects may be uncertain, they may also be "much better than anybody expected." 23 Bostrom and Ord point out that while there may be some downsides to cognitive enhancement, in order to determine the expected utility we must also consider its upsides. They submit that perhaps we can not as easily imagine the potential benefits of cognitive enhancement as we can the potential negatives. However, there is good reason to believe that the consequences, although uncertain, will be good:

Imagine a tribe of Australopithecus debating whether they should enhance their intelligence to the level of modern humans. Is there any reason to suppose that they would have been able to foresee all the wonderful benefits we are enjoying thanks to our improved intellect? Only in retrospect did the myriad technological and social gains become apparent. And it would have been even less feasible for an Australopithecus to foresee the qualitative changes in our ways of experiencing, thinking, doing, and relating that our greater cognitive capacity have enabled, including literature, art, music, humour, poetry, and the rest of Mill's "higher pleasures." All these would have been impossible without our enhanced mental capacities; who knows what other wonderful things we are currently missing out on? ... The uncertainty of the ultimate consequences of cognitive enhancement, far from being a sufficient ground for opposing them, is actually a strong consideration in their support. ${ }^{24}$

\footnotetext{
${ }^{23}$ Ibid., pp.668-669.

${ }^{24}$ Ibid., p.669
} 
By highlighting the cognitive differences between Australopithecus and Homo sapiens, we can more clearly see the great value we place on our higher cognitive capacities. Bostrom and Ord use this comparison in order to postulate the creation of comparable benefits if we enhanced our current intelligence to "posthuman" 25 levels.

\title{
Argument from Person-Affecting Ethics
}

However, even if it were true that cognitively enhanced people would lead better lives, one may still argue against enhancement from a person-affecting view of ethics. One could maintain that we should only:

\begin{abstract}
Maximise the benefits we provide to people who either already exist or who will come to exist independently of our decisions. On such views there is no general moral reason to bring into existence people whose lives will be very good. By extension, there may be no moral reason to change ourselves into radically different sorts of people whose lives would be better than the ones we currently lead. ${ }^{26}$
\end{abstract}

However, Bostrom and Ord believe they can counter this sort of argument in the case of future people by using a type of Reversal Test. They appeal to the intuition that we should not deliberately select embryos with severe genetic disabilities. If this intuition is right then either there are other non-person-affecting moral considerations to take into account (because if these embryos were not chosen then the disabled person in question would not even exist), or it is the case that selecting severely disabled embryos would negatively impact people who already exist. On either account, the Reversal Test shifts the burden of proof back onto opponents of cognitive enhancement to show why the grounds for opposing a decrease in cognitive capacities do not also act as grounds in favour of increasing cognitive capacities.

The same kind of Reversal Test can be used in the case of people who already exist. If we believe it would be a bad idea to deliberately lower our own intelligence, then we should also accept that it would be a good idea to increase our intelligence, or else justify why our current cognitive capacities are at their local optimum.

\footnotetext{
${ }^{25}$ A "posthuman" is a genetically enhanced human - someone who has transcended the boundaries of humanness.

${ }^{26}$ Bostrom and Ord, "The Reversal Test," p.670.
} 
It should be noted, however, that Bostrom and Ord recognise that use of the Reversal Test as an objection to person-affecting arguments against cognitive enhancement carries more weight in cases of slight or moderate enhancements than in the case of significant enhancements. This is because a person who has undergone a radical enhancement might effectively become a completely different person from the one who existed before. The enhancement would arguably have then been bad for the original person, since it caused them to no longer exist. However, Bostrom and Ord argue that since we do not consider it is bad for children to grow up, despite the fact that they become radically different people, why should we think it is bad for ourselves to undergo radical cognitive enhancements?

\section{RESPONDING TO THE REVERSAL TEST}

From their evaluations of the arguments from evolutionary adaptation, transition costs, risk and person-affecting ethics, Bostrom and Ord conclude that the strongest potential arguments against enhancement are not robust enough to successfully pass the Reversal Test. However, I present a more effective argument against the use of genetic cognitive enhancements in chapter 3 , which meets the initial burden of proof set by Bostrom and Ord's Reversal Test. I then go on to defend this argument against potential objections in chapter 4 . 
CHAPTER 3

\section{The Case against Cognitive Enhancement}

\section{THE REVERSAL TEST CHALLENGE}

The Reversal Test is a burden of proof argument and as such, it is very compelling. Assuming that most opponents of the genetic enhancement of intelligence would also oppose decreases in intelligence, it puts the onus on those who contend that cognitive enhancement would be worse than the status quo to offer good reason for holding intelligence to be at a local optimum. The goal of this chapter is to meet this initial burden of proof. However, I do not intend to argue that improvements in intelligence could not be beneficial to the enhanced individual. Instead, I will contend that the likely unequal distribution of cognitive enhancements will have negative effects on those who cannot afford them. Permitting enhancements would therefore be unjust.

I will not argue my case against cognitive enhancement against every conceivable objection here. While I will respond to the strongest objections to my argument in chapter 4, it is not the point of this chapter. What I do intend to establish in this chapter is that my opposition to enhancement is not influenced by the status quo bias - this will meet the Reversal Test's initial burden of proof. By responding to potential objections in chapter 4 I will then show that the arguments I offer here are sound.

However, before defending my case against cognitive enhancement, I will briefly discuss a few possible responses to the Reversal Test. Although I will ultimately reject these arguments, they are worth mentioning, if only to notify the reader of their potential use. 


\section{Possible Responses to the Reversal Test}

In their paper Bostrom and Ord critically evaluate a number of potential responses to the Reversal Test, all of which they argue are ultimately unsatisfactory. Although I will later discuss considerations of risk, I will not pursue the argument from evolutionary adaptation or the argument from person-affecting ethics, as I grant that Bostrom and Ord (and others ${ }^{27}$ ) have provided adequate responses to these. In relation to the argument from transition costs, I wish to briefly note that the cost of enhancement does not occur once in total; rather, each instance of enhancement incurs its own one-off cost. I will return to this point later.

A potentially effective way to counter Bostrom and Ord's Reversal Test is to advance an argument against enhancement that has a deontological component. Some such arguments that have been proposed include the "playing God" objection, ${ }^{28}$ Michael Sandel's "openness to the unbidden" argument, ${ }^{29}$ Leon Kass's appeal to the "wisdom of repugnance" ${ }^{30}$ and Francis Fukuyama's contention that genetic enhancement goes against human nature. ${ }^{31}$ Bostrom and Ord note that since the Reversal Test cannot diagnose cognitive biases in deontological arguments against enhancement, nonconsequentialist considerations may indeed be able to pass the test. However, where objections to enhancement are in part based on its purported consequences (as is the case with Sandel's), the Reversal Test should be able to diagnose status quo bias if and when it is present. ${ }^{32}$

\footnotetext{
${ }^{27}$ James Hudson notes, for example, that while "it would be a gross misrepresentation to portray our present social environment...there must be some incongruity between modern living conditions and genotypes adapted mostly to more primitive ages, and genetic tinkering to secure better social adaptation retains some appeal." James Hudson, "What Kinds of People Should We Create?" Journal of Applied Philosophy 17:2 (2000), p.133.

${ }^{28}$ Although not specifically a religious objection (it might also be termed the "meddling with nature" objection), it is often raised in a religious context. See, for example, "Alan Billings on 'Playing God," http://hplusbiopolitics.wordpress.com/2008/04/03/alan-billing-on-playing-god/.

${ }^{29}$ Michael Sandel, "The Case against Perfection," The Atlantic Monthly 293:3 (2004).

${ }^{30}$ Leon Kass, "The Wisdom of Repugnance," The New Republic 216:22 (1997); Leon Kass, Life, Liberty and the Defense of Dignity: The Challenge for Bioethics (San Francisco: Encounter Books, 2002).

${ }^{31}$ Francis Fukuyama, Our Posthuman Future: Consequences of the Biotechnology Revolution (New York: Farrar, Straus \& Giroux, 2002).

${ }^{32}$ Sandel's contention that permitting enhancements would encourage parents to be too controlling may pass the Reversal Test, since he also argues that parents should reduce their control over their children.
} 
However appealing any of the above concerns are for the opponent of cognitive enhancement, it will not be my method to appeal to them here. One reason for this is that many of these arguments have already been extensively discussed in the literature on the subject. ${ }^{33}$ Furthermore, simply for argument's sake I will grant that these popular concerns do not provide an adequate response to the Reversal Test. The reason for granting this concession is to establish that regardless of whether the above concerns are fully persuasive, the Reversal Test can be better met, and enhancements objected to, by a more compelling argument. In the rest of this chapter I contend that the probable distribution of cognitive enhancements will be likely to cause serious injustices to the worst-off members of society.

In order to defend this claim, I first present a method to show that wealth-based access to enhancement technologies (i.e. the private purchase of enhancements) would result in an unequal distribution of cognitive enhancements between the rich and the poor. I then introduce a principle of distributive justice, the 'no harm principle', which I argue is a plausible way of governing the distribution of genetic enhancement technologies. The no harm principle states that policies that benefit already well-off members of society are prima facie unjust if they risk serious harm to the worst-off members of society. I argue that since genetic enhancements are likely to seriously harm the poor if accessed mainly by the rich, their use is unjust according to the no harm principle. This gives us a prima facie reason to prohibit cognitive enhancements.

I contend that the unequal distribution of genetic enhancements would be likely to harm the poor in three ways. First, through an increased likelihood of serious discrimination; second, the unenhanced poor would be likely to lose valuable social and political reciprocal relationships; and third, the positional advantages conferred on the enhanced by higher intelligence may competitively harm the poor, leaving them worse off in absolute terms.

\footnotetext{
${ }^{33}$ See, for example, Matti Häyry, "Categorical Objections to Genetic Engineering - A Critique," in Ethics and Biotechnology, ed. Anthony Dyson and John Harris (London: Routledge, 1994); Anthony Dyson, "Genetic Engineering in Theology and Theological Ethics," in Ethics and Biotechnology, ed. Anthony Dyson and John Harris (London: Routledge, 1994); Thomas H. Murray, "Enhancement," in The Oxford Handbook of Bioethics, ed. Bonnie Steinbock (Oxford: Oxford University Press, 2007); Glenn McGee, "Parenting in an Era of Genetics," The Hastings Centre Report 27:2 (1997).
} 
Once I have shown why permitting wealth-based access to genetic cognitive enhancement is prima facie unjust, I consider some potential responses that could be made on behalf of the proponent of enhancement. However, I conclude that any plausible arguments that could be made in support of enhancement are ultimately ineffective. We can conclude, therefore, that permitting wealth-based access to genetic cognitive enhancement is all-things-considered unjust. Accordingly, it should not be permitted.

I then discuss a revised version of the Reversal Test. However, it too does not lead us to conclude that my opposition to enhancement is influenced by status quo bias.

I begin by showing why wealth-based access to genetic cognitive enhancements would result in the unequal distribution of enhancements between the rich and the poor.

\section{THE DISTRIBUTION OF ENHANCEMENTS}

One of the presuppositions under which Bostrom and Ord set their argument is that genetic cognitive enhancement would be "affordable". However, this assumption is problematic in two ways. First, and most obviously, as a practical rather than ideal matter, affordability is unlikely to be achievable, since enhancements would probably be very expensive and therefore unaffordable for most people. Secondly, enhancements are likely to remain unequally distributed between the rich and poor even if the ideal condition of affordability is met, since "affordability" is a relative term and does not always translate into "accessibility". The term "affordable" is often used to refer to goods and services that are not only accessible to the rich; however, goods that are inaccessible to the poor may still be considered affordable. For example, many New Zealanders would consider computers affordable, yet for those in the lowest socio-economic bracket a computer is probably not affordable. Similarly, in developed countries asthma medication and clean water are both affordable but to many people around the world these things are neither affordable nor accessible. Given these problems, wealth-based access to genetic cognitive enhancements is 
likely to result in an unequal distribution of enhancements between the rich and the poor.

\section{Enhancements Costly and Technologically Complicated}

Even leaving aside the considerable difficulties associated with developing enhancement technologies, both somatic and germline genetic enhancements are likely to be technologically complicated to administer. Somatic enhancement of intelligence would require that the introduced gene makes it into all or a majority of the enhancement candidate's brain cells. Germ-line enhancement would require that the ovum (before conception), zygote or blastomere (after conception) is enhanced. This means that the ovum must be extracted, enhanced, then fertilised (or fertilised, then enhanced) before being implanted back into the womb.

New and complicated technologies are not cheap. For example, today in New Zealand, over 30 years after the first successful in vitro fertilisation (IVF) pregnancy, one cycle of IVF still costs around NZ $\$ 10,000$ to $\$ 12,000 .^{34}$ The cost of both somatic and germline enhancements would reflect the cost of their development and the technological difficulty associated with their administration. This is likely to be much higher than the cost of IVF, given the technological advances required. However, even if enhancements eventually cost a similar amount to IVF today, at $\$ 10,000$ it is clear that many New Zealanders (and most people in developing countries) would be unable to afford them. Wealth-based access to enhancements would therefore result in radical differences in uptake rates between the rich and the poor.

It has been suggested that this unequal distribution could be somewhat mitigated by germline engineering. ${ }^{35}$ Since any enhancement would be heritable, an initially incomplete distribution of genetic enhancements could potentially have much wider effects, given time. However, relying on germline engineering to help distribute the effects of cognitive enhancement more widely is not a viable solution to access

\footnotetext{
${ }^{34}$ Littlies: For Practical Parenting, "Secondary Infertility," http://www.littlies.co.nz/page.asp?id=244; New Zealand Herald, "The High Cost of IVF," http://www.nzherald.co.nz/financialplanning/news/article.cfm?c_id=517\&objectid=10382817.

${ }^{35}$ Søren Holm, "Genetic Engineering and the North-South Divide," in Ethics and Biotechnology, ed. Anthony Dyson and John Harris (London: Routledge, 1994), p.52.
} 
problems. First, germline enhancements may be no less expensive than somatic enhancements and therefore no less unevenly distributed. Second, the wider-reaching effects of germline enhancement would take generations to be properly realised, since any significant indirect enhancement effects would not be felt until the children and grandchildren are born. Third, while the initial individual's enhancement would be passed down to their descendants, by then it is likely that the wealthy would have access to even better enhancement technologies. Fourth, families originally too poor to afford enhancements or (relevant to the global case) living in remote regions where enhancements are not available would be more likely to have offspring who also could not afford enhancements. We may then see access problems through a family line.

\section{Subsidisation of Enhancements}

A proponent of enhancement may instead suggest that non-wealth-based access to enhancement technologies would provide a solution to the prohibitive cost of cognitive enhancements for the less well-off. Returning to the IVF analogy, it may be pointed out that while IVF is expensive, the New Zealand government is able to fund up to two cycles for couples who meet specific criteria. The proponent of enhancement may therefore conclude that similar public funding of genetic enhancement technologies would ensure their widespread accessibility. Another potential solution is if the wealthy were permitted to purchase any enhancement they were willing to fully subsidise for the poor. ${ }^{36}$

In his book Citizen Cyborg, James Hughes agrees with the prediction that enhancements would be publicly funded. He evaluates Lee Silver's contention that unequal access to genetic enhancements could lead to a division between the "GenRich" and the "GenPoor":

\footnotetext{
${ }^{36}$ Non-wealth-based access to enhancement technologies would be acceptable according to the argument I will present, since the most morally problematic issues only arise because of enhancement's unequal distribution. This would also be conditional upon enhancements being medically safe and widely available to the global poor. However, as I will show, non-wealth-based access to enhancements is unlikely to be practically achievable.
} 
If genetic enhancement were to become possible, democratic publics would take to the streets with knives and guns before allowing Silver's scenario to come to pass. The lower and middle classes would insist that their children be provided with the same eugenic enhancements available to the children of the rich. In time, the U.S. government would subsidize eugenic programmes, not to create an overclass but to preserve equality, to elevate everyone's natural endowments. ${ }^{37}$

It seems to me, however, that these predictions are grossly optimistic. In the United States alone the latest figures show 47 million people without health insurance. ${ }^{38}$ Until we see rioting in America over universal health care, we can be reasonably confident that universal access to enhancements is unlikely.

Furthermore, while the New Zealand government subsidises IVF for couples who meet specific criteria, full subsidisation of enhancements ${ }^{39}$ at the same price as IVF (a very conservative estimate) would cost the country $\$ 40$ billion - about one third of New Zealand's GDP ${ }^{40}$ and four times the annual health budget. ${ }^{41}$ This figure does not include the enhancement of the roughly 57,000 babies born each year ${ }^{42}$ or the cost of enhancing immigrants. Furthermore, while the initial enhancement may incur a oneoff financial cost, each further enhancement would also be prohibitively expensive, given that technology does not remain static. A program that required the wealthy to fully subsidise any enhancements they want for the poor is similarly problematic. The cost of subsidisation means that the only reasonable assumption we can make is that enhancements would be unequally distributed between the rich and poor.

\footnotetext{
${ }^{37}$ Here Hughes relates Adam Wolfson's evaluation of Lee Silver. James Hughes, Citizen Cyborg: Why Democratic Societies Must Respond to the Redesigned Human of the Future (United States of America: Westview Press, 2004), p.133.

${ }^{38}$ National Coalition on Health Care, "Health Insurance Coverage," http://www.nchc.org/facts/coverage.shtml.

${ }^{39}$ This calculation assumes that around 4 million New Zealanders would undergo enhancements. And while some may reject enhancements for religious or cultural reasons, I cannot imagine that this will be a significant proportion of the population. However, even if many people did choose to opt out, the cost of enhancement for the rest of New Zealand still seems likely to be far too high for public funding to be practically achievable. Furthermore, the more people who choose to opt out of enhancement, the less likely public opinion will be in favour of taxpayer funding for those who opt in.

${ }^{40}$ Statistics New Zealand, "Gross Domestic Product," http://www.stats.govt.nz/products-andservices/hot-off-the-press/gross-domestic-product/gross-domestic-product-jun08qtrhotp.htm?page $=$ para004Master.

${ }^{41}$ Pete Hodgson, "Budget 06: A Health Budget for All NZ Families," beehive.govt.nz, 18 May 2006, http://www.beehive.govt.nz/?q=node/25799.

${ }^{42}$ Statistics New Zealand, "Births and Deaths: June 2006 Quarter," http://www.stats.govt.nz/store/2006/08/births-deaths-jun06qtr-hotp.htm?page=para003Master.
} 
The statistics are sufficient to show the implausibility of Hughes' claim applied globally: 19 percent - nearly 1 billion people - of the World's population subsists on less than US $\$ 1$ per day; ${ }^{43}$ inequality both within and between countries has risen; ${ }^{44}$ many developed countries, such as New Zealand, are failing to live up to their international obligations for overseas development aid; ${ }^{45}$ and while vaccination rates in developed countries are above 95 percent, they barely reach 20 percent in many developing countries. ${ }^{46}$ The enormous economic disparities between the rich World and the poor World mean that even if the ideal condition of affordable enhancements were achieved in developed countries, cognitive enhancements would remain unaffordable and inaccessible for the majority of people in developing countries. This would create serious problems of global justice.

The prohibitive cost of enhancements means that permitting only non-wealth-based access to enhancement technologies would effectively amount to a ban on any enhancement worth pursuing. Wealth-based access to enhancements therefore represents the only likely scenario for the introduction of genetic enhancement. So, while proponents of enhancement, like Hughes, are entitled to espouse its benefits to support their arguments, they are not entitled to make fanciful predictions, like assumptions of universal access, which are so unlikely to be borne out.

Economic factors may not be the only influences on the uptake rate of enhancements. Perhaps cultural beliefs will deter people from genetically enhancing themselves or their children. Currently the evidence in support of this idea is mixed, with some studies suggesting that cultural barriers do play a role in determining the uptake rates of vaccinations ${ }^{47}$ and other studies indicating that these statistics can be better

\footnotetext{
${ }^{43}$ Department of Economic and Social Affairs of the United Nations Secretariat, "The Millennium Development Goals Report 2007," (New York: The United Nations, 2007), pp.6-7.

${ }^{44}$ United Nations 2005 Millennium Development Goals Report, "Millennium Development Goals: Poverty and Hunger," reported on BBC News, http://news.bbc.co.uk/2/shared/spl/hi/in_depth/millennium_development_goals/html/default.stm. ${ }^{45}$ Oxfam Press Release, "New Zealand Development Aid Still Lags Far Behind," reported on Scoop, 4 April 2008, http://www.scoop.co.nz/stories/PO0804/S00086.htm.

${ }^{46}$ Gebre-Egziabher Kiros and Michael J. White, "Migration, Community Context, and Child Immunization in Ethiopia," Social Science \& Medicine 59:12 (2004).

${ }^{47}$ Jeremy I. Hawker et al., "Widening Inequalities in MMR Vaccine Uptake Rates among Ethnic Groups in an Urban Area of the UK during a Period of Vaccine Controversy (1994-2000)," Vaccine
} 
explained by poverty. ${ }^{48}$ However, we must be careful not to place too much moral emphasis on the issue of cultural barriers, since it is access to rather than the use of cognitive enhancements that we should seek to maximise. It should be within a person's legitimate right to bodily integrity to refuse cognitive enhancement, whatever their reasons for doing so.

This analysis shows that while Bostrom and Ord postulate "affordability", we cannot consider anything but unequal access to enhancements to be a real life practical probability. We must morally evaluate the use of enhancements under predicted real life conditions, since it is real rather than ideal conditions that lead to either good or bad consequences for people. Accordingly, our moral assessment of the use of wealth-based access to genetic cognitive enhancements should be made with the expectation that they will be unequally distributed between the rich and the poor.

\section{THE 'NO HARM PRINCIPLE'}

So far I have advanced the position that wealth-based access to genetic enhancements would result in radically different uptake rates between the rich and the poor. At this stage, a proponent of enhancement may ask, "what's wrong with an unequal distribution of cognitive enhancements?" The answer to this question will be concerned with what counts as a just distribution of goods. If the distribution of cognitive enhancements is likely to cause injustice, then we have good reason to prohibit them.

It is not my goal in this thesis to extensively debate the merits of a particular principle of distributive justice. Instead, I start by introducing a moral principle that we can accept as intuitively plausible, and I then show how we can apply this principle to the case of cognitive enhancement. And, it is clear that on a number of plausible conceptions of distributive justice, wealth-based access to genetic cognitive

25:43 (2007); Danielle C. Ompad et al., "Distribution of Influenza Vaccine to High-Risk Groups," Epidemiologic Reviews 28:1 (2006); Ellyn Micco et al., "Differential Willingness to Undergo Smallpox Vaccination among African-American and White Individuals," Journal of General Internal Medicine 19:5 Pt 1 (2004).

${ }^{48}$ Elizabeth T. Luman et al., "Uptake of Varicella Vaccination among Young Children in the United States: A Success Story in Eliminating Racial and Ethnic Disparities," Pediatrics 117:4 (2006). 
enhancements would not be permitted. If this is the case, then it provides a compelling response to the Reversal Test. So, in what follows, I will introduce a moral principle to motivate the idea that the unequal distribution of enhancements is morally different from the unequal distribution of other goods (such as expensive cars). In the rest of the chapter I will illustrate precisely why genetic cognitive enhancements should be prohibited according to this principle.

I should also briefly note at this point that the principles of distributive justice I will consider are meant to govern our background social institutions. So, while these principles should guide the distribution of cognitive enhancement technologies, they do not require people to redistribute or necessarily compensate for their natural cognitive endowments.

One potential strategy we could take is to adopt a Rawlsian view of distributive justice. A Rawlsian may use the difference principle to argue that inequalities in access to certain social primary goods (in this case genetic enhancements) should only be permitted if the distribution benefits the worst-off. ${ }^{49}$

The idea of primary goods is a valuable one. A primary good is a good that every rational person should want, regardless of their life goals and interests. For example, income is a primary good, because for whatever a person wants to do in life, a greater income is nearly always more useful in achieving those goals than a lesser income. On the other hand, musical talent is not a primary good, since it is irrelevant for the effective realisation of most goals. Following Rawls, I will take it that we should be concerned with the distribution of primary goods. ${ }^{50}$

It is in line with Rawls to consider intelligence a primary good. Being intelligent is almost always beneficial, no matter what goals a person wishes to achieve. This idea

\footnotetext{
${ }^{49}$ For more on Rawls's theory of justice see John Rawls, A Theory of Justice (Cambridge, MA: The Belknap Press of Harvard University Press, 1971); John Rawls, Political Liberalism (New York: Columbia University Press, 1993); John Rawls, Justice as Fairness: A Restatement (Cambridge, MA: The Belknap Press of Harvard University Press, 2001).

${ }^{50}$ It is debateable whether or not a fine line can be drawn between primary and non-primary goods. Nevertheless, however strict we wish to make the requirements for something being a primary good, intelligence surely meets this requirement if anything does.
} 
makes it clearer, now, why I wanted to exclude such abilities as musical talent in my discussion of cognitive enhancement. ${ }^{51}$

The difference principle would consider unjust a policy that benefited already welloff sections of the population but had no effect on the worst-off sections of society. However, it is at least arguable that a policy that benefits some and harms no one ought to be permitted. A potential problem with the difference principle, then, is that it does not capture the intuitive idea that a world where some people are benefited is better than a world where no people are benefited, all else being equal. ${ }^{52}$

Nevertheless, we can soften the difference principle in favour of another principle that does capture these intuitions. We can motivate a criticism of the unequal distribution of genetic enhancement by appealing to the strong moral intuition that a policy that benefits people who are already well-off but that harms the less well-off is inherently unfair. We can call this the 'no harm principle' of distributive justice. The no harm principle can be described more precisely as:

\section{A policy that benefits already well-off members of society but harms the worst-off members of society is prima facie unjust.}

Under the no harm principle, it is prima facie morally permissible to allow the wealthy to purchase genetic enhancements to benefit themselves, as long as their doing so is not harmful to those who cannot afford the enhancements. It is prima facie unjust to allow the wealthy to do so if this does harm the worst-off. For example, if the non-universal use of cognitive enhancements created a society like that depicted in Gattaca, where the unenhanced were prevented from being employed in any area except menial work, then this would be unjust according to the no harm principle. If the use of cognitive enhancements by the wealthy increased relative inequality but left the poor just as well off in absolute terms, then the no harm

\footnotetext{
${ }^{51}$ Remember, although we may be required to distribute cognitive enhancement technologies in accordance with the principle we choose, we are not required to make people redistribute their natural intelligence genes.

${ }^{52}$ Bertil Tungodden, "The Value of Equality," Economics and Philosophy 19:1 (2003), p.8.
} 
principle would consider it just to permit wealth-based access to cognitive enhancements.

Using the no harm principle rather than the difference principle to motivate an argument against cognitive enhancement sets a harder task for opponents of enhancement. The no harm principle must show not only that permitting wealthbased access to enhancements would fail to benefit the worst-off but that it would also harm the worst-off. As I have stated, my goal is not to extensively defend the no harm principle against other possible principles of distributive justice. Instead, I make the claim that we can accept the no harm principle as intuitively plausible. The no harm principle can then be employed to make a case against the use of genetic cognitive enhancement and so provide a compelling response to the Reversal Test (i.e. show that opposition to enhancements based on the no harm principle is not influenced by the status quo bias).

I will now briefly describe how we should handle considerations of risk under uncertainty. I will then show precisely how permitting wealth-based access to genetic cognitive enhancement would be likely to harm the poor and therefore be unjust according to the no harm principle.

\section{Risk under Uncertainty}

In chapter 2 I noted Bostrom and Ord's assertion that uncertainty about the consequences of genetic enhancement weigh more favourably on the side of permitting enhancement rather than prohibiting it. They support this assertion by appealing to the individual benefits of enhancement (highlighted by the Australopithecus example) and noting enhancement's potential social benefits (scientific, medical, environmental, social and economic).

However, my conclusions are very different. I argue instead that the harms to the poor weigh heavily in favour of prohibiting cognitive enhancement. This is because while the Reversal Test assumes a situation where everyone in society is cognitively enhanced, the actual distribution of enhancements will almost certainly be unequal. 
This creates the potential for serious moral, social, political and economic harms to those who miss out. So, we cannot appeal to its individual benefits (as Bostrom and Ord do) to support the contention that enhancements will be beneficial, as the no harm principle is primarily concerned about consequences for those who do not become enhanced. Furthermore, the social benefits of enhanced intelligence may not be as great as Bostrom and Ord claim (I will return to this point later). While of course the conclusions I will draw will be somewhat speculative, I will establish that wealthbased access to enhancements poses a real and substantial risk of harm to the poor. Illustrating precisely how unequal access to cognitive enhancements is likely to have negative consequences for the unenhanced should be given more weight than Bostrom and Ord's predicted but undefined good consequences.

I will not rely on any particular conception of risk-aversion or method of dealing with risk under uncertainty. So, I do not intend my arguments against enhancement to conform to support a sort of precautionary principle that requires enhancement's proponents to guarantee the non-universal use of enhancements will not harm the poor. However, I maintain that once I have illustrated precisely how harms may arise, the onus is then on proponents of enhancement to present good reason for thinking these harms can be avoided (although I do not think they will be able to do this). The goal of this chapter, then, is to show that harm to the poor constitutes a real and serious possibility, not that the harms are certain to occur. The initial no harm principle can therefore be altered to state:

A policy that benefits already well-off members of society but carries a significant risk of harm to the worst-off members of society is prima facie unjust.

In the rest of this chapter I will show how wealth-based access to genetic enhancements would be likely to harm the poor in three ways. First, the worst-off would be at a significant risk of harm through discrimination, because the cognitively enhanced would be likely to equate their biologically superior intellectual capacities with moral superiority. Second, if cognitive enhancement increased its users' intelligence by a substantial degree, the unenhanced would also be likely to lose valuable reciprocal social and political relationships. Third, because of the 
considerable positional value of intelligence, the poor would be at risk of suffering competitive harms that would leave them worse off in absolute terms.

\section{DISCRIMINATION}

The unequal distribution caused by permitting wealth-based access to cognitive enhancements gives rise to a major moral concern: that the unenhanced will suffer serious discrimination as a result. If already well-off members of society are enhanced to be more intelligent than the rest, "what kinds of decisions would then flow from a (warranted?) belief in biological/genetic superiority?"53 I argue in line with Søren Holm - that the enhanced would be likely to equate their biologically "better" intellectual capacities with the moral or value notion of "better." 54

\section{Personhood Criteria for Moral Equality}

James Hughes presents an argument that he believes will ensure a society consisting of both humans and posthumans would be one of moral equality. Hughes argues that the conception of moral equality should not be founded on an individual's biological capacities. Instead, he maintains that plants, animals, humans and posthumans should all be evaluated on the same criteria inherent in the notion of "personhood".

Hughes does not commit to choosing the specific requirements for personhood, but he does make some suggestions as to the sort of criteria that would be important. They include: the ability to feel pain or suffer; self-awareness; the capacity for mature reflection; reason and rationality; thought and conscience; and empathy (a capacity he suggests is essential to the expression of the other proposed criteria for personhood) ${ }^{55}$ Hughes contends that on whichever of these plausible criteria one chooses, citizenship and moral equality should be accorded to "persons" rather than "humans" or "posthumans". Holding a personhood view of equality would ensure that the enhanced and the unenhanced recognise each other as worthy of full moral respect.

\footnotetext{
${ }^{53}$ Holm, "Genetic Engineering and the North-South Divide," p.56.

${ }^{54}$ Ibid., pp.57-58.

${ }^{55}$ Hughes, Citizen Cyborg, pp.221-223 and 226.
} 
While I fully agree with Hughes' assertion that a biological criterion like "humanness" is irrelevant for determining whether two individuals have equal moral status, I believe his analysis of the situation is flawed. The mistake Hughes makes is his assumption that personhood will be as important in determining moral status to enhanced humans as it is for philosophers like Peter Singer, or for Hughes himself.

The fundamental problem with Hughes's argument is that he seems to conflate normative issues with descriptive issues about equality. That is, he implies that because moral equality should be founded on the basis of personhood, then we can be confident that it will be founded on the basis of personhood in a posthuman society. However, although according to personhood theorists, irrelevant biological traits like "humanness" or "posthumanness" should not be used to determine who has equal moral status, this does not mean that these traits will not be used to do so. Hughes quotes the transhumanist writer Ron Bailey:

\footnotetext{
Political equality has never rested on claims about human biology. After all, humanity had the same biology we have today during the long millennia in which slavery, patriarchy, and aristocratic rule were social norms. With respect to political equality, genetic differences, even engineered differences, are differences that make no difference. ${ }^{56}$
}

However, as a descriptive claim (which is what we should be concerned with when trying to evaluate the predicted real life consequences of enhancement), it is simply not true that "political equality has never rested on claims about human biology", as many of the examples chosen to illustrate this claim show clearly. Slavery, racism and the Jim Crow laws were largely justified on the grounds of blacks' supposed biologically inferior intellectual capacities. ${ }^{57}$ Women were denied suffrage and equal rights in large part because they were considered to be incapable of the levels of reason and rationality attained by men. ${ }^{58}$ History is replete with cases of moral and

\footnotetext{
${ }^{56}$ Ibid., p.114.

${ }^{57}$ While biblical justifications were also made to justify slave-keeping, for example, the perception that Africans were less intelligent than Europeans also seems to have provided a significant part of that justification, or at least provided fuel for the view that blacks were morally inferior.

${ }^{58}$ See, for example, Ellen Dubois, "Woman Suffrage: The View from the Pacific," The Pacific Historical Review 69:4 (2000). It is also telling that in response to Mary Wollstonecraft's Vindication
} 
political equality being denied on the grounds that genetic sameness in intellectual capacity (whether real or imagined) is a determining requirement of equal moral or political consideration.

It is not only different cognitive capacities that seem to justify discrimination, but that these differences are thought to be substantially genetically/biologically caused. ${ }^{59}$ And although environmental factors also influence intellectual capacity, cognitive differences perceived to be caused by the environment do not seem to generate the same claims of moral superiority. For example, it was because blacks and women were thought to have innately inferior intellects that they were denied equal rights, not because these supposed differences were thought to be caused by a lack of schooling, for example.

If the wealthy became cognitively enhanced in comparison to the rest of society then they may very well wrongly equate their biologically superior cognitive capacities with moral superiority. If perceived but imaginary differences in intellectual capacity between groups have been so often used to justify racism and sexism, then it seems that genuine, deliberately created differences will cause the enhanced to make similar claims about their moral superiority. The proponent of enhancement must be prepared to show why the real intellectual differences created through wealth-based access to cognitive enhancements will not be used to justify unequal moral consideration if imaginary differences have so often been used to justify such discrimination in the past.

Substantial intellectual differences created through an unequal distribution of cognitive enhancement would be very morally troubling in this regard. In fact, many proponents of enhancement, like Bostrom and Ord, do advocate significant increases in our cognitive capacities (such as raising our level of intelligence by the same

of the Rights of Woman an anonymous author (now know to be Thomas Taylor) published $A$ Vindication of the Rights of Brutes, parodying her arguments.

${ }^{59}$ Perhaps this problem is in part influenced by a folk conception of genetics - that biologically caused differences are somehow fundamental, whereas environmentally caused traits say nothing about one's intrinsic character. See, for example, Holm, "Genetic Engineering and the North-South Divide," p.57; Eric Turkheimer, "The Theory of Innate Differences," Cato Unbound, 21 November 2007, http://www.cato-unbound.org/2007/11/21/eric-turkheimer/race-and-iq/. 
degree that humans are smarter than Australopithecus). Moreover, even small initial enhancements would have a large effect on intelligence given time, assuming either a cumulative effect of successively small enhancements or that enhancement technologies become increasingly more powerful.

Consider the way that non-human animals are currently treated in most societies. While some philosophers, most notably Singer, ${ }^{60}$ argue for the equal moral consideration of animals and humans, this is not a widely held belief either among the public or among law-makers, and it is certainly not widely practiced. In fact, Singer is often taken to be an extremist by the mainstream press.

The issue of animal rights highlights our general failure to realise that the notion of equality is a prescriptive notion rather than a descriptive one. The existence of factory farms, sow crates, vivisection and cosmetics testing all highlight the fact that many supposedly morally important factors, like sentience, are largely ignored. ${ }^{61}$ Instead, rejection of the idea that animals deserve greater moral respect is justified by appealing to their biologically inferior cognitive capacities ("animals don't have the capacity for rationality or the ability to recognise moral duties"). ${ }^{62}$

While there has undoubtedly been progress on all fronts - in both racial and sexual equality and animal rights ${ }^{63}-$ I submit to the reader that we do not yet live in a society where moral equality is determined on the basis of personhood rather than biology. It would be a mistake to rely on enhanced humans applying a personhood theory of

\footnotetext{
${ }^{60}$ Peter Singer, Animal Liberation (New York: HarperCollins Publishers Inc., 1975); Peter Singer, "All Animals Are Equal," in Applied Ethics: Critical Concepts in Philosophy, ed. Ruth Chadwick and Doris Schroeder (London: Routledge, 2002).

${ }^{61}$ Even if one believes that we are justified in according different moral status to rational, moral and sentient beings (i.e. humans) as opposed to just sentient beings (i.e. non-human animals), the animal rights example still highlights our failure to accord even the most basic moral respect to beings that have a capacity - sentience - agreed to be so morally important. This indicates that radically enhanced humans may ignore the moral significance of capacities in unenhanced humans that we currently take to be important, and instead justify the unequal consideration of humans and posthumans in a similar way - by appealing to the enhanced's greater intellectual capacities.

${ }^{62}$ See, for example, Carl Cohen, "The Case for the Use of Animals in Biomedical Research," The New England Journal of Medicine 315:14 (1986); Bonnie Steinbock, "Speciesism and the Idea of Equality," Philosophy 53:204 (1978).

${ }^{63}$ For example, the Spanish Parliament has recently passed a law on the rights of the great apes. Martin Roberts, "Spanish Parliament to Extend Rights to Apes," Reuters, 25 June 2008. http://www.reuters.com/article/scienceNews/idUSL256586320080625?sp=true.
} 
moral equality, especially given the serious nature of the potential harm to the poor if the enhanced fail to do so. Engineering a group to be cognitively superior creates a substantial risk of discrimination against those who are not biologically and intellectually equal.

\section{Smarter Humans Equals Better Reasoning?}

However, it might be objected that the enhanced's greater cognitive capacities would make them more likely to make consistent moral judgments and so recognise that a genetic predisposition for higher intelligence is irrelevant for determining moral equality. In a smarter society, perhaps citizens would be less likely to make the mistake of equivocating between two different senses of the word "better". Nicholas Agar makes a similar proposition: "[the enhanced's] greater powers of reasoning may make them less susceptible to inconsistencies in moral judgement."64

While these observations may turn out to be correct, there is still a significant possibility that the enhanced's greater intellectual capacities will not cause them to be consistently better moral agents. If normal humans have so often attempted to create differences when there were none, the actual differences created by unequal cognitive enhancements may make the enhanced even more susceptible to the judgment that differences in biology and intellect justify differences in moral status. It is also concerning that the greater intellectual capacities of the enhanced may enable them to easily take advantage of those who are cognitively inferior.

The seriousness of the potential harms also lends weight to the view that we should err on the side of caution. By permitting wealth-based access to enhancements, society puts its most vulnerable at risk of great harm in order to benefit its least vulnerable. Perhaps this risk could be justified if enhancements were to benefit those who are already badly-off. However, the serious nature of the potential harms to the worst-off, coupled with the fact that the wealthy are, in absolute terms, very well-off

\footnotetext{
${ }^{64}$ Nicholas Agar, Liberal Eugenics: In Defence of Human Enhancement (Malden: Blackwell Publishing, 2004), p.143.
} 
already, supports taking a more conservative approach when considering whether we should permit wealth-based access to cognitive enhancements.

What I have suggested here is not a science fiction fantasy - it is the logical extension of knowledge about biased attitudes that have pervaded society in the past and that continue to exist. While it is unlikely wealthy parents will ever engineer themselves or their children to carry saddles on their backs, the wealthy's enhancement may instead endow them with boots and spurs. ${ }^{65}$ And, although we cannot know for certain whether the enhanced will consider the unenhanced as morally inferior, I have provided convincing reasons to suppose that they will in fact hold this belief. I would suggest that the onus is at least on the proponent of enhancement to provide evidence to the contrary - that the enhanced's better intellectual capacities will make them morally better as well. However, this is a burden that proponents of enhancement have not successfully overcome.

\section{RECIPROCITY}

The problem of maintaining moral equality in a society where access to cognitive enhancement is unequal is a serious one. A society's failure to accord full moral recognition to all its members will cause those who are judged to be less deserving of moral respect to be denied equal economic, social and political rights. However, even if the enhanced did recognise the unenhanced as morally valuable, there is still good reason to be concerned about the unenhanced's potential marginalisation. Nicholas Agar notes that "the problem is that full moral relationships involve more than just acknowledging the moral value of others. They require reciprocity."66 While Agar's concern is for moral relationships, I submit that reciprocity is especially important in maintaining social and political relationships.

\footnotetext{
${ }^{65}$ Thomas Jefferson used these words in the last letter he wrote (to Roger C. Weightman). Robert M. S. Mc Donald, "God and Man at Philadelphia," review of Jefferson's Declaration of Independence: Origins, Philosophy and Theology, by Allen Jayne, H-Net Reviews, March 1999, http://www.hnet.msu.edu/reviews/showrev.php?id=2893.

${ }^{66}$ Agar, Liberal Eugenics, p.144.
} 
Political and social reciprocity are extremely important to all individuals within a society, especially the most vulnerable. Which members are recognised in these relationships determines, among other things, who counts as a member of a political or social community, who is entitled to political rights or to seek positions of office (and therefore who has the right to self-determination), and who is an appropriate recipient for the distribution of social goods.

Agar compares the relationship between two citizens to the relationship between a pet owner and their pet. Although the pet owner may not ignore the moral worth of their pet, the relationship is not a reciprocal one, unlike the relationship between two fellow citizens:

Citizenship is a collective enterprise founded on the shared understanding of cooperation's great importance. We count a few marginal persons, such as the extremely young, elderly or sick, as citizens because we know this relatively minor extension preserves the motivating ideal. An entire class of unenhanced Naturals might not be so easily subsumed under a general rule of reciprocity... Perhaps the enhanced reasoning powers of the GenRich will not permit them to ignore the needs of those from whom they do not benefit, but they will grant them something short of full recognition. They will not treat them as full partners in the creation of social goods. ${ }^{67}$

If wealth-based access to cognitive enhancements made those with access very different from those without, then it may become impossible for the enhanced and the unenhanced to recognise one another in cooperative social and political relationships. The harms to those who cannot afford enhancements may be considerable. The unenhanced may be: excluded from schemes of distributive justice, if they had little of economic value to offer society; prohibited from seeking positions of office, if they are judged to be intellectually deficient to govern; and denied social and political rights, such as voting rights, if they are deemed to be rationally deficient. The enhanced would not necessarily need to consider themselves morally superior in order to do this - perhaps the enhanced would see good reason to prevent the unenhanced from seeking positions of office if they really were less capable of governing.

${ }^{67}$ Ibid., p. 144. 
Permitting wealth-based access to genetic cognitive enhancements may therefore cause the poor to lose many valuable forms of social and political cooperation.

Buchanan et al. voice a similar concern:

\begin{abstract}
The threat to the political fabric of a liberal society comes from the communities coming to believe that they no longer share a common human nature... [The enhancement of some] might result in different communities coming to view their differences as no longer the result merely of commitment and persuasion, but of their different "natures," with the result that these differences come to be regarded as irreconcilable. $^{68}$
\end{abstract}

\begin{abstract}
Although differences between groups in today's society already exist, wealth-based access to cognitive enhancement may cause the enhanced to see themselves as fundamentally different from the unenhanced. This may "undermine the possibility of social cooperation among communities within a liberal State in a way that traditional pluralism does not." 69
\end{abstract}

An increase in intelligence that resulted in a similar degree of cognitive difference between the enhanced and the unenhanced as there currently is between a human and an ape, as is advocated by Bostrom and Ord, would create differences far too great for relationships between those with access to enhancements and those without to remain reciprocal. The importance of maintaining reciprocal social and political relationships speaks strongly in favour of making sure enhancements do not make their possessors so different from others as to sever all reciprocity. Unequal use of enhancements of the kind supported by Bostrom and Ord would be almost certain to negate the possibility of reciprocation between the enhanced and the unenhanced. Permitting wealth-based access to these sorts of enhancements would therefore constitute a severe harm to the unenhanced poor.

\footnotetext{
${ }^{68}$ Allen Buchanan et al., From Chance to Choice: Genetics and Justice, (Cambridge: Cambridge University Press), 2000, p.178.

${ }^{69}$ Ibid., p.177.
} 


\section{COMPETITIVE HARMS}

The third sort of harm to the worst-off that may occur through permitting wealthbased access to genetic enhancement is competitive harm. In order to fully understand why competitive harms are likely to arise, it is helpful to examine the different ways in which intelligence can be said to have value.

\section{The Value of Intelligence}

The first value distinction we can make is the individual/social distinction. Intelligence may be valuable for the individual whose intelligence is enhanced (e.g. being able to learn a new language) or intelligence may be valuable for society (e.g. an individual's higher intelligence enables them to find a cure for a common disease).

Secondly, we can make a distinction between intrinsic value (intelligence is valuable in itself) and extrinsic value, sometimes called instrumental value (intelligence is valuable because it helps to bring about some desirable state of affairs). There are two ways to think about intelligence in this respect. One view is that intelligence is completely extrinsically valuable - it is valuable for individuals because it enables them to do other intrinsically valuable things with their lives (e.g. getting pleasure from a better understanding of science) and it is valuable for society because it improves its citizens lives in an important respect (e.g. through new technologies). A second view is that intelligence can also have intrinsic value for both individuals and society (i.e. it is good in itself for an individual to be intelligent or society to have intelligent citizens). As I will show, my arguments allow for either account of the extrinsic/intrinsic value distinction.

The third distinction we can make is between positional and non-positional value. Intelligence has individual non-positional value (either intrinsic or extrinsic) when higher intelligence would be valuable to an individual even if others were similarly or more intelligent (e.g. being able to learn new languages quickly may be valuable even if others can do the same). 
Intelligence has individual positional value when higher intelligence is valuable to an individual only because others are less intelligent. It is important to understand the difference between intrinsic and extrinsic individual positional value in this sense. Intelligence has extrinsic positional value when higher intelligence helps to secure other benefits, for example, a person's higher intelligence helps them secure a job over a less intelligent applicant. Intelligence has intrinsic positional value when high intelligence is valuable to an individual not because of any benefits their intelligence helps them acquire, but because thinking more brilliant thoughts than anyone else is good in itself. However, while intelligence plausibly has some intrinsic positional value, most of its positional value is extrinsic - it is valuable for an individual because it helps them gain other advantages.

Intelligence has social non-positional value (intrinsic or extrinsic) when having intelligent individuals within a society creates benefits for others (e.g. society's intelligent individuals develop a cure for a common disease). I will not consider the category of social positional value. The main reason for this is that any issues concerning one society's positional advantage or disadvantage over another can be more clearly explained through the collective effect of individual positional value.

In fact, all these value distinctions are important in how they relate to a fourth distinction - the absolute/positional distinction (which I briefly discussed in chapter 2). ${ }^{70}$ Intelligence has absolute value when it is valuable regardless of whether others are also intelligent, i.e. absolute value is all the non-positional value of intelligence. This is distinguished from the positional value of intelligence, which is simply the individual extrinsic positional value.

The absolute value of intelligence is determined by whether greater intelligence would be beneficial for either the individual or society even if everyone else had their intelligence enhanced. Some things that could be pointed out as being absolutely valuable to the individual are: being able to learn different languages more easily, having a greater appreciation of art and music, having the ability to pick up

\footnotetext{
${ }^{70}$ Although when I explained it in chapter 2 the difference between intrinsic and absolute value was not explicitly drawn out.
} 
complicated ideas faster and acquiring a better understanding of scientific concepts. There is also absolute social value as discussed by Bostrom and Ord: "diseases need cures, scientific questions need answers, poverty needs alleviation, and environmental problems need solutions"71 (assuming, of course, that increased intelligence can help in all these areas). Absolute value can be either intrinsic or extrinsic.

The positional value of intelligence is simply the individual extrinsic positional value. I argue that competitive harms may be caused to the poor through the unequal distribution of genetic cognitive enhancements because of this positional value, since it gives an individual competitive advantages over others who are less intelligent. For example: better exam results than one's peers, more chance of winning scholarships, being able to get into the best universities, faster promotion up the employment ladder and an increased potential to earn more money more quickly. The intrinsic positional value of intelligence is less concerning from a competitive harms perspective, since it does not contribute to an individual gaining other advantageous goods, and is therefore not included in the category of "positional value" I am interested in. ${ }^{72}$

The table on the following page shows the value distinctions we can make with regards to intelligence (if one takes the view that intelligence is only extrinsically valuable, the rows showing intrinsic value can be ignored).

\footnotetext{
${ }^{71}$ Bostrom and Ord, "The Reversal Test," p.669.

${ }^{72}$ Also remember that the intrinsic positional value of intelligence is only a minor part of its positional value.
} 
Table 1

\begin{tabular}{|c|c|c|c|}
\hline \multirow{3}{*}{ Individual } & & Positional & Non-Positional \\
\hline & Intrinsic & $\begin{array}{l}\text { Having higher intelligence } \\
\text { than others is good in } \\
\text { itself, not because it helps } \\
\text { secure other advantages. } \\
\text { Intrinsic positional value }\end{array}$ & $\begin{array}{l}\text { High intelligence is valuable } \\
\text { because it allows you to } \\
\text { think brilliant thoughts. } \\
\text { Absolute Value }\end{array}$ \\
\hline & Extrinsic & $\begin{array}{l}\text { Higher intelligence helps } \\
\text { you secure a job over a less } \\
\text { intelligent applicant. } \\
\text { Positional Value }\end{array}$ & $\begin{array}{l}\text { High intelligence is valuable } \\
\text { because it gives you a greater } \\
\text { appreciation of art and } \\
\text { music. } \\
\text { Absolute Value }\end{array}$ \\
\hline \multirow[t]{2}{*}{ Social } & Intrinsic & Not considered & $\begin{array}{l}\text { Having intelligent } \\
\text { individuals in society is good } \\
\text { in itself. } \\
\text { Absolute Value }\end{array}$ \\
\hline & Extrinsic & Not considered & $\begin{array}{l}\text { Having intelligent } \\
\text { individuals is valuable for a } \\
\text { society because they find } \\
\text { cures for common diseases. } \\
\text { Absolute Value }\end{array}$ \\
\hline
\end{tabular}

It is important to note that when considering whether a society should permit genetic cognitive enhancement, the positional value that enhancements would confer on their possessors should not be taken as a point in favour of permitting enhancement. This is because any positive positional value increased intelligence confers on an enhanced person is offset by the decrease in positional value of an unenhanced person. The positional gains and losses would cancel each other out. If intelligence only had positional value, then the use of cognitive enhancements would leave society with only costs (transition and research costs for example, as well as the other harms I have discussed). ${ }^{73}$ It is only the absolute value of enhanced intelligence that should be taken as a point in favour when deciding whether a society should permit genetic cognitive enhancement.

\footnotetext{
${ }^{73}$ As I have stated, I will not consider social positional value. Since issues of global justice are also important, I will take the view that any increase or decrease in positional value of one society compared to another would be irrational in the same way that the positional advantages and disadvantages of individuals seeking enhancements would cancel each other out.
} 
However, the positional value of intelligence is highly significant in another way. For an individual, the positional value of intelligence will be a huge point in favour of enhancement. The enhanced individual will have the competitive advantages that greater intelligence confers. It follows that the enhancement of some but not others may result in detrimental consequences - competitive harms - for the individuals who miss out.

\section{Positional Advantages Create Competitive Harms}

Since intelligence has significant positional value, the unequal distribution of cognitive enhancements would be likely to exacerbate social and economic inequalities. Gregory Kavka, for example, argues that positionally valuable but expensive goods tend "to advantage those members of society, in disproportion to their numbers, who are already most advantaged. It therefore exacerbates, rather than mitigates, existing patterns of social inequality." 74

However, as stated above, the concern with the unequal distribution of enhancement technologies is not just that some people will have a good that others do not have, but rather that the wealthy's use of such positionally valuable goods would give them great competitive advantages over the poor, leaving the poor worse off in absolute, not just relative, terms. People who become cognitively enhanced would be more likely to secure better jobs, be accepted into the best universities, earn the most money and acquire goods and services that the poor may otherwise have been able to obtain. For example, scholarships for high achievers that the poor may have had a chance of winning when up against wealthy but unenhanced competitors may become impossible to win when competing with students who are cognitively enhanced. Where effort may once have been able to compensate for some of the poor's disadvantages in a society without genetic enhancement, environmental inputs may no longer be able to compete with the substantial genetic advantages of the wealthy and enhanced.

\footnotetext{
${ }^{74}$ Gregory S. Kavka, "Upside Risks: Social Consequences of Beneficial Biotechnology," in Are Genes Us? The Social Consequences of the New Genetics, ed. Carl F. Cranor (New Brunswick, NJ: Rutgers University Press, 1994), p.168.
} 
Perhaps mild cognitive enhancements may not have significant competitively harmful effects on the poor. However, if the kind of enhancements advocated by Bostrom and Ord become available, then their unequal distribution may result in the unenhanced poor having little chance of successfully competing for worthwhile goods and services. This may leave the unenhanced worse off not only in relative terms but in absolute terms as well, thereby further violating the no harm principle.

We can now see why we should be concerned about the unequal distribution of genetic enhancement technologies, but not necessarily of other unequally distributed goods (i.e. why enhancements and expensive cars are morally different). Expensive cars and luxury yachts are not primary goods and do not seem to cause discrimination or have negative effects on reciprocity. Furthermore, cars do not in themselves have positional value - instead, they are indicators of positional advantages (like wealth).

\section{BALANCING THE BENEFITS AND HARMS}

I have so far documented three types of harms to the poor that are likely to result from permitting wealth-based access to genetic enhancements - loss of reciprocal relationships, discrimination and competitive harm. According to the no harm principle, permitting cognitive enhancement is therefore prima facie unjust.

However, in order to determine whether permitting enhancement would be overall negative for the poor, we must also consider enhancement's potential social benefits. Since intelligence has absolute social value, perhaps the poor would be indirectly benefited from having other members of their society cognitively enhanced, even if they are not enhanced themselves. ${ }^{75}$ If the absolute social benefits of higher intelligence are great enough to offset the harms to the poor, wealth-based access to genetic cognitive enhancement would in fact be morally permissible according to the no harm principle.

\footnotetext{
${ }^{75}$ We cannot, of course, consider the individual value of intelligence to offset any of the harms to the poor, since the no harm principle is concerned with evaluating the consequences for those who are not enhanced.
} 
In what follows, I will outline a number of possible scenarios for the introduction of genetic enhancement. While the postulated outcomes are, to a degree, speculative (since no one can predict the future with 100 percent accuracy), I will establish that the outcomes that the no harm principle would consider just are actually very unlikely.

\section{Potential Scenarios}

There are a number of potential social benefits to the poor to be considered. The first is the possibility that the higher intelligence of the enhanced will enable them to find solutions to the serious medical, environmental, economic and social problems most affecting the poor. These benefits may offset the immediate harms to the unenhanced so that they will be no worse off in absolute terms from a policy that permits wealthbased access to cognitive enhancement.

However, while it is certainly true that higher intelligence has had absolute social benefits (helping to facilitate scientific discoveries, foster new medical technologies and improve average well-being, for example), the inability to find solutions to the major problems the poor currently face (poverty, corruption, famine, global warming) is arguably largely due to a lack of political will rather than a lack of intelligence.

Nevertheless, perhaps proponents of enhancement could argue that higher intelligence may help to develop solutions to these problems that do not require much effort or political will on behalf of developed nations to be effective. In other words, even if a lack of political will is the reason that the current problems facing the poor have not been solved, higher cognitive capacities may be the solution.

A major problem with this response is that the purported benefits are so uncertain. This is especially concerning given that only very significant absolute benefits would adequately compensate the poor, since the likely harms are so serious. The uncertainty about how higher intelligence would help solve such problems without the need for political will surely weighs heavily on the side of caution. Looking at the problem from the perspective of the poor, it seems reasonable for the burden of proof 
to rest on proponents of enhancement in this case. That is, they must be able to give some idea as to exactly how higher intelligence might facilitate finding solutions to problems which do not require political will.

Furthermore, the moral and political marginalisation of the unenhanced due to the wealthy's cognitive enhancement may make the wealthy even more unconcerned about solving the sorts of problems most affecting the poor. Consider the fact that only a small percentage of pharmaceutical development is aimed at drugs for diseases that are widespread in developing countries, since these diseases are not common in Western countries (and are therefore not worth pursuing from a profit perspective). ${ }^{76}$ Currently, legislation in the United States and the European Union provides financial incentives for pharmaceutical companies to develop these so-called "orphan drugs" (defined as drugs for diseases suffered by fewer than 5 in 10,000 people in developed countries $^{77}$ ). While arguments can be made as to the efficacy of this legislation, it can also be pointed out that without moral and political recognition of the people who suffer from these diseases it is unlikely that attempts to develop the required treatments would have been made at all. It is clear then that the developed World still regards itself as having some sort of political or moral obligation towards the developing World, even if this concern for the poor does not go far enough. However, once the enhanced no longer regard the unenhanced as worthy of equal moral or political recognition, suffering that has little to do with Western nations may be seen as unimportant. We therefore should not have confidence that the likely harms to the poor from wealth-based access to genetic enhancement would be outweighed by the social benefits in this manner.

Nonetheless, there is a second way in which the cognitive enhancement of the rich may indirectly benefit the poor and compensate for the harms, particularly the competitive harms. Perhaps the enhanced intelligence of the wealthy would increase the total supply of primary goods and services enough to outweigh the reduction in percentage of the unenhanced's share - the pie would get bigger in other words.

\footnotetext{
${ }^{76}$ Holm, "Genetic Engineering and the North-South Divide," p.53.

${ }^{77}$ European Commission: Public Health, "The Orphan Drugs Strategy," EUROPA (The European Union On-Line), http://ec.europa.eu/health/ph_threats/non_com/rare_6_en.htm.
} 
The first problem with this scenario is that even if the total supply of goods and services were increased, significant differences created by the enhancement of the rich may put the poor at so much competitive disadvantage that they are unable to successfully compete for the extra resources.

More importantly, even if the increase in supply of the total available primary goods were enough in theory to offset the competitive disadvantage suffered by the poor, if the poor suffer discrimination, loss of reciprocity, or both (which appears likely), they would effectively be prevented from acquiring the extra primary goods. This seems quite obvious when we consider that the economic benefits gained from slavery, for example, did not go to benefit the slaves. It is therefore not implausible to assume that the marginalisation of the unenhanced in this manner would cause any theoretical benefits to them to be prevented from being practically realised.

A third way in which the less advantaged could benefit from wealth-based access to enhancement is if genetic enhancement technologies eventually decreased in price so significantly that the children or grandchildren of the current poor would have full access to them. This may mean that the immediate disadvantages suffered by the current poor (especially the competitive disadvantages) would be outweighed in the long run when enhancements become more widely available.

However, while this scenario initially appears plausible, it is also unlikely to pass the no harm principle. This seems true for two reasons. First, without the environments in which they can be made use of, genetic cognitive enhancements may benefit the poor relatively little. Genes do not work in isolation - they interact with other genes and the environment. The worst-off, even if eventually given the enhancements, would need to place those genes in an appropriate environment. Without access to those environments (education and proper nutrition, for example) it is unlikely that being genetically enhanced for greater intelligence would be enough to counteract the positional benefits conferred by increased intelligence on the wealthy. There are already undoubtedly millions of "naturally" intelligent individuals living in the developing World; however, if they are living without access to food, clean water, education and basic health care, their situation is not made much better by having a 
genetic predisposition for high intelligence. Their genetic "smarts" are therefore doing little to make them competitively more endowed.

Secondly, while old technology decreases in price over time, new inventions are not static. By the time the poor would be able to afford cognitive enhancement Version 1.0, the wealthy would be likely to have the latest and best version, therefore maintaining the competitive disparity that the original enhancement of the wealthy produced. In this case there would be no mitigation of the poor's original positional disadvantages.

By using this method of balancing the potential benefits with the potential harms we are able to see that the benefits to the poor due to the cognitive enhancement of the rich are unlikely to outweigh the substantial harms. Permitting wealth-based access to genetic cognitive enhancements would create serious moral, social, political and economic harms to the unenhanced that would be unlikely to be compensated for by the potential absolute benefits of enhancement. From this analysis it is clear that the argument from inequality, motivated by the no harm principle, judges wealth-based access to genetic cognitive enhancement prima facie unjust.

\section{COMPETING MORAL CONSIDERATIONS}

Having failed to show that use of enhancements by the wealthy would not harm the poor, proponents of enhancement may instead claim that there are other moral considerations that have not been taken into account that override the no harm principle in this case. If this is so, then even though permitting cognitive enhancements is a prima facie wrong, prohibiting them may be an all-thingsconsidered wrong. The most likely candidate for such a consideration is a personal liberty claim. If prohibiting cognitive enhancement would violate some important liberty right, then it would be wrong to prevent the wealthy from enhancing their intelligence. I will now discuss considerations of liberty and illustrate why they are not weighty enough to override the no harm principle in this case. 


\section{Personal Liberty Rights}

I should first note that proponents of enhancement cannot appeal to libertarianism to justify the use of enhancements. This is because the aim of my paper was to present the no harm principle as intuitively plausible, and then argue against cognitive enhancement based on the fact that the no harm principle had already been accepted. As libertarianism is an objection to the no harm principle itself, it cannot be considered a competing moral consideration - it is an objection to the framework of the argument, and as such, is an issue to be considered outside of this thesis.

However, it may be tempting for proponents of enhancement to frame the debate as one over self-regarding actions (actions that only affect the actor), since the issue of whether or not to permit enhancements affects what people can and cannot do to their own bodies. There is a powerful moral argument that self-regarding actions should only be restricted in exceptional circumstances (and some have argued that they should never be restricted). Perhaps this concept has been expressed most profoundly by John Stuart Mill in On Liberty:

The only part of the conduct of any one, for which he is amenable to society, is that which concerns others. In the part which merely concerns himself, his independence is, of right, absolute. Over himself, over his own body and mind, the individual is sovereign. $^{78}$

If the action of genetically enhancing oneself could rightly be counted as selfregarding, then this would make an extremely strong case for the right to use cognitive enhancing technologies. However, when actions affect others they do not count as self-regarding. The connection between methamphetamine and violent behaviour could be cited as evidence that taking "P", for example, is not a strictly self-regarding action. Similarly, actions that have an effect on the liberty or equality of others should legitimately come into the sphere of moral evaluation and potentially legal restriction. Since the poor may be penalised through competitive disadvantage, discrimination and loss of reciprocity if wealth-based access to genetic enhancements

${ }^{78}$ John Stuart Mill, On Liberty $2^{\text {nd }}$ ed. (Boston: Ticknor and Fields, 1863), p.23. 
were permitted, there is no plausible way in which one could argue that enhancing oneself is simply self-regarding.

Nonetheless, while undergoing genetic enhancement may not be a self-regarding action, the most plausible theories of liberty make a presumption in favour of personal freedom. This means that the onus should be on those who propose the restrictions on liberty to provide sound justification for doing so. However, the argument from inequality certainly makes a compelling justification for restrictions on liberty in the case of cognitive enhancements. First, as we have seen in this chapter, a lack of restriction would be likely to cause serious harm to the worst-off members of society. Second, withholding enhancement technologies requires relatively little intrusion into individuals' personal lives. For example, making sure germline enhancements are not carried out may involve monitoring fertility clinics, but it does not involve State regulation of one's everyday personal activities. Therefore, it is implausible to argue that restriction of genetic enhancement technologies constitutes too considerable an intrusion into the sphere of personal freedom, when compared to the consequences of not doing so.

Thomas Murray argues, making an analogy to performance-enhancing drugs, that:

\footnotetext{
Liberty tends to be treated as a kind of rhetorical trump card... [However] one person's liberty to use a drug that significantly enhances performance affects the other competitors. Their liberty to compete fairly and equally without using drugs is severely constrained by the drug-using athlete's actions. ${ }^{79}$
}

While not identical to the case of cognitive enhancement (taking performance enhancing drugs is cheating; sports are winner-takes-all competitions whereas pursuits in life are not) the analogy holds well enough. One person's liberty to use enhancements affects other people's liberty to be effective competitors for desirable social goods. The use of enhancements by some is also likely to morally, socially and politically marginalise others. And while a presumption should be made in favour of

${ }^{79}$ Murray, "Enhancement," p.500. 
personal freedom, the burden of justifying restrictions on liberty has certainly been met in the case of cognitive enhancement.

Liberty rights therefore do not provide competing moral considerations strong enough to override the no harm principle in this case. Accordingly, we can conclude that wealth-based access to cognitive enhancements is not only prima facie unjust, but allthings-considered unjust as well.

\section{THE NEW REVERSAL TEST}

The original Reversal Test has been shown to be ineffective in diagnosing status quo bias in the argument from inequality. The major reason for this is that when the Reversal Test asks us to consider the consequences of lowering or increasing intelligence, it implicitly assumes that the whole population's intelligence will be increased or decreased. However, when unequal access to enhancements is the practical reality, concerns arise over harms to those who miss out.

Bostrom and Ord recognise and respond to this problem. They consider the argument against enhancement where the resulting negative effects on social equality are claimed to outweigh the benefits provided by the enhancement. One way to determine the overall expected utility of enhancement where non-universal access is unavoidable, they argue, is to compare the expected negative effects on social equality with the expected benefits provided by the enhancement, and then make an assessment about the overall utility of the likely consequences. However, they object:

But realistically, there is no possibility of making this comparison in a completely scientifically rigorous way. Subjective intuitive judgement will inevitably enter into the assessment - both of what the likely consequences would be and of the goodness or badness of these consequences. We must therefore confront the possibility that these intuitions, which we perforce rely on, are biased in some way, and in particular the possibility that they are affected by status quo bias. This is where the Reversal Tests come in. Potential consequences that involve distributive concerns can be handled by the tests in the same way as other consequences. ${ }^{80}$

${ }^{80}$ Bostrom and Ord, "The Reversal Test," p.675. 
Bostrom and Ord then devise a new Reversal Test, which they argue can diagnose status quo bias in different versions of the argument from inequality:

\begin{abstract}
In the case of cognitive enhancement, we can apply the simple Reversal Test and ask whether it would be a good thing if the treatment group (those who would be given the cognitive enhancement) instead had their cognitive capacity reduced. Are we prepared to claim that the status quo would be improved if the wealthy, say, suffered slight brain damage? If we are not prepared to make that claim, then the onus shifts to those who judge that the nonuniversal use of the cognitive enhancer would have on balance bad consequences: they need to explain why we should believe that the current cognitive ability of the potential enhancement users is at a local optimum such that both an increase and a decrease should be expected to make things worse on the whole. ${ }^{81}$
\end{abstract}

So, a new challenge is set. Arguments from inequality, such as the one I have put forward, must now pass the new Reversal Test.

\title{
Responding to the New Reversal Test
}

There are three major responses to make against the new Reversal Test. First, I submit that although my argument does rely in part on subjective judgment in determining the consequences of enhancement, it also grants a lot to proponents of cognitive enhancement and so has a substantial burden of proof to overcome.

While it is certainly difficult to come to an objective assessment about the goodness or badness of the consequences of permitting genetic enhancement, it might plausibly be argued that the original choice of the no harm principle is not as influenced by the status quo bias as Bostrom and Ord may contend. To see why this is the case, let's first consider that the Rawlsian difference principle is derived through the original position, with the veil of ignorance erasing knowledge of potentially biasing factors (social position, wealth, race, sex etc.). A defender of the difference principle could then argue that these conditions actually decrease the influence of status quo bias in choosing the appropriate principle of distributive justice. Since it is even more

${ }^{81}$ Ibid., p.675. 
difficult to oppose enhancement using the no harm principle (as one has to show that enhancements would harm the poor rather than simply fail to benefit them) there is a strong case to be made that the no harm principle grants a substantial amount to proponents of enhancement. That is, in using the no harm principle to argue against genetic cognitive enhancements, the argument from inequality must meet a high burden of proof. This is a point in favour of the moral efficacy of the no harm principle.

Secondly, and more substantially, the no harm principle is able to take into account the competing moral considerations in the new Reversal Test (the right to bodily integrity), meaning that it does not in fact make the implausible judgment that the wealthy are required to reduce their natural cognitive capacities.

The no harm principle requires us to prohibit the cognitive enhancement of the wealthy because a policy that permitted wealth-based access to enhancements would be likely to seriously harm the unenhanced poor. However, this does not entail that the rich are required to decrease their normal cognitive capacities. We cannot legitimately submit an individual to neurosurgery, for example, in order to reduce their intelligence, as this would be a gross violation of that individual's bodily integrity. Any society that practiced this sort of physical coercion would be rightly considered barbaric. The no harm principle considers prima facie unjust policies that benefit the rich but risk harm to the poor. However, even the no harm principle cannot legitimise violations of important human rights, like the right to be free from physical coercion. The right to bodily integrity in this case overrides the no harm principle, meaning that it would be all-things-considered wrong to coercively submit the wealthy to brain damage.

This illustrates that competing moral considerations legitimately affect our judgments in cases such as these. We can uphold the no harm principle by prohibiting cognitive enhancement technologies without violating any legitimate rights of the wealthy. However, we cannot and should not force the wealthy to decrease their natural intelligence levels, as this would be a gross violation of their right to bodily integrity. This important point will be raised again in chapters 4 and 5 . 
Thirdly, principles of distributive justice, like the no harm principle, are meant to govern the background social institutions. The natural distribution of genes is not something which is subject to social redistribution according to these principles. Cognitive enhancement technologies, on the other hand, are legitimate subjects of principles of distributive justice. The no harm principle therefore judges wealth-based access to cognitive enhancement technologies unjust, but does not require the wealthy to decrease their natural cognitive capacities.

The consequence is that although it is unavoidable that the argument from inequality relies in part on subjective judgment in assessing the consequences of enhancement, the new Reversal Test does not show that the argument from inequality is influenced by status quo bias, and therefore does not provide any good reason for the arguments presented in this chapter to be rejected.

\section{CONCLUSION}

In this chapter I have met Bostrom and Ord's initial burden of proof challenge by illustrating that neither version of the Reversal Test shows the argument from inequality, based on the no harm principle, to be affected by status quo bias.

In order to successfully make this case, I first presented an argument to show that cognitive enhancements would be unequally distributed between the best-off (the wealthy) and the worst-off (the poor). I then introduced the no harm principle, which states that a policy that benefits those who are already well-off but that risks to harm those who are worst-off is prima facie unjust. I argued that the no harm principle is a plausible way of governing the distribution of cognitive enhancement technologies and I claimed that according to the no harm principle it would be unjust to permit the genetic enhancement of intelligence, since it would be likely to result in serious harms to the poor.

The first step in establishing this claim was to illustrate that the poor would be likely to be discriminated against if wealth-based access to enhancements were permitted. I 
showed that there is a significant risk that the enhanced would equivocate between the biological notion of better intelligence and the moral notion of better. When unequal moral consideration has so often been justified by perceived but illusory differences, it will almost certainly be justified by genuine, deliberately created differences. Secondly, I illustrated that the poor may be harmed through loss of valuable reciprocal social and political relationships. Enhancements of the kind advocated by Bostrom and Ord would create differences between the enhanced and the unenhanced far too great for reciprocity to be maintained. Thirdly, I argued that competitive harms to the poor are likely to arise because of the significant positional value of intelligence. The competitive advantages conferred on the wealthy may enable them to acquire the goods and services that the poor may otherwise have had access to, therefore making the poor worse off in absolute terms.

I also noted that in order to come to a proper assessment about the goodness or badness of the overall consequences to the unenhanced, it is important to also consider enhancement's potential social benefits. However, by presenting a number of different possible scenarios, I showed that any potential benefits to the poor would be unlikely to outweigh the substantial harms. We were therefore able to conclude that wealth-based access to cognitive enhancements is prima facie unjust.

I then argued that there are no competing moral considerations, like personal liberty rights, strong enough to override the no harm principle in this case. This showed that permitting genetic cognitive enhancements is not only prima facie unjust, but allthings-considered unjust as well, meaning that wealth-based access to cognitive enhancement technologies should not be permitted.

Finally, I examined Bostrom and Ord's new Reversal Test and showed how it is also ineffective in diagnosing status quo bias in my version of the argument from inequality.

Having met the initial burden of proof set by Bostrom and Ord's Reversal Test by showing that the argument from inequality is not influenced by status quo bias, the goal of the next chapter is to defend this argument against the strongest potential 
objections. In chapter $5 \mathrm{I}$ will consider and respond to two consistency arguments the "argument from medical treatments" and the "argument from education". If my defence of the argument from inequality rebuts these potential objections effectively, we can consider the Reversal Test to have been successfully responded to, and we can conclude that it would be wrong to permit the genetic enhancement of intelligence. 


\section{ARGUMENT FROM MEDICAL TREATMENTS}

In the last few years there has been considerable media interest in New Zealand about Herceptin, a new drug that has been shown to be effective in treating the aggressive HER2 positive form of breast cancer. The problem is that Herceptin is very expensive, and there has been debate about whether it should be funded by the New Zealand government drug agency, Pharmac. To date, Pharmac has agreed to fund the drug for up to 9 weeks of treatment. ${ }^{82}$ However, many women have been advised to take the drug for a much longer period of time, meaning that some breast cancer sufferers have received medical bills of up to $\$ 100,000$ for treatment. ${ }^{83}$ There have also been reports of women unable to afford Herceptin who have had to forgo the drug completely. ${ }^{84}$ A similar scenario occurs with other expensive and nonuniversally available drugs, like HIV/AIDS antiretrovirals, anti-malarial treatment and vaccinations. Many people in developing nations are unable to purchase these lifesaving medicines that most people in the West can afford.

This may pose a problem for the argument from inequality. If I have argued that the reason we should not permit genetic cognitive enhancements is that they will be unequally distributed between the rich and the poor, then by issue of consistency I should also hold that the rich be prohibited from purchasing expensive medical treatments unless everyone has access to them. Since there are many such drugs, like Herceptin or HIV/AIDS medication, that are not universally available, it appears my

\footnotetext{
${ }^{82}$ Pharmac has just ruled out funding the drug for 12 months. Press.co.nz, "Herceptin Funding Increase Turned Down," 7 August 2008, http://www.stuff.co.nz/4647225a24035.html.

${ }^{83}$ Sally French, "Worst Nightmare... and then a \$100k Bill," reported on Stuff.co.nz, 19 May 2008, http://www.stuff.co.nz/4549980a27346.html. ${ }^{84}$ Ibid.
} 
arguments entail that these life-saving drugs should be banned, even for those who can afford them. Bostrom and Ord suggest that opponents of enhancement who base their arguments on the unfairness of the technology's probable distribution are committed to the view that "the world would be better if nobody had access to expensive AIDS treatments, given that such treatments are not currently available to everybody." 85

If this conclusion were the inevitable consequence of accepting my argument against enhancement then this would obviously be a serious problem. However, the reasons I have given for opposing the genetic enhancement of intelligence do not entail that medical treatments should be banned for everyone if they are unable to be made available for all. This is because I have not argued that we should prohibit cognitive enhancements for the rich simply because the poor will not be able to afford them. Rather, I have argued that wealth-based access to enhancements should be banned because the use of cognitive enhancements by the best-off members of society risks serious harm to the worst-off members of society. However, the greater use of medical treatments by the rich poses far less risk of harm to the poor than the greater use of enhancements.

First, the use of non-universal medical treatments by the wealthy is much less likely to impair reciprocal relationships. Second, discrimination because of enhancement is peculiar to cognitive capacities, so health-related differences are unlikely to result in the same sort of marginalisation. And third, the greater use of medical treatments by the wealthy is also less likely to competitively harm the poor, because treatments have less positional value than cognitive enhancements.

Furthermore, even if the unequal distribution of medical treatments were potentially harmful to the poor, there are competing moral considerations in the case of medical treatments that are not present in the case of enhancements, making the use of nonuniversal medical treatments morally permissible in a way that enhancements are not.

${ }^{85}$ Bostrom and Ord, "The Reversal Test," p.675. 


\section{Reciprocity}

In chapter 3 I expressed the possibility that the non-universal use of radical cognitive enhancements may weaken ties between the enhanced and the unenhanced to such an extent that political and social reciprocation would be unlikely or impossible. To illustrate what kind of variation in intelligence would make reciprocal relationships impossible I used the comparison of the cognitive difference between a chimpanzee and a human (or a human and an Australopithecus, to use Bostrom and Ord's example).

Medical treatments do not pose the same kind of threat to reciprocity. To start with, only severe sorts of disabilities, particularly serious mental disabilities, would potentially threaten reciprocal relationships between individuals or groups. While true reciprocity between a severely disabled person and a fully able person may be impossible, treating such serious disabilities actually helps to secure better reciprocal relationships between the able and the disabled. The treatment of mental disabilities, for example, brings those who were previously disabled into the dominant cooperative framework. ${ }^{86}$ Furthermore, even if the better medical treatment of the rich raised the level required for effective reciprocity within a society, this would be likely to exclude only those with the most serious disabilities (e.g. the mentally disabled), for whom reciprocal relationships with others were already difficult or impossible to maintain.

As for the difference between the best- and worst-off societies, we may have concern that the increasing health of one group would raise the requirements for "effective participation in important forms of social cooperation," ${ }^{87}$ since disabilities are to a considerable extent determined by the social framework. However, the health gap between developed and developing nations is unlikely to reach the limit beyond which cooperative relationships can no longer be maintained. For one thing, the number of

\footnotetext{
${ }^{86}$ What I have been arguing against is the policy of wealth-based access to cognitive enhancement technologies. Enhancing a normal IQ to posthuman levels is very different, as I will illustrate in this chapter, from using genetic technologies to cure a mental disability. I will show that there is nothing inconsistent in holding that we should prohibit wealth-based access to cognitive enhancements while also maintaining that non-universal treatments for illness or disability (whether physical or mental) should be permitted (even if the treatment in question is a genetic therapy for mental disability).

${ }^{87}$ Buchanan et al., From Chance to Choice, p.319.
} 
people in developed countries with serious disabilities is low, meaning that while treatment of these individuals would make major differences to them, it is unlikely to make a significant difference to that society's overall reciprocity index. Average health differences between developed and developing countries also do not seem great enough to make inter-society cooperation impossible. We cannot reasonably argue that the risk of severing reciprocal relationships is high unless we are prepared to make the implausible claim that reciprocity between a perfectly healthy person and a person in the same nation with, say, hepatitis, is also impossible (as this difference is greater than the average health difference of the best- and worst-off populations). This is not true for the forms of cognitive enhancements advocated by Bostrom and Ord, since the disparities they would create between those with access to enhancements and those without are so extreme.

\section{Discrimination}

Discrimination against the worst-off is likely to be a significant problem with genetic cognitive enhancement because the enhanced may come to wrongly equivocate between biological notions of "better" and moral or value notions of "better". However, as I argued in some detail in chapter 3, the threat of discrimination is a particular concern for genetic cognitive enhancement, not for the improvement of health, as evidenced by the major justifications of racism and sexism.

Historically there has not been the same tendency to equate "better" in terms of health or strength with the moral "better". For example, many indigenous people were thought to be exceedingly strong but this did not prevent racism and slavery; ${ }^{88}$ we know that many animals are stronger than humans but this has not fostered the development of even basic rights for most animals. Since racism, sexism and even speciesism ${ }^{89}$ have all been largely based on perceived differences in the genetic basis

\footnotetext{
${ }^{88}$ See, for example, Carsten Anckar, Determinants of the Death Penalty: A Comparative Study of the World (Abingdon: Routledge, 2004), p.83.

${ }^{89}$ Whether or not the reader agrees that animals are in fact wrongly denied the same moral consideration that humans are entitled to, the point remains unaffected - virtually all justifications (aside from religious justifications) for holding animals in a different moral category are derived from differences in cognitive capacities. For example, some differences that have been appealed to are animals' lack of: rationality, culture, desire for self-respect, and ability to understand moral concepts
} 
of differences in intellectual capacities, the risk of mistake in equivocating between a biological notion of better health and a moral or value notion of better does not seem high.

\section{Loss of Support}

However, perhaps there are other potential harms that are peculiar to the unequal distribution of medical treatments. Buchanan et al. discuss a concern made by disability rights activists that as genetic treatments for disabilities decreases the number of those with disabilities, the remaining disabled will suffer a loss of support. This worry can also be applied to conventional medical treatments. However, Buchanan et al. note that the evidence has not supported the empirical claim that the disabled do lose support through treatment of disabilities. In fact, there has been at least one case in which "a reduction in the incidence of a genetic disease [Thalassemia]... resulted in more resources being used to support the decreasing numbers of those who had the disease." 90 It also seems to be the case that in Western societies at least, where the number of treatments is higher, there has been increasing support for the remaining disabled (for example, wheelchair ramps, disability services in the workplace and at universities, buses that "kneel" and campaigns to increase awareness about mental health). ${ }^{91}$

\section{Competitive Harm}

An unequal distribution of medical treatments is also not as competitively harmful to the poor as an unequal distribution of genetic cognitive enhancements. In chapter 3 I analysed the difference between absolute and positional value. The positional value of intelligence, for example, is the extrinsic value of a person's intelligence only because others are less (or more) intelligent. However, while intelligence has significant positional value, the value of health is mainly absolute. Being free from

and exercise moral claims. See Cohen, "The Case for the Use of Animals in Biomedical Research"; Steinbock, "Speciesism and the Idea of Equality."

${ }^{90}$ Buchanan et al., From Chance to Choice, p.267 citing Philip Kitcher, The Lives to Come (New York: Simon \& Schuster, 1996), p.85.

${ }^{91}$ Perhaps this is related to the fact that the less healthy still seem to be perceived as moral equals, and that relationships between the healthy and ill have remained reciprocal. The more secure relationships between the healthy and sick may promote or maintain concern for the worst-off. 
cancer allows a person to regain all the things that previously gave their life value, such as being able to spend time with family and friends, returning to work, playing sport or simply performing many of the everyday activities that are too difficult for those who are sick. The motivation, at least, behind undergoing treatment for a medical condition is not usually to secure competitive advantages.

Also, in many of the plausible ways one could define the "best-off", those with serious illnesses will not be included (since they can hardly be classified as well-off). However, if we have defined the categories of "worst-off" and "best-off" in economic terms, it may well be the case that many of those who seek expensive non-universal medical technologies are already part of the "best-off" category. If health is in any way positionally valuable, the use of expensive medical technologies by the best-off members of society may endow them with competitive advantages and ultimately increase their capacity to consume a greater proportion of resources in employment, education and other goods and services that the worst-off may otherwise have had access to. The morally benign status of the motivations may therefore not translate into morally benign consequences. ${ }^{92}$

While in many wealthy countries the increase in consumption of these sorts of resources may be offset by the resulting ease of pressure on the national health system, the situation for the global society (or for societies without a strong public health system) is quite different. If the majority of citizens in developed nations are able to afford medical treatments while the majority of citizens in developing nations are not, then the healthy developed nations may end up consuming an even greater percentage of other resources, leaving developing nations worse off in absolute terms.

It now seems I would be obliged, by virtue of consistency, to hold that unless universal access is achieved or until the global society becomes structured like many

\footnotetext{
${ }^{92}$ Kavka notes that "the collective effect of a large number of people performing a given type of action may not be simply the sum of the effects of each of those people performing the same type of action in isolation. Indeed, not just the magnitude, but the 'moral direction' of the effect - whether they involve human harm or benefit - may differ. Thus acts that would be beneficial if done alone may be harmful if done together, and acts that would be harmful if done alone (e.g. charging the enemy lines) may be beneficial if done together." Kavka, "Upside Risks," p.155. Lee Silver also discusses a similar effect. Lee Silver, Remaking Eden (New York: HarperCollins Publishers Inc., 1997), p.11.
} 
domestic Western societies (i.e. with basic publicly funded health care and sickness benefits) then we should withhold advantageous medical treatments even from those who are able to afford them. But surely this conclusion is absurd.

In fact, the argument from inequality does not entail that medical treatments should be banned for everyone if they are unable to be made available for all. A major reason for this is that medical treatments are unlikely to be as competitively harmful as enhancements. For one thing, the proportion of people in Western developed countries with serious disabilities is low, meaning that extra competitive advantages due to treatment of these disabilities would be negligible. Additionally, while eliminating mild illnesses (such as asthma) in the rest of the developed nations' population would greatly benefit the sufferers in terms of their health, their consumption of other resources (like employment) may be relatively unaffected. Enhancements on the other hand are more likely to increase resource consumption among the rich - first, because of the potential of enhancements to make a dramatic change in cognitive capacities and second, because every person is a potential enhancement candidate.

Furthermore, enhancements have no theoretical "end-point", unlike medical treatments. ${ }^{93}$ Eventually, the use of initially expensive medical technologies by the rich may facilitate their later uptake by the poor, assuming the cost of such technologies declines as they become more widely used. This may start to decrease the health gap between the rich and the poor, since the health of the rich may reach a point beyond which no further improvements are needed. Genetic enhancements on the other hand may not have this effect, since there is theoretically no point at which we can say their use is no longer warranted.

There is a more fundamental reason that the argument from inequality does not entail that we should ban all non-universally available medical treatments. While policies that benefit the best-off are prima facie unjust if they risk serious harm to the worst-

\footnotetext{
${ }^{93}$ In some instances, medical treatments may have no practical end-point (for example, asthma sufferers may have to use inhalers until they die). However, the theoretical goal of medicine is to restore a person to health; once this is achieved, treatment is no longer needed. Unlike enhancements, medical treatments are not aimed at making people 'better than healthy'.
} 
off, there may be circumstances in which permitting these policies is, all-thingsconsidered, morally justified or even obligatory. If there is an obligation to treat people, or if patients have a right to seek treatment, then these considerations may override the no harm principle. This means that while the non-universal use of medical treatments by the rich may be a prima facie wrong, it is not an all-thingsconsidered wrong. I will examine these competing moral considerations now and suggest how they are much stronger than any similar considerations that might arise in the case of genetic cognitive enhancement.

\section{Competing Moral Considerations}

For the moment, let's leave aside the question of whether the use of genetic enhancements is morally permissible. Instead, I want to show that while we very plausibly have obligations to treat illness and disability, it is unlikely that any such obligation arises in connection with enhancement. I am not arguing that a sort of treatment/enhancement distinction reflects a distinction between what is permissible and impermissible. Instead, I am concerned with the obligations society might have towards its ill and disabled citizens, and rights that arise in connection with these obligations. I make the claim that most treatments clearly create a moral obligation on society and generate a right on behalf of patients to seek treatment, while many enhancements, such as cognitive enhancement, do not generate these rights or obligations (although they may still be permissible). Let's consider a few examples to motivate this idea.

It is intuitively plausible that society has certain obligations toward people who have Parkinson's disease, HIV or cancer, or people who are disabled in some way, that it does not have to people wanting to become brilliant musicians or to people wanting to raise their IQ of 110 to an IQ of 200. Buchanan et al. ask us to "consider... the interest a person has in not having disabilities. Surely this is a morally legitimate 
interest." ${ }^{94}$ But what interest of equivalent weight could we appeal to in the case of cognitive enhancement? ${ }^{95}$

There are a number of plausible ways to defend the claim that the duty we have to treat those with HIV or cancer or Parkinson's disease does not arise in the case of many enhancements. One method is to use Norman Daniels' account of just health care, which is partly based on the moral obligation to ensure equality of opportunity. ${ }^{96}$ Buchanan et al. also agree that "there is a fairly broad consensus that it is important to restore to the status of 'normal competitors' those whose opportunities are diminished by disease and disability." 97 The notion of equality of opportunity therefore generates obligations on society to treat the sick and disabled but does not invoke any moral obligation towards those who are already "normal competitors" (i.e. most of the candidates for cognitive enhancement).

Similarly, on a biological functional model of disease the duty to ensure normal biological functioning motivates obligations toward treatment of, say, HIV but not of enhancing an already normal IQ.

Another extremely plausible way of illustrating the difference between medical treatments like curing cancer, for example, and cognitive enhancements is that the relief of suffering itself is one of our major moral obligations. ${ }^{98}$ Buchanan et al. claim that:

One of the most basic moral obligations human beings have [is] the obligation to prevent harm. People have especially demanding obligations to prevent harm to

\footnotetext{
${ }^{94}$ Buchanan et al., From Chance to Choice, p.267.

95 This does not say, however, that there is no interest in being enhanced. Obviously, an enhancement of cognitive capacities would have significant individual benefits. What I am claiming is that the obligations that arise in connection with medical treatments do not arise in the case of enhancement. ${ }^{96}$ See, for example, Norman Daniels, "Health-Care Needs and Distributive Justice," in Justice and Justification: Reflective Equilibrium: Reflective Equilibrium in Theory and Practice, by Norman Daniels (Cambridge: Cambridge University Press, 1996); Norman Daniels and James E. Sabin, "Determining 'Medical Necessity' in Mental Health Practice," in Justice and Justification: Reflective Equilibrium in Theory and Practice (Cambridge, Cambridge University Press, 1996).

${ }^{97}$ Buchanan et al., From Chance to Choice, p.187.

${ }^{98}$ See, for example, W. French Anderson, "Genetics and Human Malleability," The Hastings Centre Report 20:1 (1990), p.23; Jamie Mayerfield, Suffering and Moral Responsibility (New York: Oxford University Press, 1999), p.85; F. M. Randall, "Ethical Issues in Palliative Care," Acta Anaesthesiologica Scandinavica 43:9 (1999), p.954.
} 
their offspring, but through the agency of their political institutions, they also have obligations to prevent harm to others. ${ }^{99}$

The obligations to prevent harm and relieve suffering also explain why we count the treatment and prevention of disease as a moral duty, but not cognitive enhancement.

On each of these accounts, the moral obligations that arise for the treatment of illness or disease do not arise for the enhancement of normal cognitive capacities (this does not yet say that enhancements are morally impermissible).

This is not to claim that there is a perfect distinction between what would and what would not count as an obligation under each respective account. For example, it may be unclear whether or not some marginal cases do generate societal duties under the obligation to equalise opportunity. However, this issue is largely irrelevant for the purposes of my claim here. What I am arguing is that most medical treatments are clearly justified by these reasons, while many enhancements, such as cognitive enhancement, are not. The difficult distinctions in some of the cases do not make any less clear the radical difference between enhancing normal cognitive capacities and using radiotherapy to treat cancer under each of these accounts.

In fact, many proponents of enhancement accept that enhancements may not generate the same obligations as most medical treatments - they simply defend enhancements as something we are permitted to pursue. ${ }^{100}$ John Robertson, for example, argues that the use of genetic technologies to enhance one's child is morally permissible if the parents' choices can be understood in terms of procreative liberty and the enhancements would not "impose harm or burdens on others that justify discouraging or barring them." 101

\footnotetext{
${ }^{99}$ Buchanan et al., From Chance to Choice, p.18.

${ }^{100}$ See, for example, John A. Robertson, Children of Choice: Freedom and the New Reproductive Technologies (Princeton: Princeton University Press, 1994); Agar, Liberal Eugenics; Silver, Remaking Eden.

${ }^{101}$ John A. Robertson, "Ethics and the Future of Preimplantation Genetic Diagnosis," Ethics, Law and Moral Philosophy of Reproductive Biomedicine 1:1 (2005), p.99.
} 
Julian Savulescu is one of the few philosophers who argue that we are obliged to select the best genes for our children. On his account, cognitive enhancements might hold equivalent moral weight to the treatment of meningitis, for example.

Savulescu introduces the "principle of procreative beneficence", which states:

Couples (or single reproducers) should select the best child, of the possible children they could have, who is expected to have the best life, or at least as good a life as the others, based on the relevant, available information. ${ }^{102}$

However, while the principle of procreative beneficence initially seems attractive, when we consider it as applied to environmental interventions it becomes clear that Savulescu's account is not particularly plausible. The principle of procreative beneficence judges it morally impermissible for families to move from wealthier neighbourhoods to poorer ones (assuming for the sake of argument that children do better in richer suburbs) or for parents to take holidays instead of using the money to send their child to a private school. Once we understand the implications of applying the principle of procreative beneficence to social interventions, we can see that we do not have moral obligations to do the best for our children at the expense of all else; instead it seems we have these other duties - to avoid and relieve suffering, to ensure equality of opportunity. We have a duty to take our children to the doctor if they have meningitis or tonsillitis. We do not have a duty to send them to the best schools money can buy. While it may certainly be permissible to make our children the best they can be, it is implausible to consider it a requirement.

So, while there are no obligations to permit enhancement, society does have moral obligations to treat illness and disability. And given that society has these obligations, then surely patients have the corresponding right to seek treatment. This means that if we are unable to publicly fund universal medical care, a patient's right to seek treatment for their condition means that society is not justified in prohibiting access to non-universally available treatments. While non-universal access is certainly unfortunate for those unable to afford expensive medical care, it is surely more unjust

${ }^{102}$ Julian Savulescu, "Procreative Beneficence: Why We Should Select the Best Children," Bioethics 15:5/6 (2001), p.413. 
to prevent the wealthy from purchasing medical treatments, considering they have a right to do so. In short, this would be a violation of their individual rights.

Buchanan et al. make a response to the loss of support objection (which I briefly discussed earlier) that can be applied equally well to this case. They argue that "the most fundamental problem with the loss of support argument" (or any argument against the use of non-universally available medical treatments that considers any harm to the poor to be always unjust) "is that it only considers the interests of those who...have disabilities... It entirely neglects the legitimate interests that people have in not having disabilities."103

The argument from inequality has a benefit in this regard, in that it does consider the legitimate interests of both the poor and the wealthy. The no harm principle does not state that a policy that benefits the well-off but risks harms to the worst-off is necessarily an all-things-considered wrong; rather that policy is a prima facie wrong. If there are competing moral considerations to take into account - in this case, the right of the sick to seek treatment for their condition - then, all-things-considered, we may be obliged to permit that policy (i.e. to permit the non-universal use of expensive medical treatments).

Buchanan et al. convincingly argue that there is a difference between:

being harmed and being wrongly harmed. Even if the minority who remain uncured [the poor] are harmed by widespread use of the surgical intervention it would not follow they have been wrongly harmed, unless one is willing to make the implausible claim that those who elected to be cured had no right to make this choice. But whether they have a right to make such a choice will depend primarily upon whether they had a legitimate interest in avoiding being disabled and whether that legitimate interest is of such moral weight that it warrants special protection implied in the notion of a right. Having a right to do something means having a sphere of discretion to do what might otherwise be wrong, including what may contribute to the worsening of the condition of others. ${ }^{104}$

\footnotetext{
${ }^{103}$ Buchanan et al., From Chance to Choice, p.267.

104 Ibid., p.269.
} 
So, while it may be true that permitting non-universal access to medical treatments risks some harms to the poor, a prohibition against the use of these treatments would be a violation of the right a sick person has to seek treatment for their condition. The interest someone might have in becoming cognitively enhanced is not of the same moral weight and does not generate an equivalent "right". This is clearly shown in the justifications for the obligation to treat the sick that I discussed above.

None of the above justifications for the obligations that arise in connection with medical treatments arise in the case of cognitive enhancements. However, this does not in itself make cognitive enhancements impermissible. Wealth-based access to cognitive enhancements is all-things-considered morally impermissible for two reasons. First, permitting wealth-based access to enhancements is prima facie unjust because it risks serious harm to the poor. As we have seen, wealth-based access to expensive medical treatments is much less concerning in this regard. Secondly, unlike in the case of medical treatments, there are no competing moral considerations in the case of cognitive enhancement that would give the wealthy a right to use enhancements. That is, there are no moral obligations sufficiently strong to override the no harm principle, meaning that wealth-based-access to genetic cognitive enhancements is all-things-considered unjust. If the use of enhancements by the rich were not likely to harm the poor, or if the wealthy had some right to use enhancements, then we would have to conclude that cognitive enhancements should be permitted. However, this is not the case, so the unequal distribution of cognitive enhancements remains morally impermissible, while the unequal distribution of medical treatments does not. 


\section{ARGUMENT FROM EDUCATION}

I now consider a second consistency argument, which has been advanced by John Harris, ${ }^{105}$ Julian Savulescu ${ }^{106}$ and Lee Silver, ${ }^{107}$ among other proponents of enhancement. The objection begins by (rightly) noting that opponents of genetic enhancement technologies must take a position consistent with their position on environmental methods of enhancing intelligence, such as education. The objection goes on to claim that opponents of enhancement are not in fact consistent in this regard. While I will call this objection the "argument from education", I will treat it as applying to all forms of environmental cognitive enhancement. ${ }^{108}$ This argument can take two forms.

The first formulation of the argument from education is a reductio ad absurdum argument. This type of argument attempts to show the implausibility of a proposition by demonstrating that its acceptance would lead to an absurd and obviously false conclusion. Proponents of cognitive enhancement begin by accepting the proposition that wealth-based access to genetic enhancement is unjust. They then maintain that since education, like genetic cognitive enhancement, is a primary good that is also unequally distributed between the rich and the poor, the argument from inequality must also hold that education is unjust and consequently should not be permitted. Since this conclusion is obviously absurd, proponents of enhancement argue that the conclusion that it is unjust to permit wealth-based access to cognitive enhancements must be false.

In "The Reversal Test" Bostrom and Ord apply a reductio ad absurdum argument. They ask:

Whether it would have been better in the past if nobody had been taught to read given that only elites had access to education. And, considering that literacy is still

\footnotetext{
${ }^{105}$ See, for example, John Harris, "Biotechnology, Friend or Foe? Ethics and Controls," in Ethics and Biotechnology, ed. Anthony Dyson and John Harris (London: Routledge, 1994), p.221; John Harris, Wonderwoman and Superman (Oxford: Oxford University Press, 1992), p.142.

${ }^{106}$ Julian Savulescu, "Genetic Interventions and the Ethics of Enhancement of Human Beings," in The Oxford Handbook of Bioethics, ed. Bonnie Steinbock (Oxford: Oxford University Press, 2007), p.521. ${ }^{107}$ Silver, Remaking Eden, pp.137-138.

108 And I may use the terms "education" and "environmental enhancement" interchangeably.
} 
far from universal, especially in the poorest countries, would it be better if nobody in those countries (or in developed countries?) were given this kind of cognitive enhancement unless and until everybody gets it? ${ }^{109}$

The second formulation of the argument from education begins with the premise that we already accept the unequal distribution of education and other environmental methods of enhancing intelligence, so by virtue of consistency we must also accept wealth-based access to genetic cognitive enhancement.

Harris employs the second formulation of the argument from education. He asks opponents of enhancement to explain "why, if it is legitimate to try to educate our children to acquire the ability to do mathematics, it is not legitimate to genetically engineer into them a like ability.",

In assessing both of these formulations, there are three possible choices one could make. One could:

a) accept that no form of education (or genetic cognitive enhancement) be permitted until it can be made available to everyone;

b) accept that the genetic enhancement of intelligence should be permitted (and so should education); or

c) maintain that there are morally relevant differences between genetic enhancement and the forms of education and environmental enhancements that we currently employ.

Choosing (a) is not an attractive option for opponents of cognitive enhancement. If an argument against wealth-based access to intelligence-enhancing technologies is to have any force, it cannot also entail the highly implausible conclusion that all forms of education and environmental enhancements should be banned. The opponent of cognitive enhancement also cannot choose (b), for obvious reasons. Option (c), therefore, is the only feasible option. In the rest of this chapter I will illustrate why

\footnotetext{
${ }^{109}$ Bostrom and Ord, "The Reversal Test," p. 675.

${ }^{110}$ Harris, "Biotechnology, Friend or Foe?" p.221.
} 
environmental cognitive enhancements are different from genetic cognitive enhancements in morally relevant respects.

As in the argument from medical treatments, proponents of the argument from education cannot simply point to education's unequal distribution in order to make a consistency objection to the argument from inequality. Instead, they must either demonstrate that the distribution of education poses a serious risk of harm to the poor (and thereby show we are not justified in prohibiting genetic enhancements for this reason), or, they must establish that the educational advantages of the rich do not harm the poor, meaning that their genetic cognitive enhancements are also unlikely to do so.

In response to the argument from education I aim to show that while environmental and genetic methods of enhancing intelligence are not different in theory, in practice the unequal distribution of environmental enhancements does not pose as serious a risk of harm to the poor as the unequal distribution of genetic enhancements. In large part this is because current educational disparities do not create differences as substantial as those that may be created by unequal access to genetic enhancements (like the kinds of cognitive enhancements advocated by Bostrom and Ord). This difference in degree is highly significant when evaluating the effects of cognitive enhancements (whether environmental or genetic) under real life conditions. As I consider in turn each harm I discussed in the case of genetic enhancement - loss of reciprocity, discrimination and competitive harm - I will offer further reasons, specific to each case, to believe that environmental methods are less morally problematic than genetic methods of enhancing intelligence. From this analysis I hope to show that although the argument from inequality judges wealth-based access to genetic enhancements to be unjust, it does not entail that we should ban educational institutions, like Oxford and Harvard, for example, that are not accessible to everyone. 


\section{Reciprocity}

The kinds of genetic enhancements advocated by Bostrom and Ord would increase enhancement users' intelligence to the extent that political and social reciprocity between the enhanced and the unenhanced would be virtually impossible. Just as human beings cannot have effective cooperative relationships with chimpanzees, radically enhanced humans would be unable to maintain effective reciprocity with unenhanced humans. Current educational disparities, on the other hand, do not create the sorts of differences significant enough to sever political and social reciprocity between those with access to education and those without. Even the Harvardeducated are still able to be part of the same political community as those with little or no education. Any potential reciprocal harms due to unequal access to education have so far been effectively prevented by our social and political institutions.

If there were an environmental enhancement (such as a pill or a method of education) that had the effect of making reciprocal relationships between the best and least educated unlikely or impossible, then we would have good reason to consider it unjust. In Wonderwoman and Superman, Harris poses this thought experiment:

\footnotetext{
Suppose a school were to set out deliberately to improve the mental and physical capacities of its students, suppose its stated aims were to ensure that the pupils left the school not only more intelligent and more physically fit than when they arrived, but more intelligent and more physically fit than they would be at any other school. Suppose that a group of educationalists, outstanding ones of course, far more brilliant than any we know of to date, had actually worked out a method of achieving this? What should our reaction be? ... We ought to want this. It is, after all, what education is supposed to be for. ${ }^{111}$
}

Harris seems to think it obvious that to label such a school unjust is absurd. However, if Harris's school made its students smarter than those unable to attend by a degree analogous to the cognitive difference between Australopithecus and Homo sapiens, then we would have a prima facie reason to consider the school unjust. Nonetheless, the cognitive differences produced by Harris's school or by institutions like Harvard

${ }^{111}$ Harris, Wonderwoman and Superman, p.140 - my italics. 
do not seem to be this significant. Harris's example seems only to highlight the fact that individual decisions appear rationally and morally different from collective or societal decisions. Only an irrational parent would not want their child to receive these positional benefits. However, the question of whether society should want this is a different matter.

It may be argued that since a loss of social and political reciprocity is only likely to be caused by substantial intellectual differences, the no harm principle is, in theory, committed to supporting wealth-based access to minor genetic cognitive enhancements. However, while the argument from inequality may in principle judge the unequal distribution of mild enhancements just, we are in practice unlikely to be able to limit genetic enhancements to those that have effects mild enough for reciprocity to be maintained. This seems true for a number of reasons.

First, somewhat mild cognitive enhancements are not the kind of enhancements that people are likely to desire. If individuals are able to achieve the same results through less expensive environmental enhancements, then the only point of genetic enhancement will be to create really significant differences, like those advocated by Bostrom and Ord.

Secondly, even small initial genetic enhancements may ultimately have large cumulative effects. While each individual enhancement may be comparatively mild, successive use of such enhancements may produce significant differences.

Thirdly, environmental enhancements seem to have some practical limits on the differences they can create. This may not be true for genetic enhancements. For example, if one extra copy of the intelligence gene can mildly increase intelligence, perhaps 10 copies will have much greater effects. Certainly, geneticists have not yet ruled out these major enhancements. While we may be able to raise our intelligence through genetic engineering by the degree that human beings are smarter than our Australopithecus ancestors, creating such differences does not appear to be practically achievable through the environmental methods of enhancement we currently use. 
Fourth, those who are likely to have the best access to genetic enhancements (the well-off) already have the best access to environmental enhancements. While current educational disparities have not made political reciprocity between the best- and worst-off impossible, significantly greater differences are much more likely to have this effect. If existing environmental enhancements are coupled with mild or moderate genetic enhancements, then this may greatly increase the reciprocity index within a society. This means that even somewhat mild genetic enhancements may create differences too extensive for effective social cooperation to be maintained, if used by those who already have access to environmental enhancements. Slightly greater differences than those currently created by educational disparities may not make cooperative social relationships impossible; moderate or major increases may. Bostrom and Ord must be prepared to show that the use of mild genetic enhancements by those who are already environmentally enhanced will not create the sorts of differences that make reciprocity impossible.

Finally, even if we are able to limit enhancements to technologies which produce only mild effects (which seems unlikely), these enhancements are still much less significant than the kinds of enhancements Bostrom and Ord want permitted. So, even if my arguments show why only major enhancements are unjust, the argument from inequality will still have made an effective response to the Reversal Test, since the Reversal Test is supposed to show that even substantial cognitive enhancements should be permitted.

\section{Discrimination}

The difference in degree is also relevant when considering potential harms through discrimination. The relatively major differences created by genetic enhancement seem more likely to be used to justify discrimination than the comparatively minor differences created through environmental enhancement. Consider, for example, the way non-human animals are currently treated, or the justifications made for the oppression of women - that they lack the capacity for rationality. Although unequal access to education does create differences between those with the best access and those with the worst, they are not significant enough to claim that the uneducated have 
no capacity for rational thought, for example. The ability of our social institutions to prevent harms through discrimination despite the unequal distribution of environmental enhancements may be severely limited once major cognitive differences are created through genetic enhancement.

In fact, some of the empirical evidence seems to show that social enhancements have created surprisingly small intellectual gaps between the best- and worst-off. Consider, for example, the Flynn effect, named after James Flynn, the New Zealand political scientist who first documented the effect. What Flynn noticed was that IQ test scores have been steadily increasing in all countries (developed and developing) for which data is available since around the 1950s (although in some countries this increase appears to have now stopped). ${ }^{112}$

Since the Flynn effect has occurred so rapidly (increases of up to 21 IQ points over 30 years have been documented $)^{113}$ it cannot be mainly genetically caused. ${ }^{114}$ And, while the exact type of environmental cause of the Flynn effect is not certain, ${ }^{115}$ it does seem to indicate that the unequal distribution of environmental advantages has not created the intellectual differences between the best- and worst-off that might be expected. In fact, there is some evidence to suggest that average rises in IQ are significantly due to the better IQ test scores of the least intelligent. ${ }^{116}$

Some of the more popular explanations of the Flynn effect point to plausible explanations for these findings. One explanation suggests that better nutrition of the poor has helped decrease the cognitive gaps between the best- and worst-off. Another

\footnotetext{
112 These countries include Norway, Sweden, The United States, New Zealand, Brazil, China, East Germany, Israel and Kenya. See, for example, Charles Graham and Jonathan Plucker, "The Flynn Effect," Human Intelligence, http://www.indiana.edu/ intell/flynneffect.shtml; Tamara C. Daley et al., "IQ on the Rise: The Flynn Effect in Rural Kenyan Children," Psychological Science 14:3 (2003).

${ }^{113}$ Ulric Neisser, "Rising Scores on Intelligence Tests," American Scientist 85 (1997).

${ }^{114}$ It has been hypothesised, for example, that the higher fertility rates of women at the lower end of the socio-economic spectrum, who have been shown to have lower IQ scores in general, should have had a dysgenic effect. See, for example, Richard Herrnstein and Charles Murray, The Bell Curve: Intelligence and Class Structure in American Life (New York: Free Press, 1994).

${ }^{115}$ Some proposed explanations include better nutrition, more complex environments, more widespread education and increased familiarity with the types of problems tested by the IQ test.

${ }^{116}$ Roberto Colom et al., "The Generational Intelligence Gains are Caused by Decreasing Variance in the Lower Half of the Distribution: Supporting Evidence for the Nutritional Hypothesis," Intelligence 33:1 (2005), p.83.
} 
explanation, the environmental complexity hypothesis, supports the idea that social enhancements may be more easily shareable than genetic enhancements. The greater environmental complexity of 2008 compared to 1970 affects all who live in that environment, whereas genetic enhancements only raise the IQ of the individual who has been enhanced, and potentially his or her descendants.

It may be objected, however, that the explanations for the Flynn effect I have considered are relatively contentious. Also, it seems true that environmental enhancements do have the power to produce genuine differences between people (whether cognitive or educational), even if they are not as substantial as those created by genetic enhancement. This means we should not completely discount the possibility that discrimination against the worst-off will be justified by environmentally created disparities.

Nevertheless, even if education does create differences, we still have good reason to suppose that its unequal distribution is less likely to cause the well-off to discriminate against the less well-off. One reason for this is that education involves exposure to new ideas, not just an increase in cognitive capacities. And, it seems the more one is exposed to new ideas, the more likely one is to learn that a person's moral worth does not depend on factors such as one's biology or intellectual or educational capacities. There appears to be some evidence in support of the contention that biased attitudes are negatively correlated with education, with one study finding that the more educated are less likely to have negative attitudes towards homosexuality. ${ }^{117}$

However, I did previously rebut the assertion that greater cognitive capacities would necessarily entail greater moral concern for the worst-off, suggesting that while possible, we would need to have strong evidence of the efficacy of greater intelligence in preventing discrimination in order to support wealth-based access to genetic cognitive enhancements. So perhaps the suggestion that being exposed to new ideas through education makes people less likely to discriminate faces a similar problem. Nonetheless, while we may not be justified in claiming that the unequal distribution of

${ }^{117}$ Julianne Ohlander et al., "Explaining Educational Influences on Attitudes toward Homosexual Relations," Social Science Research 34:4 (2005). 
education has any advantages in this respect, there are other considerations that support the view that current educational disparities are not generally used to justify discrimination against the worst-off. These considerations cannot be invoked to support a similar conclusion with genetic cognitive enhancement.

First, education has informed us (through scientific research) that supposed biological differences in intelligence between the races and sexes, for example, are not as significant as racists and sexists have claimed. While some studies have pointed to subtle potentially innate differences between groups in a few specific abilities (one study found "men outperformed women on a visuospatial task and women outperformed men on tests of verbal fluency"118), such differences are comparatively minor. Education about the similarities and differences between groups has informed us that claims like "women are biologically incapable of rationality" are simply false. If genetic enhancements created a group with much better cognitive capacities than another, we may no longer be able to make this claim.

The second and more important consideration concerns the argument I made in chapter 3 that discrimination becomes a particularly serious problem when intellectual differences are genetically caused. Even though both genetic and social factors influence the development of one's phenotype, it is the biological causes of difference that seem to make people most vulnerable to the mistaken equivocation between the intellectual sense of "better" and the moral sense of "better". And as suggested in chapter 3, we would need to have good evidence of the power of enhanced intelligence to help avoid this mistake in order to be reasonably sure that the unenhanced would not be discriminated against.

Where differences in intelligence can be attributed solely or mainly to environmental factors, the notion of equality does not seem threatened; where genetic factors are thought to be significantly responsible for an average intellectual difference between groups, this tends to be seen as a threat to not only intellectual equality, but moral

${ }^{118}$ A. Herlitz et al., "Gender Differences in Episodic Memory," Memory \& Cognition 25:6 (1997). 
equality as well. ${ }^{119}$ Only in the former case are prohibitions against racism and sexism, for example, thought to be rationally justifiable. The fact that it is mainly due to genes and not the environment that enable humans rather than sheep to think rationally seems to justify different moral consideration of their respective interests.

I have argued this position in some detail in chapter 3 and so will not repeat the arguments here. However, I will challenge those who are not convinced that genetically created intellectual differences pose a more serious problem for discrimination than environmentally created differences to provide evidence where environmental differences have been so successfully used to justify unequal moral consideration.

\section{Competitive Harms}

In chapter $3 \mathrm{I}$ argued that since intelligence has significant positional value, the unequal distribution of genetic cognitive enhancement may cause the poor competitive harm, ultimately leaving them worse off in absolute terms. We might expect then, that the unequal distribution of education would have the same effect, since education is also a primary good with considerable positional value. For example, education is positively correlated with both income ${ }^{120}$ and health. ${ }^{121}$

However, at first glance there seem to be plausible reasons to suspect that the competitive harms to the worst-off caused by an unequal distribution of educational advantages are not as significant as the competitive harms that may be caused by genetic enhancement. For one thing, educational advantages are not as substantial as the advantages that may be engineered by the radical genetic enhancements Bostrom and Ord propose. Also, education arguably has greater absolute social value than intelligence, in part because of the way it exposes people to new ideas. Milton

\footnotetext{
${ }^{119}$ See the arguments I made in chapter 3 and their references. Perhaps some sort of folk conception of genetics is responsible for this view - biological differences are somehow fundamental and therefore morally important whereas environmental differences are not.

${ }^{120}$ U.S. Department of Commerce, "The Big Payoff: Educational Attainment and Synthetic Estimates of Work-Life Earnings," (U.S. Census Bureau, 2002), p.2.

${ }^{121}$ Lean Feinstein et al., "What Are the Effects of Education on Health?" p.172.
} 
Friedman, for example, suggests that literacy and knowledge promote "a stable and democratic society.",122

However, it may be objected that the same can be said for the genetic enhancement of literacy, for example. Furthermore, although the competitive advantages of education may be relatively less than those created by genetic enhancement, in absolute terms they are not insubstantial. Accordingly, we do not automatically have good reason to discount the potential competitive harms entirely.

Nevertheless, once we consider the potential absolute social benefits, there are good reasons to believe that the translation from theoretical into practical benefits to the poor is much more likely to occur because of others' education than because others have been genetically enhanced. I will now show why this is the case.

\section{Balancing the Benefits and Harms}

First, we should remember that the harms to the poor due to genetic enhancement are likely to be greater than those created by an unequal distribution of environmental enhancements. Wealth-based access to genetic cognitive enhancements is likely to seriously harm the poor through discrimination and loss of reciprocity. As we have already seen, unequal access to environmental enhancements is much less problematic in both these respects. Also, the greater differences produced by genetic enhancement mean that its competitive harms may be much more serious. These are two points to bear in mind in this section, because it means that potential benefits of environmental enhancements have to compensate for much less.

In chapter 3 I argued that the harms to the worst-off caused by wealth-based access to cognitive enhancement would be unlikely to be offset by the absolute social benefits of the well-off's higher intelligence. Since reciprocity may have become impossible, and since the enhanced are likely to regard the unenhanced as less than moral equals, they may also reject the idea that the unenhanced poor are deserving of social benefit,

${ }^{122}$ Milton Friedman, "The Role of Government in Education," in Economics and the Public Interest, ed. Robert A. Solo (New Brunswick, NJ: Rutgers University Press, 1955), p.124. 
and may be unwilling to provide the resources needed to solve the problems most affecting the poor. On the other hand, we have seen that unequal access to environmental enhancements is significantly less likely to result in the poor's marginalisation, which means that any theoretical social benefits to the poor through others' education will be more likely to be practically realised.

I also argued that any increase in the total supply of primary goods due to cognitive enhancement would be unlikely to compensate for the reduction in percentage of the unenhanced's share, due to reasons similar to those discussed above. We may be more optimistic about the unequal distribution of environmental enhancements in this respect, since the poor will be more effective in acquiring the extra primary goods if they are not morally and politically marginalised.

I further suggested that the disbursing effect of genetic technologies (i.e. that enhancement technologies may decrease in price over time, enabling the descendants of the current poor to access them) would be unlikely to mitigate harms through competition, discrimination and loss of reciprocity. One reason for this was that I was sceptical about the genes being able to be placed in an appropriate environment genetic enhancements may be of little benefit if they cannot be made use of by education, for example. Second, given that new technologies do not remain static, the wealthy's ability to continually acquire the latest technologies (i.e. the latest and most powerful enhancement) may maintain the original disparity that the unequal access to enhancement technologies produced.

Education arguably acts similarly to genetic technologies in an important respect - the uptake of education by the well-off facilitates the eventual education of the worst-off. Given that (in the absence of genetic enhancements) the average genotype of the rich and poor is roughly similar, the eventual education of the less well-off means both their environmental and genetic inputs are similar to the rich's. On the other hand, without the right environments, the eventual genetic enhancement of the poor may achieve comparatively little. 
Furthermore, although new forms of education are not static (using computers and calculators to help learn, for example) they do not seem to change quite as rapidly as new technologies. Whereas genetic enhancement causes the poor to be continually at a disadvantage because of the uptake of new technologies by the rich, it seems that the more widespread education is, the further it goes to mitigating the original disparity caused by its initial unequal distribution. Institutions like Harvard change over time, but not in a comparably radical fashion to new technologies. While the rich will still have advantages (private education, for example), the public education of the poor will greatly benefit them.

This analysis has compared three potential harms to the poor - discrimination, loss of reciprocity and competitive harm. I have found that even though environmental and genetic methods of enhancing intelligence are not morally different in theory, they are nonetheless morally different in practice because the unequal distribution of environmental enhancements poses a substantially lesser risk of harm to the poor than the unequal distribution of genetic enhancements. There is one final point to make in this regard. I will now suggest that in the case of many environmental enhancements, there are competing moral considerations that make their restriction more morally problematic than the restriction of genetic enhancements.

\section{Competing Moral Considerations}

In order to illustrate how two situations with similar effects may be judged morally differently on the no harm principle, it is helpful to contrast two different methods of genetically enhancing intelligence - the use of genetic technologies and choosing one's mate.

Let's suppose that IQ is almost completely heritable. Let's also suppose that all high IQ individuals decide only to reproduce one-another, and that over time this group becomes cognitively enhanced, causing harm to the less intelligent. Since my arguments have shown wealth-based access to genetic cognitive enhancement technologies to be unjust because of similar types of harms, this seems to indicate that I am committed to supporting a policy that would prevent people from choosing their 
own partners, and perhaps even force them to reproduce with people of a particular level of intelligence.

However, this is not the case. Although I have argued that we should not permit the unequal distribution of genetic enhancement technologies, this does not mean the State should seek to prevent similar harms caused by selective reproduction by prohibiting the more intelligent from freely choosing their mate, coercing them into having children with people of the State's choosing, or instituting a policy of compulsory sterilisation. This would be an incredible violation of an individual's rights. But as we have already seen in chapter 3 and in responding to the argument from medical treatments, no rights are violated by withholding genetic technologies.

The example given above illustrates that competing moral considerations can make actions with similar consequences morally very different. And, in the case of many environmental methods of enhancing intelligence, there seem to be competing moral considerations that are absent in the case of using genetic technologies to enhance intelligence. This may justify treating the two cases differently.

I want to now suggest that the use of many environmental enhancements can be defended by considerations of personal liberty. Although I argued in the case of genetic enhancements that liberty is not a "trump card", I also noted that the most plausible theories of liberty make a presumption in favour of personal freedom (i.e. the onus should be on those who favour the restrictions). As previously discussed, genetic enhancement technologies can be prohibited with minimal interference in personal liberty. However, it would be impossible to regulate many environmental influences without considerable State intrusion into its citizens' lives. This may mean that those who advocate restrictions on these environmental enhancements cannot meet the required burden of proof.

Take two potential environmental cognitive enhancements - good nutrition and reading to one's child. Would we really think it justified to prohibit parents from reading to their children? Parents read to their children not only to enhance their intellect, but to spend quality time together and improve the parent-child relationship. 
Furthermore, the risk of harm to the poor through these kinds of environmental influences is low (as evidenced by the arguments in this chapter). A prohibition on reading to one's children would require the State to constantly monitor the private lives of its citizens - to not only ban or restrict the sale of books but also to make sure parents did not create their own stories to read. In this case, it would be difficult to show that the risk of harm to the poor was great enough to justify such significant restrictions on liberty.

The same is true for improved nutrition, which not only may cause IQ gains but is also important for health (the value of which has been discussed earlier in the chapter). To harm one's child by not providing good nutrition would be wrong. Furthermore, State regulation of individuals' food intake would require constant interference in people's lives. Withholding a genetic technology on the other hand does not require these constant intrusions.

I have clearly shown in this analysis the morally relevant differences between genetic and environmental methods of cognitive enhancement. By illustrating in each case the practical differences between the two, we are able to see that although using education and genetic technologies to improve intelligence are not morally different in theory, they are nonetheless morally different when evaluated by the no harm principle under real life conditions.

\section{CONCLUSION}

This chapter has been concerned with presenting and responding to two consistency objections to the argument from inequality - the argument from medical treatments and the argument from education.

In the first part of this chapter I showed why the argument from medical treatments is ineffective in showing that the argument from inequality requires all non-universally available medical treatments to be banned. I illustrated that health differences between the rich and the poor are not likely to cause discrimination against the less healthy, nor are they likely to make people so different from one another that political 
reciprocation and social cooperation are impossible. Furthermore, I argued that the better health of some is less likely to severely harm the poor in competitive terms.

More fundamentally, I established that the obligations of society to treat disease and disability, and the corresponding right of the sick to seek treatment, mean that it would be morally wrong to prohibit the non-universal use of medical treatments for those who can afford them. These rights and obligations are justified by the obligation to protect equality of opportunity, to ensure normal biological functioning, and the duty to prevent harm and relieve suffering. However, none of these obligations, rights or duties arise in the case of genetic cognitive enhancements, and so cannot be invoked to justify their non-universal use.

In responding to the argument from education, I established that while environmental and genetic methods of enhancing intelligence are not in principle different, in practice, an unequal distribution of environmental enhancements is not likely to cause as significant harms to the poor as an unequal distribution of genetic enhancements.

In the case of reciprocity, I argued that the gaps that can be engineered through environmental enhancements are not significant enough to pose a threat to reciprocity, unlike the potential differences created through genetic enhancements. I also showed that restricting cognitive enhancement technologies to ones that had only a mild effect is unlikely to be practically achievable. I then suggested that the somewhat lesser potential of environmental enhancements to engineer difference as compared to genetic enhancements means that the unequal distribution of education is also less likely to result in discrimination. More importantly, I maintained that the equivocation between the different senses of "better" seems to be a particular problem for biological, rather than environmental, causes of intellectual difference. I also suggested that competitive harms to the poor due to environmental disparities are likely to be less than those caused by genetic disparities. Furthermore, we saw that the translation from theoretical into practical benefits seems more likely to occur due to environmental rather than genetic cognitive enhancements. Finally, I suggested that there are competing moral considerations in the case of many environmental 
enhancements - that their restriction may require unjustified intrusion in personal liberty - that are not present in the case of genetic enhancements.

Together, these practical differences show that while the argument from inequality judges wealth-based access to genetic cognitive enhancements morally impermissible, it does not require us to prohibit the non-universally available environmental cognitive enhancements that are currently employed.

This analysis has shown that we have good reason to reject both the argument from medical treatments and the argument from education. Therefore, given that these consistency arguments are supposed to be the strongest potential objections to the argument from inequality, we can conclude that the arguments presented in chapter 3 and defended here make a successful response to the Reversal Test.

In chapter 5 I consider a new method for testing for status quo bias that Bostrom and Ord present as a further burden of proof challenge to arguments that successfully overcome the Reversal Test. I argue that this new method also fails to show that the argument from inequality is influenced by status quo bias. 


\section{The Double Reversal Test}

\section{THESIS OBJECTIVES}

The main goal of this thesis has been to meet the Reversal Test's burden of proof challenge by illustrating that opposition to wealth-based access to cognitive enhancements, based on considerations of inequality and justice, is not influenced by the status quo bias. Having met the initial burden of proof in chapter 3 and responded to the strongest potential objections to my argument in chapter 4 , the burden of proof now lies with proponents of cognitive enhancement to provide good evidence for thinking that the injustices I have predicted are unlikely to come about (although I have strong doubts that this can be done). Accordingly, my goal of successfully responding to the Reversal Test has been achieved.

\section{THE ORIGINAL DOUBLE REVERSAL TEST}

However, the Reversal Test is not the extent of Bostrom and Ord's burden of proof challenge. At the end of their paper they construct a further hurdle for opponents of enhancement - the Double Reversal Test. If an argument against enhancement passes the Reversal Test, the burden of proof shifts back onto proponents of cognitive enhancement, at which time Bostrom and Ord put forward the Double Reversal Test. The Double Reversal Test attempts to shift the onus back onto enhancement's opponents:

Disaster! A hazardous chemical has entered our water supply. Try as we might, there is no way to get the poison out of the system, and there is no alternative water source. The poison will cause mild brain damage and thus reduced cognitive functioning in the current population. Fortunately, however, scientists have just 
developed a safe and affordable form of somatic gene therapy which, if used, will permanently increase our intellectual powers just enough to offset the toxicityinduced brain damage. Surely we should take the enhancement to prevent a decrease in our cognitive functioning. ${ }^{123}$

In the first situation we judge it best to use genetic cognitive enhancement to offset the brain-damage caused by the poisoned water supply. Then:

\begin{abstract}
Many years later it is found that the chemical is about to vanish from the water, allowing us to recover gradually from the brain damage. If we do nothing, we will become more intelligent, since our permanent cognitive enhancement will no longer be offset by continued poisoning. Ought we try to find some means of reducing our cognitive capacity to offset this change? Should we, for instance, deliberately pour poison into our water supply to preserve the brain damage or perhaps even undergo simple neurosurgery to keep our intelligence at the level of the status quo? Surely, it would be absurd to do so. Yet if we don't poison our water supply, the consequences will be equivalent to the consequences that would have resulted from performing cognitive enhancement in the case where the water supply hadn't been contaminated in the first place. Since it is good if no poison is added to the water supply in the present scenario, it is also good, in the scenario where the water was never poisoned, to replace that status quo with a state in which we are cognitively enhanced. ${ }^{124}$
\end{abstract}

In the second situation (once the poison has disappeared), the only plausible conclusion is that we should refrain from trying to offset the cognitive enhancement and should allow our intelligence to gradually increase when the population begins to recover. Bostrom and Ord argue that since the consequence of non-interference is identical to the consequence of permitting cognitive enhancement under normal circumstances, then there is no good reason to suppose that permitting cognitive enhancements in the normal case would have negative overall consequences. To claim that it is morally permissible for the population to become cognitively enhanced as a result of the poison wearing off in the Double Reversal Test but morally impermissible to allow the genetic enhancement of intelligence under normal circumstances is evidence of status quo bias, they argue. Bostrom and Ord note:

\footnotetext{
${ }^{123}$ Bostrom and Ord, "The Reversal Test," p.672.

${ }^{124}$ Ibid., p.672.
} 
The Double Reversal Test works by combining two possible conceptions of the status quo. On the one hand, the status quo can be thought of as defined by the current (average) value of the parameter in question. To preserve this status quo, we intervene to offset the decrease in cognitive ability that would result from exposure to the hazardous chemical. On the other hand, the status quo can also be thought of as the default state of affairs that results if we do not intervene. To preserve this status quo, we abstain from reversing the original cognitive enhancement when the damaging effects of the poisoning are about to wear off. By contrasting these two perceptions of the status quo, we can pin down the influence that status quo bias exerts on our intuitions about the expected benefit of modifying the parameter in our actual situation. ${ }^{125}$

Bostrom and Ord claim that the Double Reversal Test is effective in rebutting a range of arguments against cognitive enhancement, such as the arguments from risk, transition costs, evolutionary adaptation and person-affecting ethics, as these concerns are already taken into account in forming our judgments about permitting intelligence increases once the poison has disappeared. That is, when considering whether it would be good for the already enhanced population to let their intellectual capacities increase once the brain damage begins to reverse, our answer already takes into account the potential negatives of the consequences of this decision. Maintaining that we should not intervene to offset the intelligence-increasing effect of the enhancement therefore supposedly shows that opposition to enhancements in the normal case is influenced by status quo bias.

However, the Double Reversal Test turns out to be an ineffective tool in diagnosing status quo bias in arguments such as mine that take the unequal distribution of enhancements to be a major moral concern. The Double Reversal Test assumes a situation in which everyone in society is genetically enhanced, therefore automatically negating any concerns about injustices occurring through the unequal distribution of enhancements. In the normal case, there is no such guarantee of universal access to enhancements, which is what gave rise to the argument from inequality in the first place. Since an unequal distribution of enhancements is most likely, the Double Reversal Test as a tool in applied ethics should take this practical reality into account.

125 Ibid., p.673. 


\section{THE NEW DOUBLE REVERSAL TEST}

In fact, Bostrom and Ord acknowledge that, for the reason I have outlined, the original Double Reversal Test cannot properly diagnose status quo bias in arguments from inequality. So, they modify the test slightly. The new Double Reversal Test is meant to once again place the burden of proof with those who oppose cognitive enhancement due to its unequal distribution. The new Double Reversal Test evaluates cases where enhancement technologies would be unevenly distributed between the rich and the poor:

\footnotetext{
If the release of a hazardous chemical threatened to reduce cognitive ability among the potential enhancement users [the wealthy], would it be a good thing if they could use the permanent enhancement to stave off the impending decline? And if so, would it also be a good thing if, when the effects of the poison eventually started to wear off, the enhancement users refrained from taking steps to maintain their intellectual status quo (e.g. by injecting themselves with a neurotoxin)? If the answer to both these questions is yes, then there is a strong prima facie case for thinking that it would be good overall - despite the assumed negative effect on equality - if the enhancement option is developed. ${ }^{126}$
}

Of course, Bostrom and Ord are assuming that people will answer 'yes' in both cases. The intuitive response is that the wealthy should use genetic cognitive enhancements to stave off a decline in cognitive capacities, and should not to try to offset the enhancement once the poison has worn off. Bostrom and Ord note that the consequence of answering 'yes' in both situations in the new Double Reversal Test is that the wealthy become cognitively enhanced while the poor do not. They maintain that there is therefore no good reason for opponents of cognitive enhancement to contend that there is injustice in the unequal distribution of enhancements in the normal case, since we have already judged exactly the same consequence to be morally permissible in the new Double Reversal Test. There is therefore a strong prima facie case for supposing that arguments from inequality suffer from the same status quo bias as other arguments against enhancement do. The conclusion we are meant to draw, therefore, is that genetic cognitive enhancements should be permitted.

${ }^{126}$ Ibid., pp.675-676. 
However, as I will show below, this argument is unsound. Indeed, I contend that the new Double Reversal Test is fundamentally flawed.

\section{Competing Moral Considerations}

Bostrom and Ord fail to illustrate a logical inference from the conclusion that we should permit genetic cognitive enhancement in the new Double Reversal Test to the conclusion that we should permit genetic cognitive enhancement under normal circumstances. In the new Double Reversal Test we can identify two distinct situations. The first situation is where the wealthy are threatened with intellectual regression if they do not undergo cognitive enhancement in response to being poisoned. In the first situation the only plausible position is that the wealthy should undergo the cognitive enhancement (this can be justified intuitively as well as by the arguments presented in chapter 4 on the use of medical treatments).

The more interesting second situation is where the intelligence-decreasing effects of the poison start to wear off. The wealthy can either do nothing (and therefore become smarter) or intervene, with neurosurgery for example, to offset the effects of the permanent enhancement (and therefore maintain their "normal" intellectual capacities). Again, it appears that the only plausible answer is that the wealthy should refrain from taking steps to offset the enhancement. However, this answer does not lead to the conclusion that in the normal situation we should permit the wealthy to purchase cognitive enhancements.

Bostrom and Ord argue that in the new Double Reversal Test there is a conflict between two different interpretations of the status quo, which supposedly shows that status quo bias affects the argument from inequality. However, it seems to me that there is not so much an inconsistency between two perceptions of the status quo, but instead a conflict between the competing moral considerations that are present in the new Double Reversal Test's second situation but absent in normal circumstances.

On the one hand, we have the no harm principle, which states that policies that benefit the well-off are prima facie unjust if they are likely to harm the worst-off. A 
commitment to the no harm principle would seem to require the wealthy to offset the intelligence-increasing effects of the initial enhancement in the second situation. On the other hand, however, forcing people to undergo neurosurgery or poison themselves would be a major violation of their right to bodily integrity. And as I argued in chapter 3 , even the no harm principle cannot justify violations of such a fundamental right.

The right to bodily integrity is recognised in many moral theories and is a vital component of Western and international political and legal systems. For example, the Universal Declaration of Human Rights guarantees "the right to life, liberty and security of person"; ${ }^{127}$ patients have the right to refuse treatment, even when that treatment would be beneficial for them; vaccinations are not compulsory, even though the unvaccinated are placing themselves and others in positions of greater risk. It is only in exceptional circumstances, normally where others are put at immediate risk of serious injury, illness or death, are violations of the right to bodily integrity permitted (such as isolating people with life-threatening contagious diseases). ${ }^{128}$

So, while the increasing intelligence of the wealthy in the Double Reversal Test may harm the poor, when the right to bodily integrity is taken into account it becomes evident that the cognitive enhancement of the rich is not an all-things-considered wrong, even if it is a prima facie wrong. However, there are no such competing moral obligations when considering whether to permit enhancement under normal conditions. We are therefore justified in holding that while cognitive enhancement of the wealthy is permissible in the new Double Reversal Test, it is morally impermissible in the normal situation. It follows that the new Double Reversal Test does not show status quo bias in the argument from inequality.

In order to further illustrate: we cannot simply consider the fact that the wealthy will become cognitively enhanced in isolation from other factors present - we must consider the issues in context. The problem with the new Double Reversal Test is

\footnotetext{
${ }^{127}$ Article 3. United Nations General Assembly, "The Universal Declaration of Human Rights," 10 December 1948, http://www.un.org/Overview/rights.html.

${ }^{128}$ Other exceptional circumstances include hospitalisation and treatment of the mentally ill who pose a serious physical danger to themselves or others, and incarcerating people as criminal punishment.
} 
easily identifiable once we recognise this point. While two separate actions might both have the consequence $x$, if we are concerned about means or about justice, it does not entail that the two actions are morally equivalent. For example: let's suppose that in situation A, outcome $x$ will result if we do not interfere (i.e. if we no nothing). Let's now suppose that in situation B, we can bring $x$ about only by providing something, $y$, to directly cause $x$. It is not inconsistent to argue that it is morally permissible for $x$ to come about through non-interference in situation A but morally impermissible to directly cause $x$ by providing $y$ in situation B.

Consider this scenario: Miranda and Ethan want to start a family and eventually they conceive a baby. However, Ethan soon changes his mind and tries to persuade Miranda to have an abortion. Already pregnant, Miranda has the right to have the baby - it is morally wrong to force Miranda to have an abortion as this would be a gross violation of her right to bodily integrity. ${ }^{129}$ Now consider a second scenario: Sally is deeply in love with Jude and desperately wants to start a family with him. However, Jude does not want children with her. Sally has no right to be provided with Jude's sperm in order to have his child, as this would violate Jude's own rights. $^{130}$

Note that in the second scenario if Sally has the right to be provided with something $y$ (sperm) the outcome would be the same as non-interference in scenario one - a baby is born against the father's will. However in scenario one there is a legitimate and overriding claim of justice on behalf of the woman (the right to bodily integrity) that is not present in the second scenario. The right of Miranda to not have an abortion

\footnotetext{
${ }^{129}$ This is not to say that there is no legitimate discussion to be had about whether Ethan is morally obliged to provide child support, for example.

${ }^{130}$ This fictional scenario is actually very similar to a real life British case in which a woman sued for the right to use frozen IVF embryos against her ex-partner's wishes. When Natalie Evans discovered she had ovarian cancer, she and her partner Howard Johnston underwent IVF treatment and had the embryos frozen, since the cancer treatment was predicted to leave Ms Evans infertile. However, the couple split up before the embryos were implanted. Mr Johnston withdrew his consent for his former partner to use the embryos, as he no longer wanted to have children with her. Ms Evens then applied to the courts to have Mr Johnston's decision overturned and the case ultimately went to the Grand Chamber of the European Court of Human Rights. The Guardian reported that "the ruling said the judges did not consider that Ms Evans' 'right to respect for the decision to become a parent in the genetic sense should be accorded greater weight' than her former partner's decision not to have a child with her." Reported by James Sturcke and Karen McVeigh, "Woman Loses Final Embryos Appeal," Guardian.co.uk, 10 April 2007, http://www.guardian.co.uk/uk/2007/apr/10/health.humanrights.
} 
against her will does not entail that Sally has a corresponding right to be provided with something (sperm) that would have the same result - a baby is born against the father's will.

While not completely analogous, parallels can be drawn between this case and the case of genetic cognitive enhancement. In the second baby case, the only relevant moral consideration is that of Jude's right to not have his sperm taken against his will. Analogously, when considering whether to permit wealth-based access to enhancements under normal conditions, the only relevant moral consideration is the no harm principle, ${ }^{131}$ which prohibits wealth-based access to cognitive enhancement technologies because of harms to the poor. However, in the first baby case, Miranda's right to bodily integrity means she cannot be forced to have an abortion against her will. Paralleling this, in the new Double Reversal Test the wealthy cannot be forced to undergo neurosurgery (despite the harm to the poor), as this would involve a violation of their right to bodily integrity. This example illustrates that simply because the wealthy have a right to preserve their cognitive enhancement through non-interference in extraordinary circumstances (i.e. in the new Double Reversal Test) does not mean they have the right to be provided with access to cognitive enhancements under ordinary circumstances.

The Double Reversal Test fails because it implies that when two outcomes are identical, the actions that produced those outcomes are the same in all morally relevant respects. However, my analysis shows that this is false. To see how the right to bodily integrity affects the conclusions we should draw from the new Double Reversal Test, consider my revised Double Reversal Test in which potential claims of bodily integrity have been eliminated:

If the release of a hazardous chemical threatened to reduce cognitive ability among the wealthy, would it be a good thing if they were provided with daily cognitive enhancing injections to stave off the impending decline of their cognitive capacities? And if so, would it also be a good thing if, when the effects of the poison eventually start to wear off, the enhancement users were continued to be supplied with the daily

\footnotetext{
${ }^{131}$ Given that the personal liberty considerations that could be appealed to in this case are not strong enough to override the no harm principle (as argued in chapter 3 ).
} 
injections so that their cognitive capacities would continue to increase? If the answer to both these questions is yes, then there is a strong prima facie case for thinking that it would be good overall - despite the assumed negative effect on equality - if the enhancement option is developed. ${ }^{132}$

In this revised Double Reversal Test, our intuitions are completely different. While the answer to the first question is 'yes' (we should provide the wealthy with daily intelligence-enhancing injections to stave off cognitive decline), the answer to the second question is clearly 'no' (we should not continue to supply the wealthy with the injections once the poison has worn off). If we think the no harm principle should be applied in the normal situation, there should be no opposition to maintaining that once the poison has disappeared from the water supply, those no longer at risk of braindamage do not have the right to continue to be supplied with the cognitive-enhancing injections. When we remove the competing moral consideration of bodily integrity, our judgments about the unequal distribution of cognitive enhancements become the same for my revised Double Reversal Test as they are in the normal situation.

\section{CONCLUSION}

Neither the original Double Reversal Test nor the new Double Reversal Test shows my version of the argument from inequality to be influenced by status quo bias. Bostrom and Ord fail to realise that there are competing moral considerations in the Double Reversal Test cases that are not present in the normal situation. The right to bodily integrity in the new Double Reversal Test overrides the no harm principle, meaning that while the cognitive enhancement of the rich is a prima facie wrong, it does not turn out to be an all-things-considered wrong. However, there are no such competing moral obligations in normal circumstances, meaning that permitting wealth-based access to cognitive enhancement remains all-things-considered unjust. Therefore, Bostrom and Ord cannot use the conclusion that we should permit cognitive enhancement in the new Double Reversal Test to infer that we should also permit wealth-based access to cognitive enhancements in the normal situation.

${ }^{132}$ Bostrom and Ord "The Reversal Test," pp.675-676 - altered to suit my purposes. 


\section{CHAPTERS REVIEW}

In the very first paragraphs of this thesis I noted how future genetic enhancement technologies have the potential for both good and bad. This means that it is important to morally evaluate the issues surrounding the use of genetic enhancements before the technologies are developed, in order to know whether we should prohibit or welcome their use. I also noted that we should not assume that one argument will suffice for determining the moral status of using genetic enhancements generally; instead, it may turn out that some enhancements are morally permissible while others are not. Accordingly, my moral evaluation was to be concerned solely with arguing against the genetic enhancement of intelligence (specifically, responding to Bostrom and Ord's Reversal Test).

In chapter 2 I examined Bostrom and Ord's contention that subjective judgments can often be influenced by psychological biases. I presented their Reversal Test, which they use to diagnose status quo bias in arguments against cognitive enhancement. The Reversal Test poses a burden of proof challenge to opponents of cognitive enhancement: if one is to argue that we should neither decrease nor increase our cognitive capacities, then one should supply good reasons for holding that the status quo (our current level of intelligence) cannot be improved. If no sound justification can be offered, this indicates that the argument against enhancement suffers from status quo bias and is therefore not morally compelling.

In chapter 3 I responded to the Reversal Test by arguing that while enhanced intelligence may be beneficial for the individual, the probable unequal distribution of enhancements is likely to cause serious injustices to those who miss out. In order to 
establish this claim, I first showed that despite Bostrom and Ord's ideal assumption of affordability, wealth-based access to genetic enhancement technologies would result in enhancements being unequally distributed between the rich and the poor. Secondly, I introduced the no harm principle of justice, which I argued is an intuitively plausible way of governing the distribution of cognitive enhancement technologies. Once considerations of risk under uncertainty were taken into account, the no harm principle stated:

A policy that benefits the best-off members of society but carries a significant risk of harm to the worst-off members of society is prima facie unjust.

I then showed that permitting wealth-based access to genetic cognitive enhancements would be likely to harm the unenhanced poor in three ways, and so violate the no harm principle. First, the enhanced would be likely to discriminate against the unenhanced, by equating their biological intellectual superiority with moral superiority. Second, the poor may be harmed through loss of valuable forms of reciprocal political and social relationships. Third, wealth-based access to cognitive enhancements would be likely to competitively harm the poor, by leaving them unable to compete for resources they might otherwise have been able to acquire.

By using a method of balancing the potential benefits of enhancement with the potential harms, we also saw that any absolute social benefits would be unlikely to compensate for the harms caused by discrimination, loss of reciprocity and competitive disadvantages. The unequal distribution of enhancements would therefore be on balance bad for the poor, meaning that permitting wealth-based access to enhancements is prima facie unjust.

I then addressed whether any competing moral considerations weigh heavily enough to override the no harm principle and so make wealth-based access to enhancements morally permissible, all-things-considered. I suggested that the most likely candidate for a competing moral consideration is some sort of personal liberty right. However, given the seriousness of the harms to the poor and the fact that prohibiting enhancements requires relatively little interference in personal freedom, I showed that 
any liberty considerations are not strong enough to override the no harm principle in this case. Accordingly, we could conclude that wealth-based access to genetic cognitive enhancements would be all-things-considered unjust.

The final task of chapter 3 was to examine the new Reversal Test, which Bostrom and Ord revise in an attempt to diagnose status quo bias in arguments from inequality. The new Reversal Test works by noting that most of those who oppose increases in the wealthy's intelligence would also oppose decreases in the wealthy's intelligence. This shifts the onus onto those who oppose enhancement on grounds of its unequal distribution - they must justify why the wealthy's current level of intelligence is at a local optimum.

However, I demonstrated that the new Reversal Test is also ineffective in showing the argument from inequality to be influenced by status quo bias. The reason we cannot submit the wealthy to brain damage in order to reduce their cognitive capacities is not that the wealthy's level of intelligence is necessarily at a local optimum, but that brain-damaging someone or forcing neurosurgery on them would be a gross violation of an individual's right to bodily integrity. This means that although increasing the wealthy's intelligence through cognitive enhancement is morally impermissible, so too is coercively decreasing their intelligence.

By showing the argument from inequality to be free from status quo bias, the objective in chapter 3 of meeting the Reversal Test's initial burden of proof challenge had been successfully achieved.

The goal of chapter 4 was to examine and rebut the strongest potential objections to the argument from inequality. I considered two consistency arguments - the argument from medical treatments and the argument from education. Both arguments can be expressed: since education and medical treatments are primary goods that are unequally distributed between the rich and the poor, the argument from inequality entails we should prohibit education and non-universal medical treatments for everyone if they are unable to be made available for all. Proponents of enhancement 
claim that since this conclusion is obviously absurd, the argument from inequality must be unsound.

In the case of medical treatments, I showed that their unequal distribution is unlikely to be harmful to the poor through discrimination, loss of reciprocity or loss of support. I also argued that competitive harms are less likely to occur because of the unequal distribution of medical treatments than they are through the unequal distribution of cognitive enhancements. However, the most important part of my response was to illustrate that the non-universal use of medical treatments is justified by society's obligation to treat illness and disease, and the corresponding right of patients to seek treatment for their conditions. Neither these rights nor these obligations arise in connection with cognitive enhancement. This explains why we should permit the private purchase of non-universally available medical treatments, but prohibit wealthbased access to genetic cognitive enhancements.

In rebutting the argument from education, I maintained that even though environmental and genetic methods of enhancing intelligence are not morally different in theory, we are nonetheless justified in coming to different conclusions about their respective moral permissibility. This is because in practical terms, the differences created by an unequal distribution of environmental enhancements are much less likely to harm the poor than the differences created by an unequal distribution of genetic enhancements.

First, I argued that while the intellectual differences produced by wealth-based access to genetic enhancements may be so extensive that reciprocity becomes no longer possible, the differences created by educational disparities are highly unlikely to be significant enough to sever cooperative relationships between the best- and worst-off. I also showed that while the argument from inequality may in theory judge mild genetic enhancements morally permissible, in practice we are unlikely to be able to restrict enhancements to ones that have only a mild effect.

Second, I argued that the smaller differences created by environmental enhancements (evidenced by the Flynn effect) are less likely to cause discrimination. More 
importantly, I returned to the arguments made in chapter 3 that the tendency to equivocate between the different senses of "better" is a particular problem when cognitive differences are genetically, rather than environmentally, caused.

Third, by again considering the difference in degree, I noted that the competitive harms to the poor due to others' education may be less extensive than the competitive harms due to others' cognitive enhancement. Furthermore, I submitted that the absolute social benefits of education are more likely to compensate for competitive harms than the absolute social benefits of enhancement. This seems true for a number or reasons: one, the benefits of education have to compensate for less harm; two, in the case of education the poor are not morally and politically marginalised; and three, the eventual education of the poor will greatly benefit them, while their eventual enhancement may mean little if they cannot place their genes in an appropriate environment, or if the wealthy continue to acquire the latest and best enhancements.

Finally, I maintained that prohibiting or strictly regulating many environmental enhancements would require considerable restrictions on personal liberty; far more so than if genetic enhancement technologies were prohibited. I suggested that these competing moral considerations make the restriction of many environmental enhancements more morally problematic than the restriction of genetic enhancements.

By presenting my case against cognitive enhancement in chapter 3 and rebutting the strongest potential objections to my argument in chapter 4, the argument from inequality was ultimately shown to meet the Reversal Test's burden of proof challenge.

In chapter 5 I tackled Bostrom and Ord's second burden of proof argument. The Double Reversal Test attempts to diagnose status quo bias in arguments against enhancement by showing that since the outcome we judge as morally acceptable in the Double Reversal Test is identical to the outcome of permitting enhancement under normal conditions, opposition to cognitive enhancement (including the argument from inequality, which is taken into account in the new Double Reversal Test) is influenced by status quo bias. 
I rebutted the new Double Reversal Test by illustrating that it introduces competing moral considerations that are not present when considering whether to permit cognitive enhancements under normal conditions, meaning that it is ineffective in showing the argument from inequality to be influenced by status quo bias. The competing moral consideration of bodily integrity means that requiring the wealthy to undergo brain surgery in order to maintain their intellectual status quo would be a gross violation of their rights. However, no such rights are violated by withholding genetic technologies in the normal situation. Therefore, we are justified in concluding that while we must permit the rich's intelligence to increase once the poison has worn off in the new Double Reversal Test, we should not permit the wealthy to purchase cognitive enhancements under normal conditions.

The argument from inequality based on the no harm principle has therefore been shown to pass both the simple Reversal and Double Reversal Tests. Consequently, the burden of proof challenges that Bostrom and Ord set have been successfully met.

\section{OTHER PSYCHOLOGICAL BIASES?}

It is interesting to note that, contrary to the argument I have submitted, many proponents of enhancement (including Bostrom and Ord) espouse the wonderful benefits of cognitive enhancement. In the paper "Why I Want to be a Posthuman When I Grow Up" Bostrom writes:

You have just celebrated your $170^{\text {th }}$ birthday and you feel stronger than ever. Each day is a joy. You have invented entirely new art forms... You are communicating with your contemporaries using a language...that has a vocabulary and expressive power that enables you to share and discuss thoughts and feelings that unaugmented humans could not even think or experience. You play a certain kind of new game which combines... artistic expression, dance, humour, interpersonal dynamics, and various novel faculties and the emergent phenomena they make possible, and which is more fun than anything you ever did during the first hundred years of your existence. When you are playing this game with your friends, you feel how every fiber of your body and mind is stretched to its limit in the most creative and imaginative way, and you are creating new realms of abstract and concrete beauty 
that humans could never (concretely) dream of. You are always ready to feel with those who suffer misfortunes, and to work hard to help them get back on their feet. You are also involved in a large voluntary organization that works to reduce suffering of animals in their natural environment... Things are getting better, but already each day is fantastic. ${ }^{133}$

If this scenario accurately represented the likely reality of permitting genetic cognitive enhancements, then it would probably be more difficult to justify their prohibition. However, the problem with Bostrom's predictions is that they are simply too fantastic and uncertain. The far-fetched nature of the scenario Bostrom presents suggests that judgments made by proponents of enhancement may also be negatively influenced by psychological biases.

Ian Newby-Clark and Michael Ross examine some potentially relevant biases. In a series of studies they found that people were generally "much more hopeful about their futures than their pasts seem to warrant" and "the process of thinking of a future event and judging it as likely took longer for likely negative events than likely positive events." 134 This indicates that judgments about the future may be more positive than the evidence would warrant. Additionally, while loss aversion may caution opponents of enhancement to also consider enhancement's benefits, another cognitive bias - the durability bias - may also mean that transhumanists' predictions about the goodness of the consequences of enhancement may be somewhat overestimated. $^{135}$ Other studies have also confirmed psychological biases that make people "unrealistically optimistic about future life events."136 Further research into the processes of human decision making may reveal that some of the arguments made by proponents of enhancement are also influenced by various psychological biases.

\footnotetext{
${ }^{133}$ Nick Bostrom, "Why I Want to be a Posthuman When I Grow Up," in Medical Enhancement and Posthumanity (Forthcoming), ed. Bert Gordijn and Ruth Chadwick (Springer, 2008), accessed on http://www.nickbostrom.com/posthuman.pdf, p.5.

${ }^{134}$ Ian R. Newby-Clark and Michael Ross, "Conceiving of the Past and Future," Personality and Social Psychology Bulletin 29:7 (2003), p.815.

${ }^{135}$ See, for example, Timothy D. Wilson et al., "Focalism: A Source of Durability Bias in Affective Forecasting," Journal of Personality and Social Psychology 78:5 (2000).

${ }^{136}$ Neil D. Weinstein, "Unrealistic Optimism about Future Life Events," Journal of Personality and Social Psychology 39:5 (1980), p.806.
} 
In any event, regardless of whether Bostrom and Ord's predictions about the benefits of enhancement are influenced by cognitive biases, the Reversal Test and the Double Reversal Test remain legitimate and compelling challenges to opponents of enhancement. That said, neither the simple Reversal Test nor the Double Reversal Tests are effective in showing that opposition to enhancement based on the no harm principle is influenced by the status quo bias. As we have seen in this thesis, wealthbased access to genetic cognitive enhancements can be successfully opposed by the argument from inequality. 


\section{References}

Agar, Nicholas. Liberal Eugenics: In Defence of Human Enhancement. Malden: Blackwell Publishing, 2004.

Anckar, Carsten. Determinants of the Death Penalty: A Comparative Study of the World. Abingdon: Routledge, 2004.

Anderson, W. French. "Genetics and Human Malleability." The Hastings Centre Report 20:1 (1990): pp.21-24.

Bostrom, Nick. "Existential Risks: Analysing Human Extinction Scenarios and Related Hazards." Journal of Evolution and Technology 9:1 (2002). http://www.jetpress.org/volume9/risks.html.

—. "Why I Want to be a Posthuman When I Grow Up," in Medical Enhancement and Posthumanity (Forthcoming), ed. Bert Gordijn and Ruth Chadwick (Springer, 2008), on http://www.nickbostrom.com/posthuman.pdf (accessed 3 February 2008).

Bostrom, Nick, and Toby Ord. "The Reversal Test: Eliminating Status Quo Bias in Applied Ethics." Ethics 116:4 (2006): pp.656-79.

Buchanan, Allen, Dan W. Brock, Norman Daniels, and Daniel Wikler. From Chance to Choice: Genetics and Justice. Cambridge: Cambridge University Press, 2000.

Canada Communicable Disease Report. "Canadian National Report on Immunization, 1996." Public Health Agency of Canada. http://www.phac-aspc.gc.ca/publicat/ccdrrmtc/97vol23/23s4/index.html (accessed 20 July 2008).

Chadwick, Ruth, and Doris Schroeder, eds. Applied Ethics: Critical Concepts in Philosophy. Vol. 4. London: Routledge, 2002.

Cohen, Carl. "The Case for the Use of Animals in Biomedical Research." The New England Journal of Medicine 315:14 (1986): pp.860-70. 
Colom, Roberto, Josep M. Lluis-Font, and Antonio Andrés-Pueyo. "The Generational Intelligence Gains are Caused by Decreasing Variance in the Lower Half of the Distribution: Supporting Evidence for the Nutritional Hypothesis." Intelligence 33:1 (2005): pp.83-91.

Cranor, Carl F. Are Genes Us? The Social Consequences of the New Genetics. New Brunswick, NJ: Rutgers University Press, 1994.

Daley, Tamara C., Shannon E. Whaley, Marian D. Sigman, Michael P. Espinosa, and Charlotte Neumann. "IQ on the Rise: The Flynn Effect in Rural Kenyan Children." Psychological Science 14:3 (2003): pp.215-19.

Daniels, Norman. "Health-Care Needs and Distributive Justice." In Justice and Justification: Reflective Equilibrium in Theory and Practice. Cambridge: Cambridge University Press, 1996. pp.179207.

. Justice and Justification: Reflective Equilibrium in Theory and Practice. Cambridge: Cambridge University Press, 1996.

Daniels, Norman, and James E. Sabin. "Determining "Medical Necessity" in Mental Health Practice." In Justice and Justification: Reflective Equilibrium in Theory and Practice, edited by Norman Daniels. Cambridge: Cambridge University Press, 1996. pp.232-56

Department of Economic and Social Affairs of the United Nations Secretariat. "The Millennium Development Goals Report 2007." New York: The United Nations, 2007.

Dubois, Ellen. "Woman Suffrage: The View from the Pacific." The Pacific Historical Review 69:4 (2000): pp.539-51.

Dyson, Anthony. "Genetic Engineering in Theology and Theological Ethics." In Ethics and Biotechnology, edited by Anthony Dyson and John Harris. London: Routledge, 1994. pp.25971.

Dyson, Anthony, and John Harris, eds. Ethics and Biotechnology. London: Routledge, 1994.

European Commission: Public Health. "The Orphan Drugs Strategy." EUROPA (The European Union On-Line). http://ec.europa.eu/health/ph_threats/non_com/rare_6_en.htm (accessed 14 August 2008).

Feagin, Joe R. Systemic Racism: A Theory of Oppression. Abingdon: Routledge, 2006. 
Feinstein, Leon, Ricardo Sabates, Tashweka M. Anderson, Annik Sorhaindo, and Cathie Hammond. "What are the Effects of Education on Health?" OECD, 2006.

French, Sally. "Worst Nightmare... and then a \$100k Bill." Stuff.co.nz, 19 May 2008. http://www.stuff.co.nz/4549980a27346.html (accessed 21 May 2008).

Friedman, Milton. "The Role of Government in Education." In Economics and the Public Interest, edited by Robert A. Solo. New Brunswick, NJ: Rutgers University Press, 1955. pp.123-44.

Fukuyama, Francis. Our Posthuman Future: Consequences of the Biotechnology Revolution. New York: Farrar, Straus \& Giroux, 2002.

Gilovich, Thomas, Dale W. Griffen, and Daniel Kahneman. Heuristics and Biases: The Psychology of Intuitive Judgment. Cambridge: Cambridge University Press, 2000.

Graham, Charles and Jonathan Plucker. "The Flynn Effect." Human Intelligence: Historical Influences, Current Controversies, Teaching Resources. http://www.indiana.edu/ intell/flynneffect.shtml (accessed 12 June 2008).

Harris, John. "Biotechnology, Friend or Foe? Ethics and Controls." In Ethics and Biotechnology, edited by Anthony Dyson and John Harris. London: Routledge, 1994. pp.216-230.

—. Wonderwoman and Superman. Oxford: Oxford University Press, 1992.

Hartman, Raymond S., Michael J. Doane and Chi-Keung Woo. "Consumer Rationality and the Status Quo." Quarterly Journal of Economics 106:1 (1991). pp.141-62.

Häyry, Matti. "Categorical Objections to Genetic Engineering - A Critique." In Ethics and Biotechnology, edited by Anthony Dyson and John Harris London: Routledge, 1994. pp.20215.

Herlitz, A., L. G. Milsson, and L. Bäckman. "Gender Differences in Episodic Memory." Memory \& Cognition 25:6 (1997): pp.801-11.

Herrnstein, Richard, and Charles Murray. The Bell Curve: Intelligence and Class Structure in American Life. New York: Free Press, 1994.

Hodgson, Pete. "Budget 06: A Health Budget for All NZ Families." beehive.govt.nz, 18 May 2006. http://www.beehive.govt.nz/?q=node/25799 (accessed 9 October 2008). 
Holm, Søren. "Genetic Engineering and the North-South Divide." In Ethics and Biotechnology, edited by Anthony Dyson and John Harris. London: Routledge, 1994. pp.47-63.

Howard, Robert W. "Preliminary Real-World Evidence that Average Human Intelligence Really is Rising." Intelligence 27:3 (1999): pp.235-50.

Hudson, James. "What Kinds of People Should We Create?" Journal of Applied Philosophy 17:2 (2000): pp.131-43.

Hughes, James. Citizen Cyborg: Why Democratic Societies Must Respond to the Redesigned Human of the Future. United States of America: Westview Press, 2004.

Human Enhancement and Biopolitics. "Alan Billings on 'Playing God."' http://hplusbiopolitics.wordpress.com/2008/04/03/alan-billing-on-playing-god/ (accessed 12 April 2008).

Hunt-Grubbe, Charlotte. "The Elementary DNA of Dr Watson." Times Online, 14 October 2007. http://entertainment.timesonline.co.uk/tol/arts_and_entertainment/books/article2630748.ece (accessed 16 October 2007).

Kahneman, Daniel, and Amos Tversky. "Conflict Resolution: A Cognitive Perspective." In Choices, Values and Frames. Cambridge: Cambridge University Press, 2000. pp.473-88.

, eds. Choices, Values and Frames. Cambridge: Cambridge University Press, 2000.

Kahneman, Daniel, Jack L. Knetsch, and Richard H. Thaler. "Anomalies: The Endowment Effect, Loss Aversion, and Status Quo Bias." Journal of Economic Perspectives 5:1 (1991): 193-206.

Kahneman, Daniel, Paul Slovic, and Amos Tversky, eds. Judgement Under Uncertainty: Heuristics and Biases. Cambridge: Cambridge University Press, 1982.

Kass, Leon. Life, Liberty and the Defense of Dignity: The Challenge for Bioethics. San Francisco: Encounter Books, 2002.

—. "The Wisdom of Repugnance." The New Republic 216:22 (1997). pp.17-26.

Kavka, Gregory S. "Upside Risks: Social Consequences of Beneficial Biotechnology." In Are Genes Us? The Social Consequences of the New Genetics, edited by Carl F. Cranor. New Brunswick, NJ: Rutgers University Press, 1994. pp.155-79.1 
Kiros, Gebre-Egziabher, and Michael J. White. "Migration, Community Context, and Child Immunization in Ethiopia." Social Science \& Medicine 59:12 (2004): pp.2603-16.

Kitcher, Philip. The Lives to Come. New York: Simon \& Schuster, 1996.

Littlies: For Practical Parenting, "Secondary Infertility," http://www.littlies.co.nz/page.asp?id=244 (accessed 4 February 2008).

Luman, Elizabeth T., Pamela L. Y. H. Ching, Aisha O. Jumaan, and Jane F. Seward. "Uptake of Varicella Vaccination among Young Children in the United States: A Success Story in Eliminating Racial and Ethnic Disparities." Pediatrics 117:4 (2006): pp.999-1008.

Mc Donald, Robert M. S. "God and Man at Philadelphia." Review of Jefferson's Declaration of Independence: Origins, Philosophy and Theology, by Allen Jayne. H-Net Reviews, March 1999. http://www.h-net.msu.edu/reviews/showrev.php?id=2893 (accessed 23 September 2008).

McGee, Glenn. "Parenting in an Era of Genetics." The Hastings Centre Report 27:2 (1997): pp.16-22.

Micco, Ellyn, Andrea D. Gurmankin, and Katrina Armstrong. "Differential Willingness to Undergo Smallpox Vaccination among African-American and White Individuals." Journal of General Internal Medicine 19:5 Pt 1 (2004): pp.451-55.

Mill, John Stuart. On Liberty $2^{\text {nd }}$ ed. (Boston: Ticknor and Fields, 1863).

Murray, Thomas H. "Enhancement." In The Oxford Handbook of Bioethics, edited by Bonnie Steinbock. Oxford: Oxford University Press, 2007. pp.491-515.

National Coalition on Health Care. "Health Insurance Coverage." http://www.nchc.org/facts/coverage.shtml (accessed 3 June 2008).

Neisser, Ulric. "Rising Scores on Intelligence Tests." American Scientist 85 (1997). pp.440-47.

Newby-Clark, Ian R., and Michael Ross. "Conceiving of the Past and Future." Personality and Social Psychology Bulletin 29:7 (2003): pp.807-18.

Newson, Ainsley, and Robert Williamson. "Should We Undertake Genetic Research on Intelligence?" Bioethics 13:3/4 (1999): pp.327-42. 
New Zealand Herald. "The High Cost of IVF." http://www.nzherald.co.nz/financialplanning/news/article.cfm?c_id=517\&objectid=10382817 (accessed 12 October 2008).

Ohlander, Julianne, Jeanne Batalova, and Judith Treas. "Explaining Educational Influences on Attitudes toward Homosexual Relations." Social Science Research 34:4 (2005): pp.781-99.

Ompad, Danielle C., Sandro Galea, and David Vlahov. "Distribution of Influenza Vaccine to HighRisk Groups." Epidemiologic Reviews 28:1 (2006): pp.54-70.

Oxfam Press Release. "New Zealand Development Aid Still Lags Far Behind."

Scoop, 4 April 2008. http://www.scoop.co.nz/stories/PO0804/S00086.htm (accessed 7 April 2008).

Press.co.nz. "Herceptin Funding Increase Turned Down." 7 August 2008.

http://www.stuff.co.nz/4647225a24035.html.

Randall, F. M. "Ethical Issues in Palliative Care." Acta Anaesthesiologica Scandinavica 43:9 (1999): pp.954-56.

Rawls, John. Justice as Fairness: A Restatement. Cambridge, MA: The Belknap Press of Harvard University Press, 2001.

—. Political Liberalism. New York: Columbia University Press, 1993.

. A Theory of Justice. Cambridge, MA: The Belknap Press of Harvard University Press, 1971.

Roberts, Martin. "Spanish Parliament to Extend Rights to Apes." Reuters, 25 June 2008. http://www.reuters.com/article/scienceNews/idUSL256586320080625?sp=true (accessed 1 July 2008).

Robertson, John A. Children of Choice: Freedom and the New Reproductive Technologies. Princeton: Princeton University Press, 1994.

_ Philosophy of Reproductive Biomedicine 1:1 (2005): pp.97-101.

Samuelson, William and Richard Zeckhauser. "Status Quo Bias in Decision Making." Journal of Risk and Uncertainty 1:1 (1988), pp.7-59. 
Sandel, Michael. "The Case against Perfection." The Atlantic Monthly 293:3 (2004). pp.50-62.

Savulescu, Julian. "Genetic Interventions and the Ethics of Enhancement of Human Beings." In The Oxford Handbook of Bioethics, edited by Bonnie Steinbock. Oxford: Oxford University Press, 2007. pp.516-35.

__. "Procreative Beneficence: Why We Should Select the Best Children." Bioethics 15:5/6 (2001): pp.413-26.

Silver, Lee. Remaking Eden. New York: HarperCollins Publishers Inc., 1997.

Singer, Peter. "All Animals Are Equal." In Applied Ethics: Critical Concepts in Philosophy. Vol.4. Edited by Ruth Chadwick and Doris Schroeder. London: Routledge, 2002. pp.51-79.

Animal Liberation. New York: HarperCollins Publishers Inc., 1975.

Practical Ethics 2nd ed. Cambridge: Cambridge University Press, 1993.

Statistics New Zealand. "Births and Deaths: June 2006 Quarter."

http://www.stats.govt.nz/store/2006/08/births-deaths-jun06qtr-hotp.htm?page=para003Master (accessed 25 September 2008).

Statistics New Zealand. "Gross Domestic Product."

http://www.stats.govt.nz/products-and-services/hot-off-the-press/gross-domesticproduct/gross-domestic-product-jun08qtr-hotp.htm?page=para004Master (accessed 1 October 2008).

Steinbock, Bonnie, ed. The Oxford Handbook of Bioethics. Oxford: Oxford University Press, 2007.

—. "Speciesism and the Idea of Equality." Philosophy 53:204 (1978): pp.247-56.

Sturcke, James and Karen McVeigh. "Woman Loses Final Embryos Appeal." Guardian.co.uk, 10 April 2007. http://www.guardian.co.uk/uk/2007/apr/10/health.humanrights (accessed 10 April 2007).

Tungodden, Bertil. "The Value of Equality." Economics and Philosophy 19:1 (2003): pp.1-44. 
Turkheimer, Eirc. "The Theory of Innate Differences." Cato Unbound, 21 November 2007. http://www.cato-unbound.org/2007/11/21/eric-turkheimer/race-and-iq/ (accessed 12 December 2008).

Tversky, Amos, and Daniel Kahneman. "Advances in Prospect Theory: Cumulative Representation of Uncertainty." In Choices, Values and Frames, edited by Daniel Kahneman and Amos Tversky. Cambridge: Cambridge University Press, 2000. pp.44-66.

—. "Judgement Under Uncertainty: Heuristics and Biases." In Judgement Under Uncertainty: Heuristics and Biases, edited by Amos Tversky and Daniel Kahneman. Cambridge: Cambridge University Press, 1982. p.3-20.

"Loss Aversion in Riskless Choice: A Reference-Dependent Model." The Quarterly Journal of Economics 106:4 (1991): pp.1039-61.

— . "The Framing of Decisions and the Psychology of Choice." Science 211:4481 (1981). pp.45358.

United Nations 2005 Millennium Development Goals Report. "Millennium Development Goals: Poverty and Hunger." BBC News. http://news.bbc.co.uk/2/shared/spl/hi/in_depth/millennium_development_goals/html/default.st m (accessed 22 January 2008).

United Nations General Assembly, "The Universal Declaration of Human Rights," 10 December 1948, http://www.un.org/Overview/rights.html (accessed 8 August 2008).

Weinstein, Neil D. "Unrealistic Optimism about Future Life Events." Journal of Personality and Social Psychology 39:5 (1980): pp.806-20.

Wilson, Timothy D., Thalia Wheatley, Jonathan M. Myers, Daniel T. Gilbert, and Danny Axsom. "Focalism: A Source of Durability Bias in Affective Forecasting." Journal of Personality and Social Psychology 78:5 (2000): pp.821-36. 